\title{
Development of OTM Syngas Process and Testing of Syngas Derived Ultra-clean Fuels in Diesel Engines and Fuel Cells Budget Period 3
}

\section{Topical Report}

For Reporting Period Starting January 1, 2003 thru December 31, 2004

Principal Authors:

E.T. (Skip) Robinson, Principal Investigator, Torix

John Sirman, Program Administrator, Praxair

Prasad Apte, Ceramic Manufacturing Manager, Praxair

Xingun Gui, Chief Engineer, Advanced Combustion and Control, International Truck and Engine Corp.

Tytus R. Bulicz, Project Development Engineer, International Truck and Engine Corp.

Dan Corgard,, Senior Development Engineer, Future Technology, International Truck and Engine Corp.

Siv Aasland, Staff Engineer, Statoil

Kjersti Kleveland, Staff Engineer, Statoil

Ann Hooper, Process Supervisor, Foster Wheeler

Leo Bonnell, Process Supervisor, Foster Wheeler

John Hemmings, Director, Technology and Chemicals, Foster Wheeler

Jack Chen, Senior Development Associate, Praxair

Bart A. van Hassel, Senior Development Associate, Praxair

Report Issue Date: May, 2005

DOE Cooperative Agreement No. DE-FC26-01NT41096

Submitting Organizations:

Primary: $\quad$ Praxair, Inc.

P.O. Box 44

175 East Park Drive

Tonawanda, NY 14150

Subcontractors: Statoil ASA

Postuttak

N-7005 Trondheim, Norway

Torix, Inc

7165 Hart St., Suite B

Mentor, OH 44060

International Truck and Engine Corp.

BP America Production Company 10400 W. North Avenue

$150 \mathrm{~W}$. Warrenville Road

Melrose Park, IL 60160

Mail Code $\mathrm{H}-5$,

Naperville, IL 60566

Foster Wheeler USA Corporation

2020 Dairy Ashford Road

Houston, TX 77077 


\section{DISCLAIMER}

This report was prepared as an account of work sponsored by an agency of the United States Government. Neither the United States Government nor any agency thereof, nor any of their employees, makes any warranty, express or implied, or assumes any legal liability or responsibility for the accuracy, completeness, or usefulness of any information, apparatus, product, or process disclosed, or represents that its use would not infringe privately owned rights. Reference herein to any specific commercial product, process, or service by trade name, trademark, manufacturer, or otherwise does not necessarily constitute or imply its endorsement, recommendation, or favoring by the United States Government or any agency thereof. The views and opinions of authors expressed herein do not necessarily state or reflect those of the United States Government or any agency thereof.

\section{ABSTRACT}

This topical report summarizes work accomplished for the Program from January 1 , 2003 through December 31, 2004 in the following task areas:

Task 1: Materials Development

Task 2: Composite Development

Task 4: Reactor Design and Process Optimization

Task 8: Fuels and Engine Testing

8.1 International Diesel Engine Program

Task 10: Program Management

Most of the key technical objectives for this budget period were achieved. Only partial success was achieved relative to cycle testing under pressure

Major improvements in material performance and element reliability have been achieved. A breakthrough material system has driven the development of a compact planar reactor design capable of producing either hydrogen or syngas. The planar reactor shows significant advantages in thermal efficiency and costs compared to either steam methane reforming with $\mathrm{CO} 2$ recovery or autothermal reforming. .

The fuel and engine testing program is complete The single cylinder test engine evaluation of UCTF fuels begun in Budget Period 2 was finished this budget period. In addition, a study to evaluate new fuel formulations for an $\mathrm{HCCl}$ engine was completed. 


\section{TABLE OF CONTENTS}

$\begin{array}{lc}\text { Abstract } & \frac{\text { Page }}{1} \\ \text { List of Tables } & 3 \\ \text { List of Figures } & 3 \\ \text { List of Acronyms } & 4\end{array}$

1.0 Executive Summary 5

2.0 Introduction 8

3.0 Progress and Results by Task

3.1 Task 1: Materials Development 8

3.2 Task 2: Composite Development 12

3.3 Task 4: Reactor Design and Process Optimization 15

3.4 Task 8: Fuels and Engine Testing 21

3.5 Task 10: Program Management 34

4.0 Conclusions 34

5.0 References $\quad 35$

Appendix 1: International Truck \& Engine SCTE Results 36

Appendix 2: International Truck \& Engine $\mathrm{HCCl}$ Test Results 43

Appendix 3: BP Preparation of HCCl Fuels 53 


\begin{tabular}{|c|l|c|}
\hline Table No & \multicolumn{1}{|c|}{ Title } & Page \\
\hline 1 & Normalized flux results of membrane candidate materials & 9 \\
\hline 2 & $\begin{array}{l}\text { Thermal and chemical expansion behavior of membrane candidate } \\
\text { materials }\end{array}$ & 10 \\
\hline 3 & Thermal and chemical expansion of LCM65 type film candidates & 11 \\
\hline 4 & Thermal and chemical expansion of MM2 type film candidates & 12 \\
\hline 5 & Preliminary hydrogen study results & 17 \\
\hline 6 & $\begin{array}{l}\text { Economic comparison of OTM GSR and conventional SMR } \\
\text { processes for hydrogen production with CO2 recovery }\end{array}$ & 18 \\
\hline 7 & Cost Targets for OTM Equipment in a 25,000 BPD FTGTL Plant & 20 \\
\hline 8 & Cost Comparison of OTM-2 Syngas versus Conventional ATR & 21 \\
\hline 9 & SCTE fuel inspections & 23 \\
\hline 10 & Scope and range of engine simulation domain & 27 \\
\hline 11 & HCCl fuel blending components & 31 \\
\hline 12 & HCCl Fuel candidate blending results & 32 \\
\hline 13 & Selected fuel blends for HCCl single engine testing & 33 \\
\hline
\end{tabular}

\section{List of Figures}

\begin{tabular}{|c|l|c|}
\hline Figure No & \multicolumn{1}{|c|}{ Title } & Page \\
\hline 1 & High temperature conductivity of OTM candidates & 11 \\
\hline 2 & Thermal expansion behavior of MM@ and OTM film candidates & 13 \\
\hline 3 & Life and cycle test results for LCM61/MM2 composite disk & 14 \\
\hline 4 & Before and after photographs of LCM61/MM2 composite disk & 14 \\
\hline 5 & Oven cycle test results for LCM88/MM2 composite disk coupon & 15 \\
\hline 6 & Conceptual scale drawing of the OTM GSR hydrogen plant & 19,20 \\
\hline 7 & Intake valve closing with variable lift duration & 28 \\
\hline 8 & Valve event phasing & 28 \\
\hline 9 & Variable lift with fixed duration & 29 \\
\hline 10 & $\begin{array}{l}\text { Results of the full factorial evaluation of the effects of intake and } \\
\text { exhaust valve event variations (at 2000RPM/50\% load pt) on ECR }\end{array}$ & 30 \\
\hline 11 & Summary of the effect of ECR on BSFC for simulated valve strategies & 30 \\
\hline
\end{tabular}




\section{List of Acronyms}

ATR Auto-thermal reforming

BDC Bottom dead center

BPO BP Oxygenate

BSFC Brake Specific Fuel Consumption

$\mathrm{Cl}$

Compression ignition

CIDI

ECR

EGR

F-T

FTGTL

GHR

IMEP

IVC

IVO

$\mathrm{HCCl}$

LCM

MCTE

MM

OTM

OTM-2

OTM-3

P-0

Compression ignition, direct injection

Effective compression ratio

Exhaust gas recirculation

Fischer-Tropsch

Fischer Tropsch Gas to Liquids

Gas heated reformer

Indicated Mean Expanded Pressure

Intake valve closing

Intake valve opening

Homogeneous Charge Compression Ignition

Lead candidate material

Multi-Cylinder Test Engine

Alternative material systems

Oxygen Transport Membrane

Compact planar reactor design optimized for F-T syngas production

Compact planar reactor design optimized for low emission hydrogen production

SCTE

Small bench scale test reactors capable of testing single OTM tubes up to 8 inches in length at elevated pressures and temperature.

SMR

Single Cylinder Test Engine

TDC

TF

Steam methane reforming

Top dead center

TFd

TFC

TP

TT

ULS

ULSD

WA

Target Flux

Target flux for dense disks

Target flux for composite systems

Target Pressure

Target Temperature

Ultra-low Sulfur

Ultra-low Sulfur Diesel

Variable valve actuation 


\subsection{Executive Summary}

In this budget period, the program has two major goals:

- OTM Syngas and Hydrogen Technology: lower capital costs, lower operating costs, lower emissions and smaller footprint compared to conventional syngas or hydrogen plants. The baseline technology for comparison of large scale hydrogen production costs is steam methane reforming.

- UCTF in Advanced Diesel Engines: understanding of UCTF impact on contemporary diesel engine performance and emissions and potential of new $\mathrm{HCCl}$ engines and fuels to meet longer term performance and emissions targets.

The specific objectives and status are summarized below:

- Develop a durable OTM system for hydrogen that meets interim cyclability, flux and life targets.

- In an extended life test, demonstrate an oxygen flux $0.6 T F, 500$ hours and 10 thermal and compositional cycles without degradation at TT. This critical goal was achieved with the proprietary film/substrate system LCM61/MM2. Most recently a flux of 0.7 TF has been achieved at 0.9 TF with a similar system.

- Demonstrate the same performance in a pressurized reactor at 0.9TT and 1.38 TP. One system has achieved partial success at $0.8 T \mathrm{TT}$ and 1.38TP. Stress analyses models indicate the OTM should survive the higher pressure. Failures in testing are believed to be the result of apparatus design that places additional stress on the system. This is being addressed.

- Determine performance and economic targets for an OTM hydrogen system to achieve a $20 \%$ economic advantage over conventional steam methane reforming. Evaluate performance targets for the compact planar reactor to achieve a $20 \%$ reduction in syngas capital costs relative to conventional autothermal reforming with cryogenic oxygen for FTGTL.

- This study evaluated several different configurations of OTM based reactors including stand alone and modified SMR reactors. The study showed that the OTM-3 compact planar reactor is a step change improvement in hydrogen production costs if $\mathrm{CO}_{2}$ capture is desired or mandated.

- A benchmarking study to assess technical and cost targets for the OTM-2 compact planar reactor versus conventional ATR FTGTL was completed. Cost targets for the OTM technology to achieve a $20 \%$ advantage relative to ATR in a 25,000 BPD FTGTL plant were determined at two pressure levels. In addition it was shown that at full FTGTL reactor pressure, the OTM-2 design can achieve a syngas capital cost reduction of 28 to $44 \%$

- Select reactor type (planar versus tubular) by $2 \mathrm{Q} 04$.

- Complete. A compact planar reactor design (OTM-2) which utilizes the MM2 substrate system was selected for large scale syngas production. A similar reactor design, OTM-3, was selected for hydrogen production. 
- Complete BP and International Truck and Engine fuel testing and engine development program by $2 Q 04$.

- This task was completed in the 4Q04 with the successful conclusion of the $\mathrm{HCCl}$ fuel evaluation work.

Under the revised scope of work for this budget period, work was performed only under Tasks $1,2,4,8$ and 10. A brief summary of results by task is shown below:

Task 1, Material Development

The goal of this task is to develop superior materials for fabricating OTM elements. The approach is to develop two types of materials with different functions- a robust substrate for mechanical strength and an OTM film material for oxygen transport. Both materials must be chemically and physically compatible.

The primary substrate materials, LCM65 or MM2, were chosen early in this budget period. Both of these materials have little or no chemical expansion and exhibit excellent high temperature strength and creep properties. Work thus focused on developing OTM film materials that are robust and compatible with LCM29 and MM2 . To this end, forty nine new membrane materials were fabricated and characterized in Budget Period 3. One system has met our flux, life and cycle goals, LCM61/MM2. Other materials show great promise for improving performance and durability under more severe conditions.

\section{Task 2, Composite Element Development}

Numerous disk and tubular elements were fabricated for flux and life/durability testing. A new fabrication technique for making thin OTM films has been developed. This new method has resulted in significant improvements in flux. Work continues to optimize this fabrication process.

The LCM61/MM2 system successfully completed two life/cycle durability tests. This achievement satisfies one of the key goals of this budget period.

A larger scale planar test element ( 4 in by 4 in.) has been fabricated. This process will be adapted to fabricate planar channels and sub-sections in the next budget period.

Task 4, Reactor Design and Process Optimization

Evaluations of the OTM technology for hydrogen applications were completed. The results show significant thermal efficiency and cost advantages, especially if greenhouse gas control is required. A compact planar reactor design has been developed through computer modeling of the chemical and physical processes (chemical reactions, heat and mass transfer). Interestingly, the limiting design parameter in most cases is heat transport, not oxygen flux. A low pressure syngas application has been identified with early commercialization potential. 
A benchmarking study to determine target OTM equipment costs for a 25,000 BPD FTGL plant was completed. The benchmark syngas technology is autothermal reforming with cryogenic oxygen. The study evaluated cost tradeoffs for both a low and high pressure OTM syngas reactor design. The study showed that the OTM -2 reactor design can achieve cost reductions of 28 to $44 \%$ relative to the benchmark technology at full FTGTL pressure.

Task 8, Fuels and Engine Testing

The SCTE diesel test work with syngas derived ultra-clean fuels was completed. Fischer Tropsch diesel combined with a proprietary BP syngas derived oxygenate showed substantial reduction in all air emissions targets (NOx, soot, carbon monoxide) over most of the test nodes.

In addition, work on the $\mathrm{HCCl}$ fuel and engine development task was completed. A model of the 4.5L V6 diesel engine was developed using GT-Power Cycle Simulator software.. The model was used to evaluate valve timings and lift profiles strategies and guide the $\mathrm{HCCl}$ engine development and fuel testing program. The study concluded that a variable valve actuation system capable of simultaneous control of intake valve closing and intake valve lift at fixed intake valve opening has a significant potential for becoming the $\mathrm{HCCl}$ enabling technology.

BP developed a matrix of fuel components and conducted a blending study of 24 test fuel mixtures. Three fuels were selected for testing in the single cylinder $\mathrm{HCCl}$ test engine. The three fuels contained both diesel and gasoline fuel components and were more volatile than diesel but less volatile than gasoline.

The three fuels were compared against a benchmark ULS diesel fuel. An experimental design was used to evaluate three engine parameters: EGR, swirl and No. 2 injection timing. All fuels showed substantial reduction in soot versus the ULS base fuel. Fuels 2 and 3 achieved significant reductions in NOx as well as soot. However all fuels showed an increase in hydrocarbon emissions relative to the base fuel. No deterioration in fuel consumption (BSFC) was observed with the three $\mathrm{HCCl}$ fuels. These experiments are the foundation for a more in-depth study of fuel properties and engine parameters

\section{Task 10, Project Management}

All progress reports were completed and submitted on time. All key objectives were completed. A six month no-cost extension was granted to allow completion of Task 8 . and part of Task 2.

We participated in a DOE sponsored peer review in Houston June, 2003. In addition, three progress update meetings were held with the DOE in July 2003, June 2004 and December 2004. A paper was submitted for the Spring AIChE meeting, under the natural gas utilization topic in April 2004 and a similar paper was presented at the March 2003 ACS meeting. 


\subsection{Introduction}

The DOE's Office of Fossil Energy created strategic partnerships targeted at the development and verification of advanced fuel-making processes that utilize fossil feedstocks. These processes will enable the production of ultra-clean transportation fuels that improve the environment, while also expanding and diversifying the fossil resource base. In response to the DOE's solicitation for research and development leading to the production of ultra-clean transportation fuels from fossil resources, Cooperative Agreement number DE-FC26-01NT41096 for work entitled "Development of OTM Syngas Process and Testing of Syngas-Derived Ultra-clean Fuels in Diesel Engines and Fuel Cells" was awarded to Praxair.

The objectives of this project are: (1) develop an advanced syngas technology, based on Oxygen Transport Membranes (OTMs), that will provide a step change reduction in the cost of converting natural gas to a spectrum of liquid transportation fuels and thereby improve the prospects for meeting vehicle emissions targets with cost competitive ultra clean transportation fuels (UCTFs); (2) evaluate the performance of, and emissions from selected syngas-derived UCTFs in advanced vehicle propulsion systems, including advanced diesel engines with post treatment and fuel cells; and 3) develop an optimized UCTF/diesel engine/exhaust after treatment system capable of meeting emission regulations beyond 2007.

The scope of work was modified for this budget period to include development of the OTM syngas technology for hydrogen production. Hydrogen is an ultra-clean fuel and a co-product of syngas, and is an integral part of the OTM commercialization roadmap.

\subsection{Progress and Results by Task}

\subsection{Task 1: Materials Development}

\subsubsection{Goal - Task 1}

The Recipient shall fabricate, test and characterize OTM film and substrate materials with the goal of developing a more robust and cost effective OTM element in comparison to the lead candidate material, LCM1.

\subsubsection{Experimental - Task 1}

The experimental facilities and methods in Task 1 were described in detail in the Topical Report for Budget Period 1 [Ref. 1].

\subsubsection{Task 1 Results and Discussion}

The goal of this task is to develop superior materials for fabricating OTM elements. The approach is to develop two types of materials with different functions- a robust substrate for mechanical strength and an OTM film material for oxygen transport. Both materials must be chemically and physically compatible.

\subsubsection{Substrate materials}

The primary substrate materials, LCM65 or MM2, were chosen early in this budget 
period. Both of these materials have little or no chemical expansion and exhibit excellent high temperature strength and creep properties. These materials are close analogs of the materials selected at the end of Budget Period 2 (LCM29 and MM1).. Materials work is focusing on improving the performance and durability of the oxygen transport membrane material.

\subsubsection{Membrane materials}

The focus of this subtask is to develop OTM film materials that are robust and compatible with LCM29 and MM2. To this end forty nine new membrane materials were fabricated and characterized in Budget Period 3.

In addition, a review of all prior interaction studies between membrane material components and substrate candidates was completed to guide optimization studies. Two membrane components were shown to be the key factors effecting high temperature performance and life. A number of material formulations have been developed that eliminate these components. Table 1 shows the flux results of five new materials without the undesirable components. All of these materials achieved acceptable fluxes at TT, but some (LCM 74, 77 and 80 ) were found to be unstable after prolonged exposure at TT. LCM74 and LCM80 were retested at $0.8 \mathrm{TT}$. At this temperature the materials were stable and showed no sign of decomposition or phase change.

Table 1: Normalized flux results of membrane candidate materials

\begin{tabular}{|c|c|c|c|c|c|}
\hline Disc & Fuel composition & $\mathrm{TT}$ & $0.9 \mathrm{TT}$ & $0.8 \mathrm{TT}$ & $E_{\mathbf{a}}$ \\
\hline \multirow{2}{*}{ LCM74 } & $70 \% \mathrm{H}_{2} / 30 \% \mathrm{CO}_{2}$ & $0.8 \mathrm{TF}$ & - & - & \multirow{2}{*}{$\begin{array}{c}79 \\
\mathrm{~kJ} / \mathrm{mole}\end{array}$} \\
\hline & $85 \% \mathrm{H}_{2} / 15 \% \mathrm{CO}_{2}$ & $1.2 \mathrm{TF}$ & $0.6 \mathrm{TF}$ & $0.3 T F$ & \\
\hline \multirow{2}{*}{ LCM77 } & $70 \% \mathrm{H}_{2} / 30 \% \mathrm{CO}_{2}$ & $0.9 \mathrm{TF}$ & - & - & \multirow{2}{*}{$\begin{array}{c}72 \\
\mathrm{~kJ} / \mathrm{mole}\end{array}$} \\
\hline & $85 \% \mathrm{H}_{2} / 15 \% \mathrm{CO}_{2}$ & $1.1 \mathrm{TF}$ & $0.6 \mathrm{TF}$ & $0.3 T F$ & \\
\hline \multirow{2}{*}{ LCM78 } & $70 \% \mathrm{H}_{2} / 30 \% \mathrm{CO}_{2}$ & $1.2 \mathrm{TF}$ & - & - & \multirow{2}{*}{$\begin{array}{c}62 \\
\mathrm{~kJ} / \mathrm{mole}\end{array}$} \\
\hline & $85 \% \mathrm{H}_{2} / 15 \% \mathrm{CO}_{2}$ & $1.4 \mathrm{TF}$ & $0.7 \mathrm{TF}$ & $0.4 \mathrm{TF}$ & \\
\hline \multirow{2}{*}{ LCM79 } & $70 \% \mathrm{H}_{2} / 30 \% \mathrm{CO}_{2}$ & 1.0TF & - & - & \multirow{2}{*}{$\begin{array}{c}94 \\
\mathrm{~kJ} / \text { mole }\end{array}$} \\
\hline & $85 \% \mathrm{H}_{2} / 15 \% \mathrm{CO}_{2}$ & $1.1 \mathrm{TF}$ & $0.5 \mathrm{TF}$ & $0.2 \mathrm{TF}$ & \\
\hline \multirow{2}{*}{ LCM74 } & $70 \% \mathrm{H}_{2} / 30 \% \mathrm{CO}_{2}$ & - & - & $0.4 \mathrm{TF}$ & \multirow{2}{*}{ - } \\
\hline & $85 \% \mathrm{H}_{2} / 15 \% \mathrm{CO}_{2}$ & - & - & $0.4 \mathrm{TF}$ & \\
\hline \multirow{2}{*}{ LCM80 } & $70 \% \mathrm{H}_{2} / 30 \% \mathrm{CO}_{2}$ & - & - & $0.2 \mathrm{TF}$ & \multirow{2}{*}{ - } \\
\hline & $85 \% \mathrm{H}_{2} / 15 \% \mathrm{CO}_{2}$ & - & - & $0.3 T F$ & \\
\hline LCM81 & $70 \% \mathrm{H}_{2} / 30 \% \mathrm{CO}_{2}$ & $1.0 \mathrm{TF}$ & & & $\begin{array}{c}89^{\star} \\
\mathrm{kJ} / \text { mole }\end{array}$ \\
\hline
\end{tabular}


Thermal and chemical expansion of these materials were measured in a Baehr Dilatometer DIL 802 and compared to other membrane materials. Results of thermal expansion measurements in air are shown below in Table 2.

Chemical expansion behavior of these materials was also measured relative to air at $0.9 \mathrm{TT}$. Table 2 shows the relative expansion in three different gas compositions which represent a $\mathrm{pO}_{2}$ range from $\sim 10^{-5}$ to $\sim 10^{-13}$ bar.

Table 2: Thermal and chemical expansion behavior of membrane materials

\begin{tabular}{|l|l|l|l|l|}
\hline & $\begin{array}{c}\text { Normalized } \\
\text { Average } \\
\text { TEC }\end{array}$ & \multicolumn{3}{|c|}{$\begin{array}{c}\text { Chemical expansion } \\
\text { At 0.9TT } \\
\text { Relative to air (\%) }\end{array}$} \\
\cline { 3 - 5 } & & in CO & I\%CO in $\mathrm{CO}_{2}$ & 5\%CO in $\mathrm{CO}_{2}$ \\
\hline LCM7 & 1.21 & 0 & 0.02 & 0.035 \\
\hline LCM82 & 1.19 & 0 & 0 & 0.03 \\
\hline LCM15 & 1.53 & 0.13 & $>0.24$ & \\
\hline LCM87 & 1.10 & 0 & 0.03 & 0.07 \\
\hline LCM40 & 1.16 & 0 & 0.03 & 0.20 \\
\hline LCM83 & 1.29 & 0.02 & 0.07 & 0.08 \\
\hline LCM84 & 1.27 & 0.015 & 0.06 & \\
\hline LCM85 & 1.29 & 0.02 & 0.07 & 0.085 \\
\hline LCM86 & 1.29 & 0.02 & 0.06 & \\
\hline LCM77* & 1.16 & $-0.06^{*}$ & -0.04 & \\
\hline LCM80* & 1.17 & $-0.05^{*}$ & -0.03 & \\
\hline LCM74* & 1.18 & $-0.04^{*}$ & -0.02 & $0.13-0.150$ \\
\hline
\end{tabular}

Many of these materials show good expansion behaviour relative to air (less than 0.1 $\%$ ), however some materials $\left(^{*}\right)$ contract at reduced $\mathrm{pO}_{2}$. Based on the behaviour of similar materials, this is an unexpected result that may be advantageous.

More recent tests have focused on materials with promising high temperature stability and conductivity properties. Results of conductivity tests are shown below in Figure 1 .. 


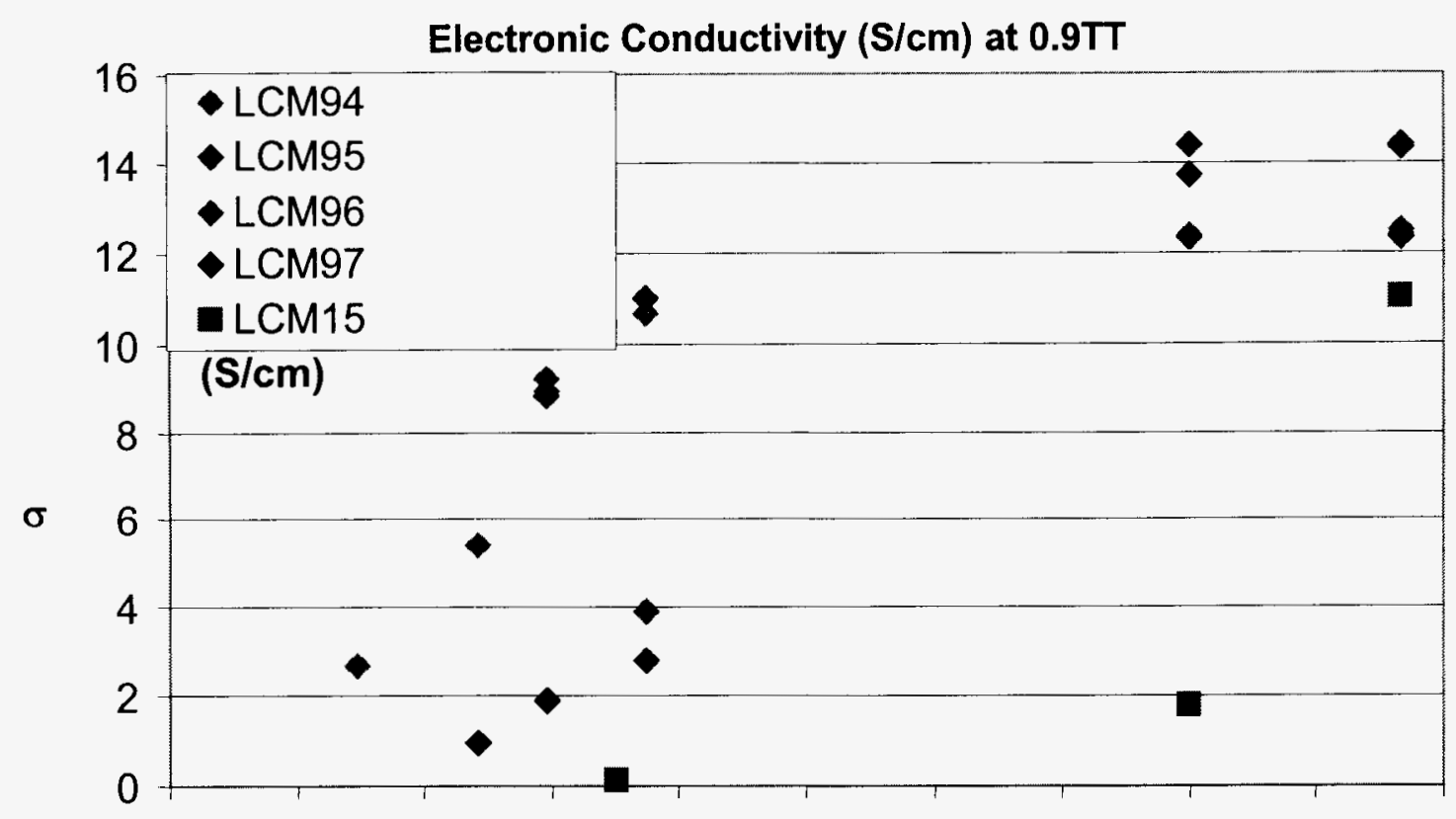

Relative $\log \mathrm{pO} 2$

Figure 1: High temperature conductivity of OTM candidates

In comparison to our benchmark material, LCM15, these new materials exhibit significantly higher conductivity at low pO2.

Thermal and chemical expansion behaviour of these materials was also measured. Results are summarized below in Table 3 LM94 and 95 both show good chemical expansion behaviour. More testing is planned with these materials

Table 3 : Thermal and chemical expansion of LCM65 type film candidates.

\begin{tabular}{|c|c|c|c|c|c|c|}
\hline \multirow[t]{2}{*}{ New Materials } & \multirow[t]{2}{*}{ Normalized TEC } & \multicolumn{5}{|c|}{$\begin{array}{c}\text { Chemical expansion } \\
\text { at } 0.9 \mathrm{TT} \\
\text { relative to air }(\%) \\
\end{array}$} \\
\hline & & 8 & 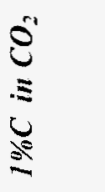 & 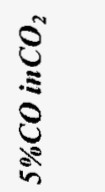 & ¿̊ & $\begin{array}{l}\Sigma \\
8^{\circ} \\
8^{\circ}\end{array}$ \\
\hline LCM94 & 1.06 & 0 & 0 & 0.05 & 0.13 & 0.24 \\
\hline LCM95 & 1.00 & 0 & 0.03 & 0.08 & 0.16 & 0.25 \\
\hline LCM96 & 1.22 & 0 & 0.31 & 0.41 & 0.54 & \\
\hline LCM97 & 1.16 & 0 & 0.18 & 0.21 & 0.24 & \\
\hline
\end{tabular}


The above OTM materials are targeted for the LCM12 system. A number of materials are also being developed for the MM2 system. These include LCM71-73, LCM75, LCM83, 84, LCM88-93, and LCM98

Results of the LCM90-93 are encouraging. These materials show substantially improved chemical expansion behaviour in comparison to the benchmark LCM15. Fluxes of these materials are adequate and high temperature stability is expected to be good. Cycling results of some of these materials are reported later and show good robustness.

Table 4: Thermal and chemical expansion of MM2 type film candidates.

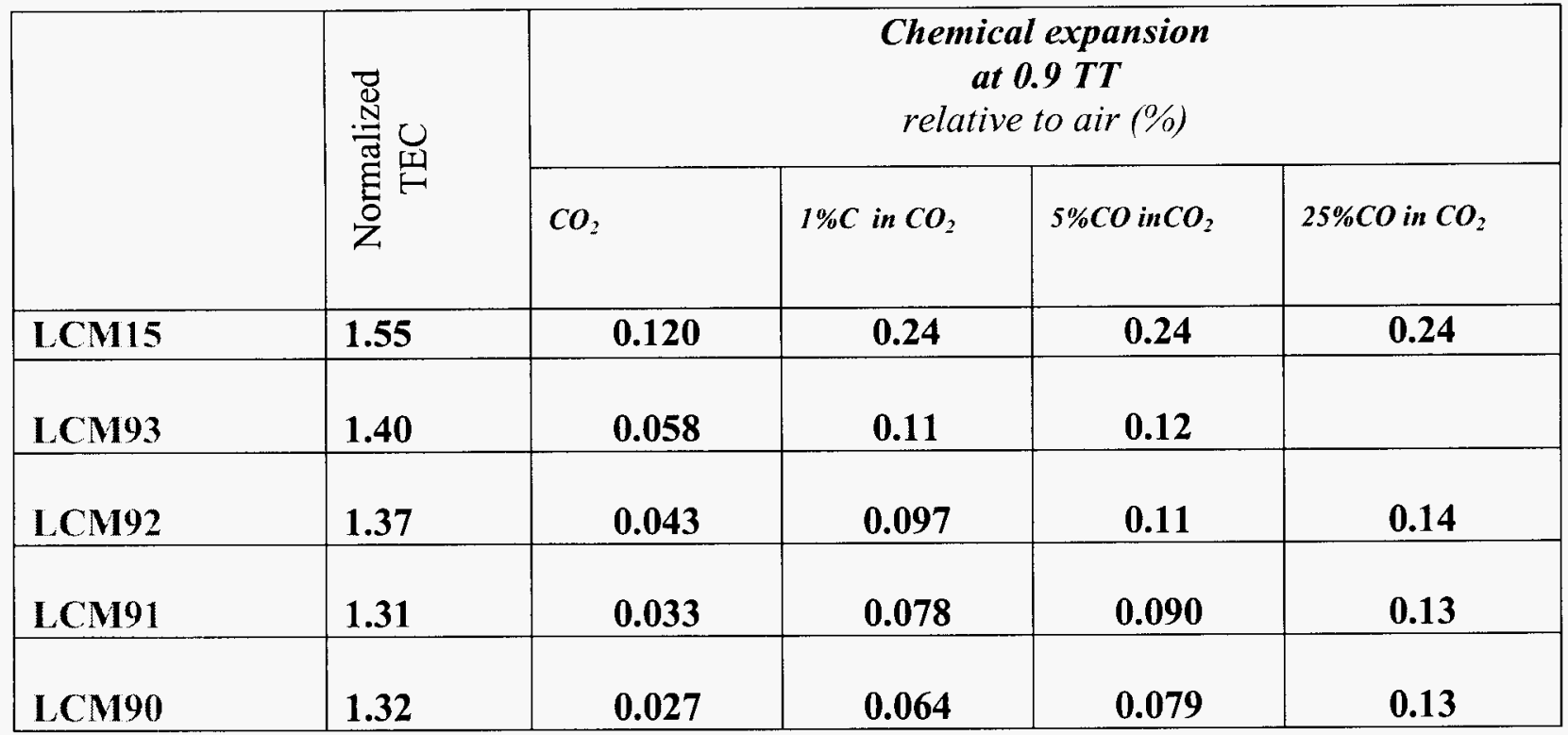

\subsection{Task 2: Composite Development}

\subsubsection{Goal - Task 2}

The Recipient shall develop advanced composite OTM elements and the techniques for fabricating these elements at the bench scale. The goal is to develop robust, low cost, high flux elements that can survive multiple temperature and fuel composition cycles while maintaining structural integrity at target pressure differentials.

Milestone:

- In an extended life test, demonstrate an oxygen flux of $0.6 T F, 500$ hours and 10 thermal and compositional cycles without degradation at TT.

\subsubsection{Experimental - Task 2}

The experimental facilities and methods in Task 2 were described in detail in the Topical Report for the Period Jan. 1 through Oct. 31, 2001 [Ref. 1].

\subsubsection{Results and Discussion - Task 2}


Composite development focused on the LCM61/MM2 system. Figure 2 below shows that these materials have very similar thermal expansion characteristics.

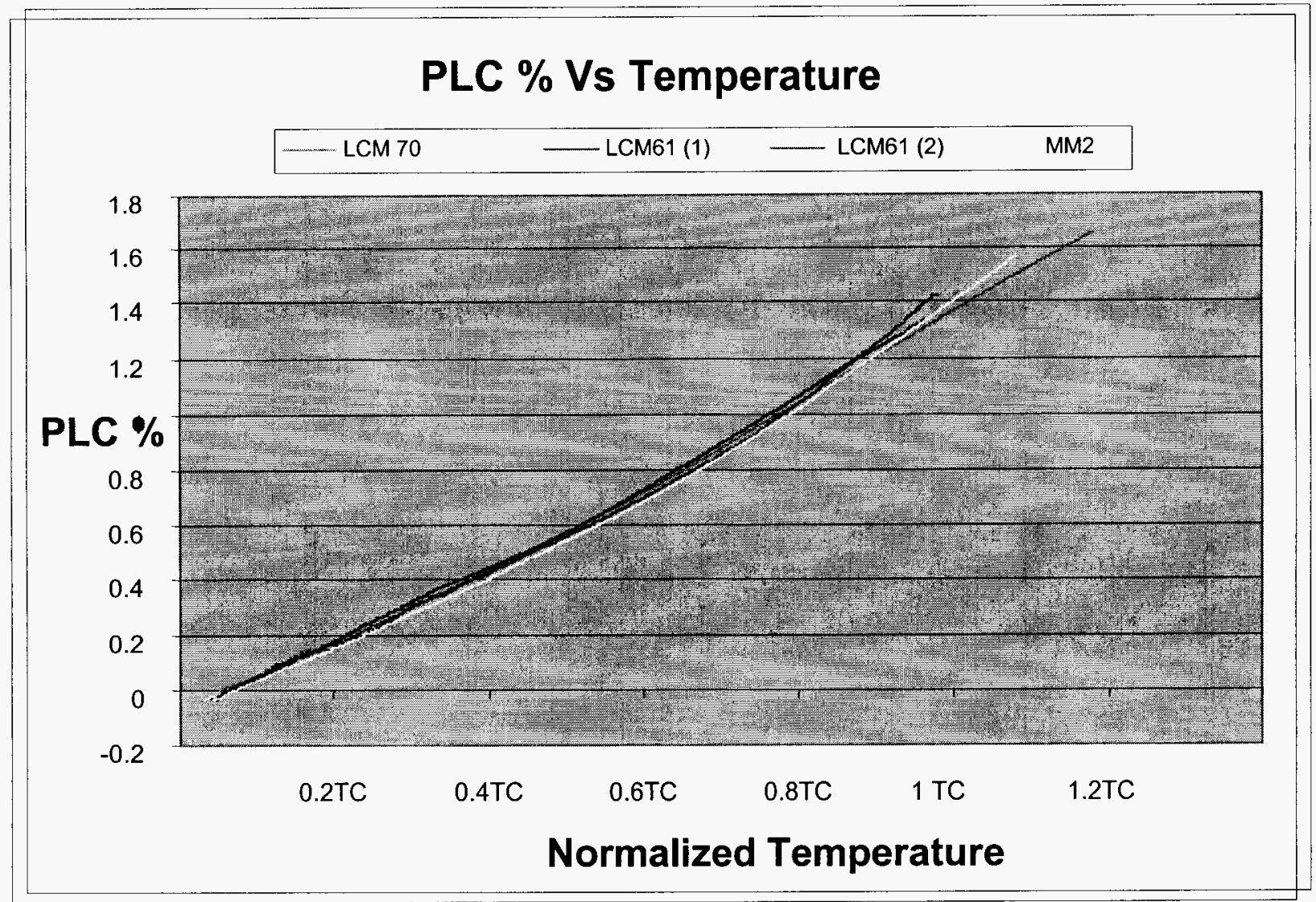

Figure 2: Thermal expansion behavior of MM2 and OTM material candidates

An LCM61 on MM2 disk was fabricated and tested in the disk reactor. The disk achieved a flux of 0.4TFc at TT. The disk was subjected to ten thermal and twelve compositional cycles. The disk was removed after the fourth cycle and examined. The disk showed no signs of cracking or leaking, per both physical examination and a pressurized gas permeability test. The disk was reloaded and completed another six thermal cycles. The flux did not degrade, nor did the measured leak rate increase during the 336 hour test. Again, the disk showed no signs of cracking or corrosion after the severe life and durability test. This is a very important confirmation of the LCM61/MM2 system.

A second test of the LCM61 on MM2 disk was performed in the disk reactor. The disk achieved a flux of 0.6TFc at TT and maintained this flux for over 500 hours. The disk was also subjected to ten thermal and twelve compositional cycles. The flux performance and temperature cycling are shown in Figure 3. 


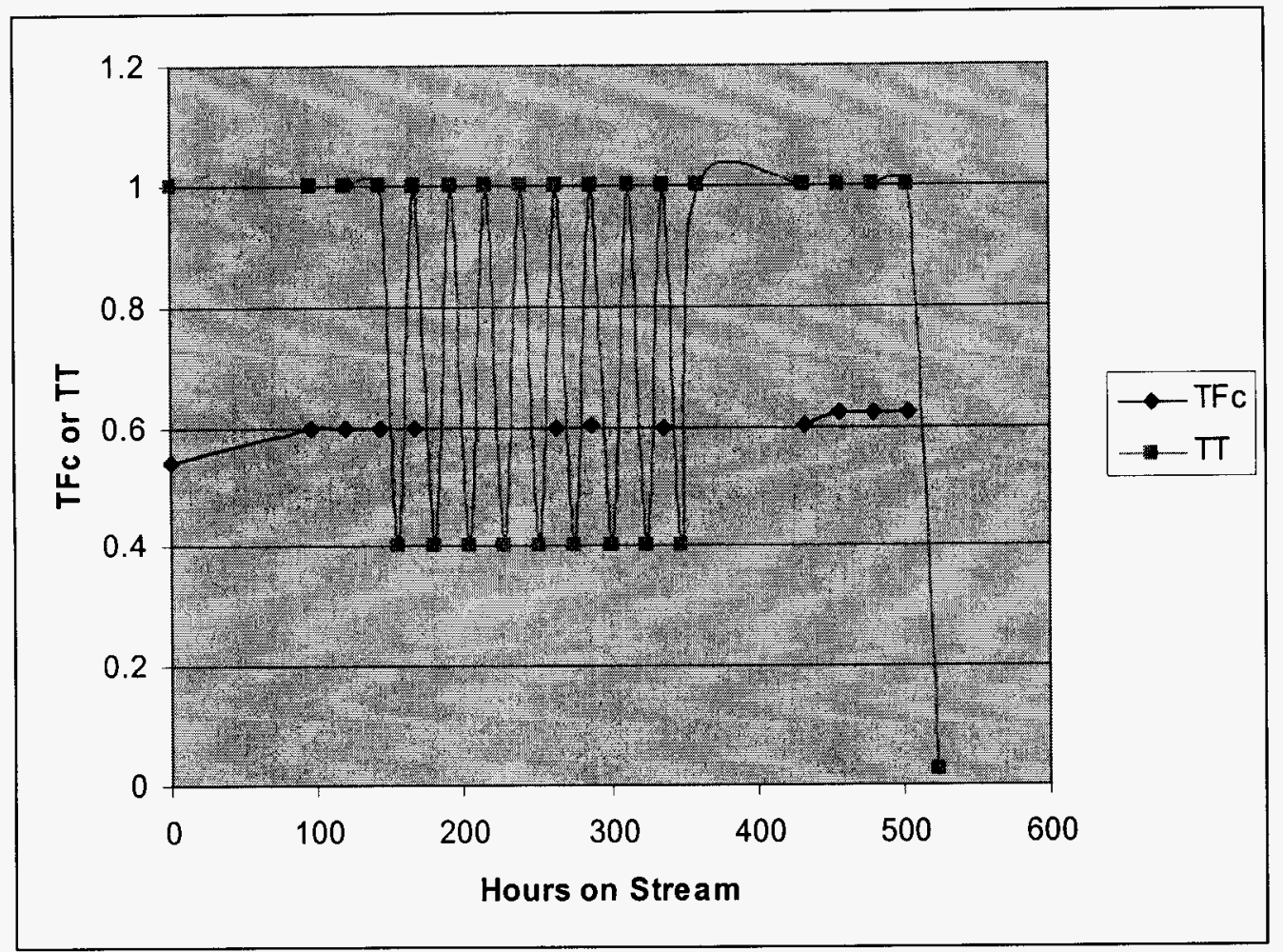

Figure 3: Life and cycle test results for LCM61/MM2 composite disk

The disk was removed after the final cycle and examined. The disk showed no signs of cracking or delamination. SEM analysis also showed no stress cracks of any kind. Photographs of the disk are shown below in Figure 4. This achieved a major Budget Period 3 milestone for flux, life and durability.

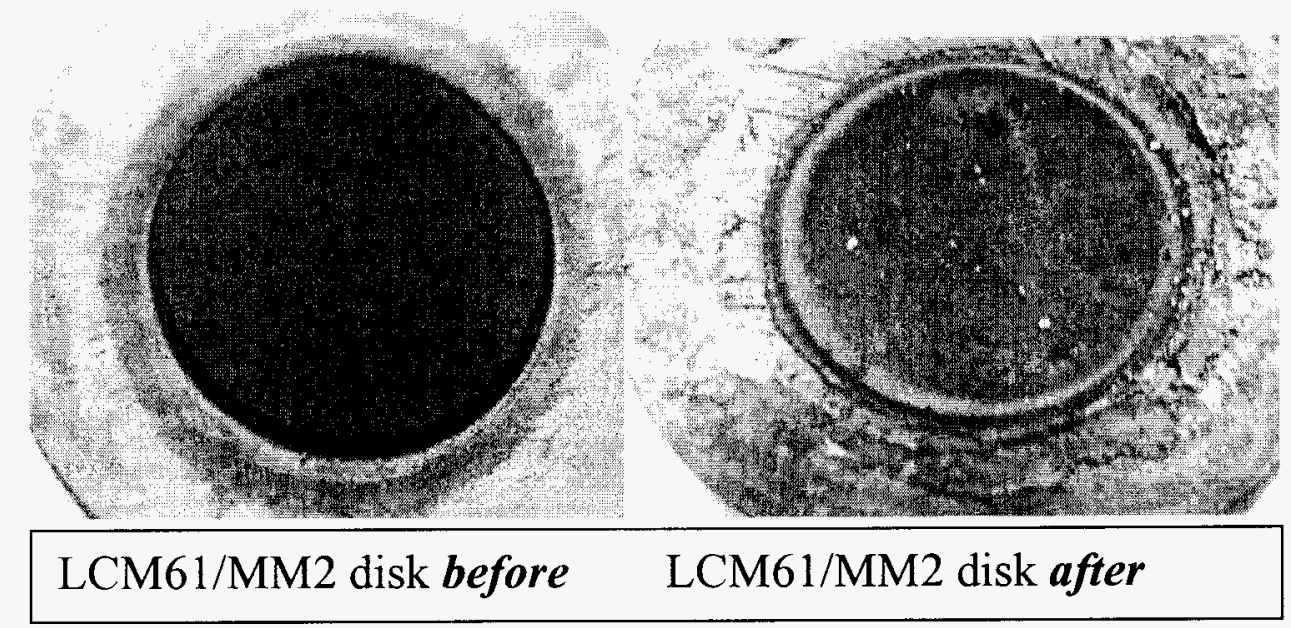

Figure 4: Before and after photographs of LCM61/MM2 composite disk

An LCM62 on MM2 composite disk was fabricated and run for 480 hours at TT. The disk achieved a steady flux of $0.6 T F c$. The sample was then subject to 10 thermal 
cycles and 12 compositional cycles. Although flux did not degrade over this time, microcracks were observed in the sample after removal from the test reactor. The cracks may be attributable to chemical expansion in the LCM62. For this reason LM62 will be abandoned.

A new system, LCM89/MM1, was prepared and subjected to oven cycle tests. The film material showed no signs of cracking or spalling after 80 cycles from room temperature to $0.9 \mathrm{TT}$. The first 10 cycles were conducted at a rate of $2^{\circ} \mathrm{C} /$ minute and the final 70 were cycled at $5^{\circ} \mathrm{C} /$ minute. The samples were held at $0.9 \mathrm{TT}$ for 1 hour before cooling.

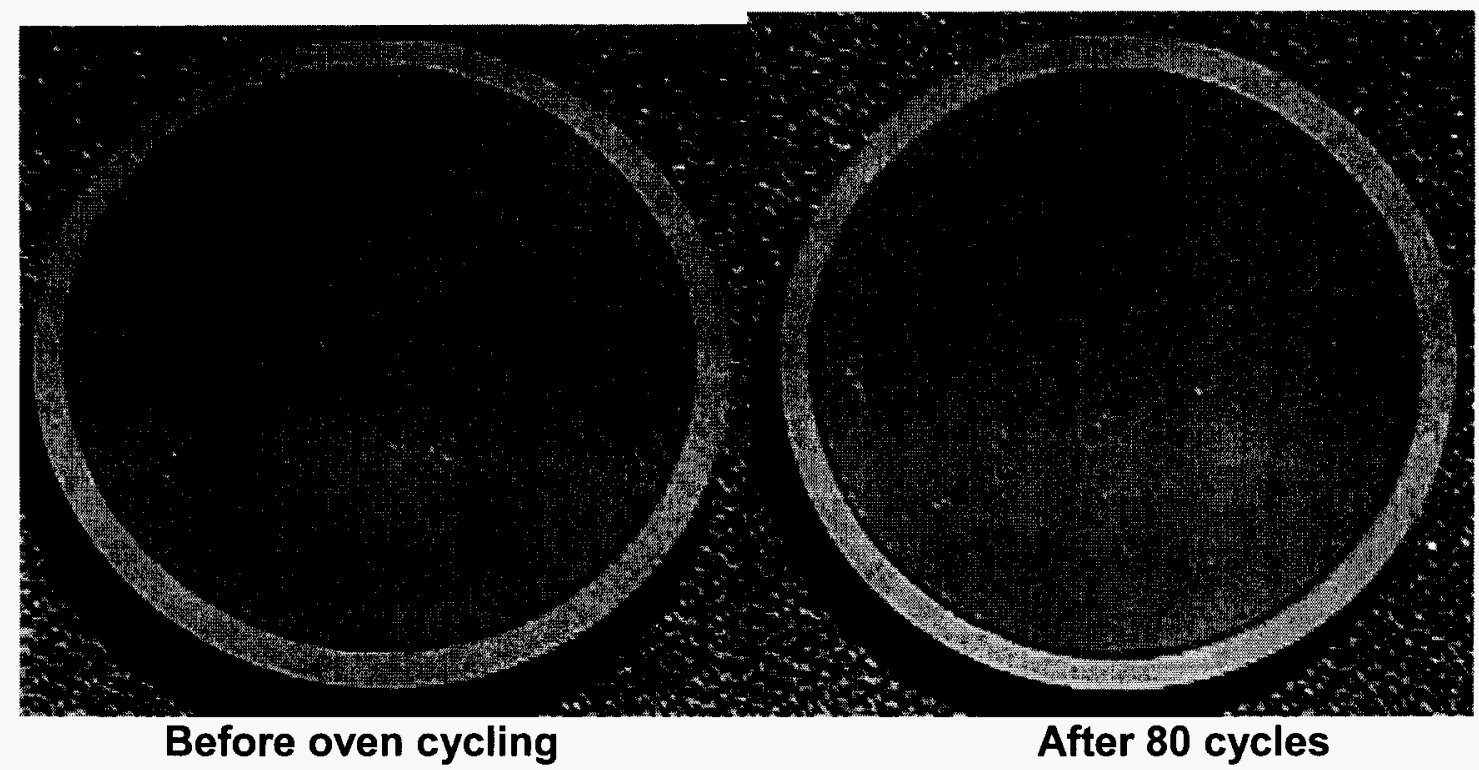

Figure 5: Oven cycle test results for LCM88/MM2 composite disk coupon

This new system promises to be more stable at high temperatures

In addition, a new film application technique is being developed that produces robust, dense, but very thin OTM films. An LCM761/MM2 disk made by this technique with a 50 micron film, achieved a flux of $0.64 \mathrm{TF}$ at $0.9 \mathrm{TT}$. A second disk completed a 480 life/cycle test at $0.9 \mathrm{TT}$. It achieved a steady flux of $0.60 \mathrm{TF}$.

\subsection{Task 4: Reactor Design and Process Optimization}

\subsubsection{Goal - Task 4}

Develop the commercial OTM syngas and hydrogen processes, including reactor design and catalyst deployment, reactor components (seals, internals, isolation devices, high temperature tube sheet, etc), and ancillary processes (feed pre-treatment, preheat, syngas cooling). Task 4 includes the operation of bench scale units, $\mathrm{P}-0$, which are used to evaluate small OTM elements (tubes or disks) at high pressure. Task 4 also includes mathematical modeling, process scale up and economic evaluation. 
Milestones:

- Demonstrate robust performance of an OTM system in a pressurized reactor at $0.9 \mathrm{TT}$ and 1.38TP

- Determine performance and economic targets for an OTM hydrogen system to achieve a $20 \%$ economic advantage over conventional steam methane reforming.

- Evaluate performance targets for the compact planar reactor to achieve a $20 \%$ reduction in syngas capital costs relative to conventional autothermal reforming with cryogenic oxygen for FTGTL.

- Select reactor type (planar versus tubular) by $2 \mathrm{Q} 04$

\subsubsection{Experimental - Task 4}

The experimental facilities and methods in Task 4 were described in detail in the Topical Report for the Period Jan. 1 through Oct. 31, 2001 [Ref. 1].

\subsubsection{Results and Discussion}

\subsubsection{High pressure disk reactor}

A high disk pressure reactor was built. It is capable of prolonged operation at 1.4TP and $0.9 T T$. LCM61/MM2 disks with $1.0 \mathrm{~mm}$ substrates had film failures, ostensibly due to deformation of the substrate under the hydraulic pressure differential of 1.3 TP. Subsequent tests with a $1.5 \mathrm{~mm}$ substrate survived three pressure and thermal cycles from room temperature to $0.8 \mathrm{TT}$ and ambient pressure to $0.56 \mathrm{TP}$.

\subsubsection{OTM Reactor Study}

The development of a new class of OTM materials has allowed us to reevaluate the tubular OTM element strategy. These new materials are amenable to planar geometries with small channels and passages. Consequently, a new reactor design has been developed in this Budget Period, employing a fundamentally new architecture based on planar, not tubular element fabrication. Details of this reactor design are proprietary and patent pending. This compact design has unique advantages in terms of thermal efficiency, emissions control and obviously plant size and footprint area. Computer modeling of the chemical and physical processes (heat and mass transfer) has shown that the limiting design parameter is heat transport, not oxygen flux.

Two planar reactor designs have been developed. The OTM-2 reactor is optimized for producing high pressure syngas for FTGTL applications. The OTM-3 reactor is optimized for producing hydrogen and sequestering $\mathrm{CO}_{2}$. The OTM membrane operates at a much lower pressure differential than the OTM-2 reactor configuration.

The reactor design is staged to allow optimal use of materials based on process severity. A low temperature inlet region will employ less expensive structural and OTM materials. The high temperature stage, if required, (it depends on product application) will employ suitable structural and OTM materials, which generally become more expensive as design temperature increases. 
Currently the LCM61/MM2 system is adequate for the low temperature stage. Some improvements in film durability are required for the second stage, which $t$ is the prime focus of the materials development team.

\subsubsection{Foster Wheeler OTM Hydrogen Study}

Foster Wheeler has completed an evaluation of OTM technology for producing hydrogen from natural gas. The base case is a 100 MMSCFD Gulf Coast steam methane reforming (SMR) hydrogen plant utilizing Foster Wheeler furnace technology and a conventional PSA for hydrogen purification. The study also compared advanced OTM designs to an SMR plant with a gas heated reformer (SMR/GHR). This configuration will produce the highest yield of hydrogen per mole of methane feed. An OTM process configuration and reactor design was developed that exceeded the SMR/GHR hydrogen yield efficiency and almost eliminates the production of NOx. In addition, all waste gases are nitrogen free, thus greatly facilitating carbon dioxide sequestration. A comparison of the cases is shown below in Table 5.

Table 5: Hydrogen study results

\begin{tabular}{|l|l|c|c|c|}
\hline & \multicolumn{1}{|c|}{ Units } & $\begin{array}{c}\text { SMR Base } \\
\text { Case }\end{array}$ & $\begin{array}{c}\text { SMR/GHR } \\
\text { Case }\end{array}$ & $\begin{array}{c}\text { Best OTM } \\
\text { Case }\end{array}$ \\
\hline $\mathrm{H} 2$ yield & $\begin{array}{l}\text { Mole H2 } \\
\text { /Mole } \mathrm{CH} 4\end{array}$ & 2.44 & 2.74 & 2.86 \\
\hline NOx production & Ton/Yr & 142 & 105 & $\mathrm{Nil}$ \\
\hline Export steam & $\mathrm{KLb} / \mathrm{Hr}$ & 191 & $\mathrm{Nil}$ & $\mathrm{Nil}$ \\
\hline OPEX & $\$ \mathrm{MM} / \mathrm{yr}$ & 80.6 & 71.5 & 70.7 \\
\hline Steam credit & $\begin{array}{l}\$ \mathrm{MM} / \mathrm{yr} \\
@ \$ 5.50 / \mathrm{klb}\end{array}$ & 9.1 & 0.0 & 0.0 \\
\hline Net OPEX & $\$ \mathrm{MM} / \mathrm{yr}$ & 71.5 & 71.5 & 70.7 \\
\hline
\end{tabular}

The results show that OTM is efficient at converting methane to hydrogen and can do so without direct air combustion of fuel, which will create NOx. The OTM however requires a large blower to supply air to the membranes and thus has a non-trivial power cost penalty. This can be reduced by lowering the pressure drop of air through the OTM reactor membrane passages and improving the recovery of oxygen in the reactor, both of which are development goals for the next phase of the program.

This study showed that the OTM process has a distinct thermal efficiency advantage for producing hydrogen from natural gas. In addition, the OTM-3 planar \ reactor, which is explained in more detail below, has an added benefit of producing almost zero NOx while easily sequestering over $95 \%$ of the potential $\mathrm{CO} 2$ emissions. A follow-up study by Foster Wheeler shows that the cost of capturing CO2 with the OTM GSR is well under $50 \%$ of the cost of conventional amine scrubbing technology when more or less complete $\mathrm{CO} 2$ removal is required. Further this system will recover $100 \%$ of the available $\mathrm{CO} 2$ (compared to $92 \%$ for the most efficient amine configuration), will emit 
almost no NOx and yield considerably more hydrogen than conventional SMR. These results are shown below in Table 6 .

Table 6. Economic Comparison of OTM-3 and Conventional SMR for hydrogen production with $\mathrm{CO} 2$ recovery and compression.

\begin{tabular}{|c|c|c|c|}
\hline Parameter & Units & $\begin{array}{c}\text { SMR with } \\
\text { CO2 recovery } \\
\text { of syngas } \\
\text { and flue gas }\end{array}$ & OTM-3 Case \\
\hline $\mathrm{H} 2$ yield & $\begin{array}{l}\text { Mole H2 /Mole } \\
\mathrm{CH} 4\end{array}$ & 1.45 & 2.57 \\
\hline Electricity & KW & 2,663 & 18,220 \\
\hline $\mathrm{CO} 2$ production & TPD & 3,359 & 2,018 \\
\hline CO2 emissions & TPD & 284 & - \\
\hline CO2 Recovery & & $92 \%$ & $100 \%$ \\
\hline Estimated NOx emissions & Ton $/ \mathrm{Yr}$ & 346.2 & Nil \\
\hline TOTAL COSTS, \$/year & & $181,599,405$ & $112,330,036$ \\
\hline Hydrogen cost & \$/MSCF & 2.49 & 2.49 \\
\hline CO2 Cost w/compression & $\$ / T$ & 76.09 & 31.31 \\
\hline
\end{tabular}

Note that a significant amount of energy is required in both cases to compress the $\mathrm{CO}_{2}$ to pipeline pressure (3300 psig). It should be immediately apparent that the hydrogen yield for the OTM-3 case is comparable to conventional technology without $\mathrm{CO}_{2}$ recovery, whereas in the SMR case, the yield is closer to $60 \%$. This is a consequence of the vast amount of natural gas required as fuel to raise steam for the amine systems..

Looked at slightly differently, in the case where $\mathrm{CO} 2$ has no value, but instead must be sequestered at a cost of $\$ 10$ per ton. The SMR -Amine system above produces hydrogen at $\$ 5.38 / \mathrm{MSCF}$, while the GSR is able to produce hydrogen at $\$ 3.32 / \mathrm{MSCF}$. In this context, it is clear that the penalty for $\mathrm{CO} 2$ sequestration in the GSR case is modest and potentially affordable, while with conventional technology it is very large.

Seen in this light, the GSR is an enabling technology for the hydrogen economy.

The OTM-3 reactor scheme results in an extremely compact configuration as shown in Figure 6 This technology could be a BACT candidate for hydrogen if both $\mathrm{CO}_{2}$ and NOx become regulated pollutants. 
Figure 6. Comparison of Conventional Hydrogen SMR Plant with Amine $\mathrm{CO} 2$ Recovery and the OTM GSR Technology.

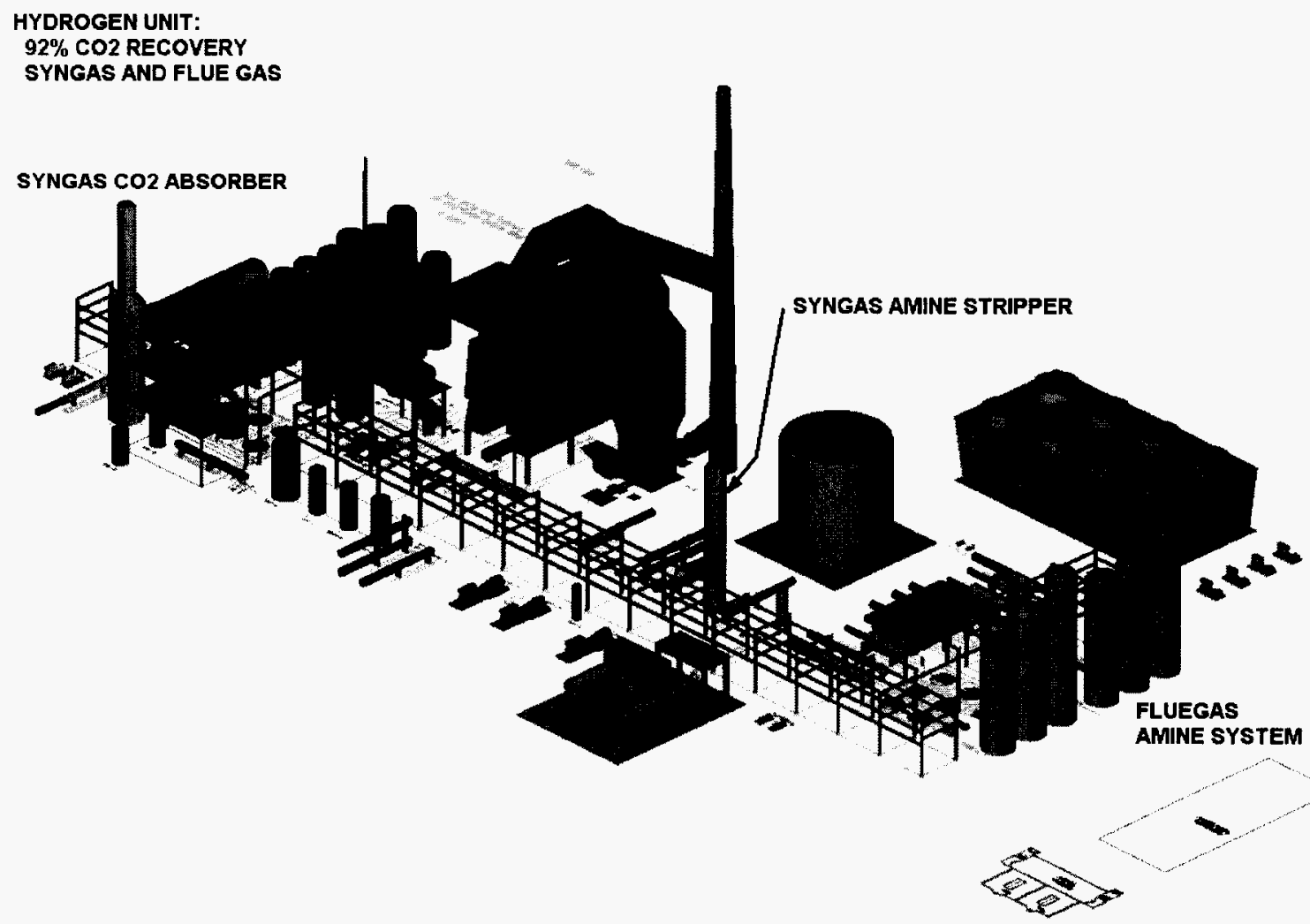

6a-Conventional SMR with PSA and Amine Scrubbing to Recover $92 \%$ of total $\mathrm{CO}_{2}$ emissions by scrubbing high pressure syngas and low pressure flue gas 


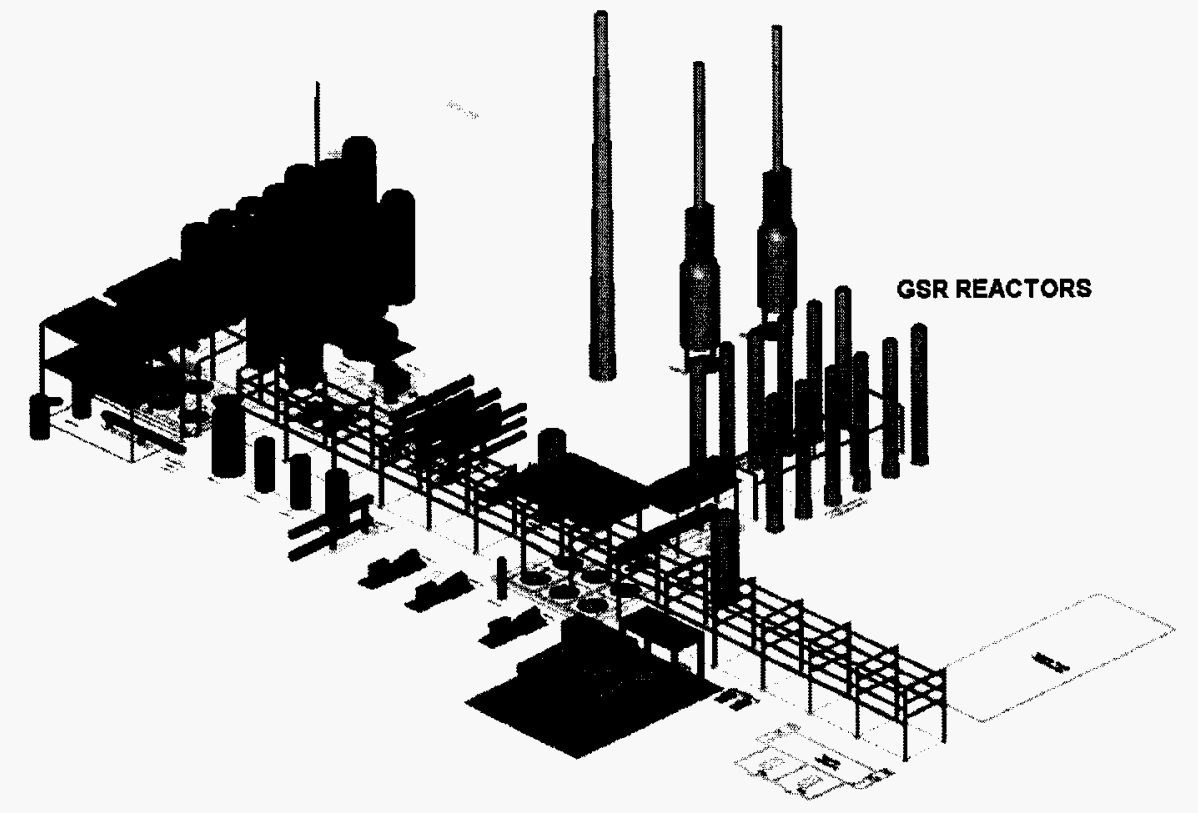

\section{6b-OTM-3 Hydrogen Plant with 100\% CO2 Recovery}

\subsubsection{FTGTL Application}

Foster Wheeler has completed a study of a 25,000 BPD OTM based Fischer Tropsch Gas to Liquids plant (FTGTL). The purpose of this study is to update our understanding of the economic incentives and cost and performance targets for the new OTM technology which has been developed. Results are shown below in Table 7.

Table 7: Cost Targets for OTM Equipment in a 25,000 BPD FTGTL Plant

\begin{tabular}{|c|c|c|}
\hline $\begin{array}{c}\text { Savings from ATR } \\
\text { Base Case }\end{array}$ & $\begin{array}{c}\text { Cost of Production } \\
\text { Plus ROI (\$/bbl) }\end{array}$ & $\begin{array}{c}\text { OTM Equipment } \\
\text { Target Cost (\$MM) }\end{array}$ \\
\hline $5 \%$ & 25.50 & 163.2 \\
\hline $10 \%$ & 24.16 & 130.7 \\
\hline $15 \%$ & 22.82 & 98.0 \\
\hline $20 \%$ & 21.48 & 65.4 \\
\hline
\end{tabular}

The OTM-2 reactor was sized and costed for the above 25,000 BPD GTL plant. Two reactor designs were evaluated. The " $A$ " design employs a single high temperature material for the entire reactor length. The " $b$ " design stages the reactor so that lower cost materials can be used in lower temperature regions of the reactor. In addition, the "B" reactors configured so that ID and FD fans can be used to supply fresh air and remove the depleted air from the reactor. A cost comparison is shown below in Table 8 . 
The OTM-2 planar reactor design shows cost reductions relative to conventional ATR with cryogenic oxygen of 28 to $44 \%$. This shows that the economic potential for the OTM planar type reactor is very robust.

Table 8: Cost Comparison of OTM-2 Syngas Process and Conventional ATR

\begin{tabular}{|l|c|c|c|}
\hline & $\begin{array}{c}\text { ATR Case } \\
\text { \$MM }\end{array}$ & $\begin{array}{c}\text { OTM -2 (A) with } \\
20 \text { psi blower } \\
\$ M M\end{array}$ & $\begin{array}{c}\text { OTM -2 (B) } \\
\text { staged } \\
\$ M M\end{array}$ \\
\hline $\begin{array}{l}\text { ASU/ATR (including extra } \\
\text { power supply) }\end{array}$ & 164.75 & & \\
\hline OTM Modules, Installed & & 71.70 & 62.42 \\
\hline Air/DA Exchangers & & 12.52 & 12.52 \\
\hline Syngas Cooling to 1250oF & & 3.75 & 3.75 \\
\hline Balance of Syngas Island & 25.40 & 19.61 & 21.65 \\
\hline Air moving equipment & & 30.00 & 6.25 \\
\hline TOTAL & 190.15 & 137.57 & 106.58 \\
\hline Saving compared to ATR & & $28 \%$ & $44 \%$ \\
\hline
\end{tabular}

In addition to the high pressure syngas application FTGTL, a low pressure syngas application has been identified with early commercialization potential. This opportunity may be pursued as a means to fast track the syngas technology development. Learnings could have significant impact on large scale high pressure syngas systems.

\subsubsection{CFD Modeling}

A CFD model with a mass transport and membrane kinetic code was completed for the high pressure disk reactor utilizing subroutines developed for other reactor models. The model has been used to understand thermal profiles in the OTM membrane and surrounding reactor shell and internal devices. The model shows the non-isothermal behavior of the oxygen membrane transport process and the effect of the relatively large internal reactor surface area on methane conversion. With proper calibration, the CFD model can be used to subtract out internal surface area effects and interpret nonisothermal reaction and transport data.

\subsection{Task 8: Fuels and Engine Testing}

\subsubsection{Diesel Engine and Exhaust Treatment}

\subsubsection{Goal - Diesel Engine and Exhaust Treatment}


The goal of this task is to understand the relationship between ultra-clean fuel properties and their impact on the emissions and performance of an advanced CIDI and exhaust treatment system under development at International Truck and Engine.

\subsubsection{Experimental - Diesel Engine and Exhaust Treatment}

Pictures and description of the SCTE are shown in the Topical Report for the Period Jan. 1 through Oct. 31, 2001 [Ref. 1].

\subsubsection{Results and Discussion - Diesel Engine and Exhaust Treatment}

In Budget Period 3 this Task focused on two goals: 1) completing the evaluation of ultraclean transportation fuels in conventional diesel engines and 2) completing the exploratory program in $\mathrm{HCCl}$ engine and fuel development. Both test programs are conducted on highly instrumented single cylinder test engines (SCTE) at International's facilities in Melrose Park, III.

\subsection{Ultra-clean fuel testing in conventional diesel engines.}

In Budget Period 3, three ultra-clean diesel fuels were tested in the SCTE and compared to a baseline No.2 conventional diesel fuel. The three ultra-clean fuels are : 1) Fischer Tropsch (FT) diesel fuel obtained from Sasol, LTD, 2) a commercial, petroleum based, ultra-low sulfur (ULS) diesel fuel and 3) the same ULS with a BP oxygenate (BPO) blended to achieve $10 \%$ oxygen in the fuel. The fuel properties and engine performance and emission results are reported in the Budget Period 2 Topical Report. The study concluded that the FT diesel fuel shows a clear advantage in reducing NOx and soot in comparison to conventional No.2 diesel. The study also clearly showed that the BPO at $10 \%$ oxygen level (in ULS) reduces both NOx and soot in comparison to that ULS fuel. .Thus this syngas derived additive may be useful in improving the emission performance of the "cleanest" commercial diesel fuels available today. The high oxygenate level however resulted in fuel consumptions that were higher than expected based on fuel calorific content, suggesting that some other inefficiencies in engine performance were occurring due to the BPO. [Ref. 3] Thus a second test with only $5 \%$ oxygenate was planned for Budget Period 3 . These results are reported below.

\subsection{Test Objective}

Objective of this phase is to evaluate the steady-state emission performance in a Single Cylinder Test Engine (SCTE) of the ultra- low sulfur diesel fuel blended with BP oxygenate (BPO) to yield $5 \mathrm{wt} . \%$ oxygen content and compare to the tests results from Budget Period 2. The $5 \%$ oxygenate fuel was prepared by BP Research in Naperville, III. Using an ultra-low sulfur diesel fuel supplied by International. Detailed discussion of the general test methodology used in establishing the engine data sets for this program has been provided in the $4 \mathrm{Q} 01$ Report. [Ref. 2]

Table 9. Summarizes inspections of the ULS and ULS with 5\% oxygen. 
Table 9: SCTE fuel inspections

\begin{tabular}{|c|c|c|c|}
\hline & & $\begin{array}{c}\text { ULS Base } \\
\text { Fuel }\end{array}$ & $\begin{array}{l}\text { ULS 5\%O } \\
\text { Blend }\end{array}$ \\
\hline Cetane \# & & 47.6 & 66.7 \\
\hline Destilation & $\operatorname{deg} F$ & & \\
\hline Initial Point & & 364 & 339 \\
\hline 10 & $\%$ & 401 & 397 \\
\hline 30 & $\%$ & 459 & 469 \\
\hline 50 & $\%$ & 488 & 517 \\
\hline 70 & $\%$ & 510 & 559 \\
\hline 90 & $\%$ & 588 & 614 \\
\hline End Point & & 666 & 653 \\
\hline Carbon & $\mathbf{m} \%$ & & 81.1 \\
\hline Hydrogen & $\mathbf{m} \%$ & & 13.6 \\
\hline O avg, & $\mathbf{m} \%$ & & 5.22 \\
\hline Specific Gravity & & 0.842 & 0.83 \\
\hline Total Sulfur & Mass ppm & $<10$ & 5 \\
\hline Aromatics & Vol \% & 29 & 27 \\
\hline Flashpoint & $\operatorname{deg} F$ & 170 & 133 \\
\hline Viscosity @ 40C & cSt & 2.5 & 2.13 \\
\hline H/C Ratio & & 1.82 & \\
\hline Net Heat Of Comb & BTU/lb & 18457 & 17659 \\
\hline
\end{tabular}

\subsection{Test Description}

In its general outline the test is similar to the test conducted in the period Starting July 1 , 2002 and Ending September 30, 2002 when the fuel blend with 10\% oxygenate was evaluated. Because of the passage of time between these tests, the configuration of the SCTE testing facility has been changed to address requirements of progressing technology. Therefore, some details of the general set-up and engine operating points in the current test differ somewhat from the 2002 tests as follows:

- Engine is now configured with the Common Rail (CR) Injection System and accordingly optimized combustion system consisting of a different combustion chamber geometry and injector nozzle spray pattern;

- Injection strategy now includes the pilot injection and post injection needed to control the NOx emission levels required by the '07 EPA rules.

- Speed and load conditions of four test points: Mode 4, 6, 7 and 8 have changed somewhat relatively to the original definitions due to certain shifts in location of the sensitive emission control areas of the engine operating map,

- Based on the previous experience with the oxygenated fuel testing, where both "constant fuel" and "constant toque" tests protocols were used and produced similar engine performance trends, it was decided to employ a "constant fuel" approach only for these tests.. 


\subsection{Discussion of Test Data}

As in the previous discussions of the engine investigation, the results of the emission and fuel consumption performance comparisons between the ultra low sulfur baseline fuel and the 5\% oxygenated test fuel are presented here as the trade-offs between the NOx and Soot as well as between the NOx and BSFC. These trade-offs have been generated by changes in combinations of settings of major combustion control parameters such as injection timing of various injection events (represented by start of combustion, SOC), air/fuel ratio and concentration of EGR in intake air. Comparison between performance of both investigated fuels have been conducted at four points of the engine operating map designated as Mode 4, 6, 7 and 8 and considered to be the significant overall contributors to result of the HD FTP emission certification cycle. The actual discussed data are summarized graphically and tabulated numerically in Appendix I, Fig.1, Fig.2 and Table 2 for Mode 4, Fig.3, Fig.4 and Table 3 for Mode 6, Fig.5, Fig. 6 and Table 4 for Mode 7, and finally, in Fig.7, Fig. 8 and Table 5 for Mode 8.. Tables include definitions of operating conditions at each of the test points as well as the information on specific combinations of control settings driving obtained emission trade-offs. The tables also include the comparison of performance results obtained for both the baseline and the 5\% oxygenated fuel. Fig.1, Fig. 3, Fig.5 and Fig. 7 , in addition to Nox-Soot trade-off, include also the data sets representing Indicated Mean Expanded Pressure (IMEP) which is a measure of cycle work performed by expanding cylinder charge on the piston. The inserts imbedded in these figures show overlays of the Heat Release Rates (HRRs) for pairs of compared fuels for specific test settings delineated by the circles. This additional information is provided to demonstrate the differences in an actual combustion process caused by the fuels.

Based on review of these data, the following observation can be made:

- When comparing the results obtained with $10 \%$ oxygenated fuel, the $5 \%$ oxygenated fuel is showing much lower reduction in IMEP at fixed fuelling conditions relative to the base fuel. Actually, for the certain calibrations of some operating points increase in IMEP, directly correlated to improvement in gravimetric fuel consumption, could be achieved. One of the reasons for this more desirable performance of $5 \%$ oxygenated fuel is that its calorific value is closer to that of base fuel.

- Comparisons of Heat Release Rates show that almost in all cases there are visible differences in start and progression of combustion of oxygenated and base fuels which also can contribute to improvement in thermo-efficiency of the process. In addition to the presence of extra oxygen in the mixture, the higher cetane number of oxygenated fuel seems also to play a role in modifying combustion. 
- Smoke reduction at all operating conditions and calibration points over the baseline fuel is quite evident. While at some operating conditions the extent of this reduction is lower than levels observed with the $10 \%$ oxygenate blend, in general, decrease in smoke is significant. Interestingly, in the case of the pilot injection which is known for its significant smoke penalty with conventional fuel, the $5 \%$ oxygenate blend provides consistent reduction in smoke by 60 to $80 \%$. One of possible explanation of this phenomenon is that the higher concentration of active radicals is being formed in the pilot phase of oxygenated fuel combustion which intensifies the oxidation of soot later in the cycle.

- As with previous highly oxygenated fuel there is a consistent and quite substantial reduction in NOx, which persist for all cases but the pilot injection strategy. Considering a relatively low level of NOx due to the pilot injection strategy and the high concentration of EGR used in this test coupled with highly oxidizing combustion environment demonstrated by very significant soot reduction, such behavior of a NOx seems to be not unexpected.

In general, the relative emission/BSFC performance of the oxygenated fuel vs. the base low sulfur fuel can be can be summarized as follow:

Mode 4 (1000rpm/4 bar IMEP with pilot injection strategy)

- Range of Soot reduction: from $66 \%$ reduction to $87 \%$,

- Range of NOx increase: from 5 to $25 \%$

- Range of BSFC: from $2 \%$ improvement to $32 \%$ deterioration

Mode 6 (2060rpm/10 bar IMEP with post-injection strategy):

- Range of Soot reduction: from 23 to $46 \%$

- Range of NOx: reduction from 4 to $28 \%$

- Range of BSFC: from $10 \%$ improvement to $11 \%$ deterioration

Mode 7 (3108rpm/7.5 bar IMEP with single injection strategy):

- Range of Soot reduction: from 4 to $26 \%$

- Range of NOx: from $13 \%$ reduction to $2 \%$ increase

- Range of BSFC: from $18 \%$ improvement to $3 \%$ deterioration

Mode 8 (3000rpm/17.5 bar IMEP):

- Range of Soot reduction: from 16 to $26 \%$

- Range of NOx: reduction from 15 to $21 \%$

- Range of BSFC deterioration: from 2 to $10 \%$

\subsection{General Conclusions from Oxygenated Fuels Testing}


1. The testing of low sulfur fuel blends with $10 \%$ and $5 \%$ BPO oxygenate provides strong evidence of significant soot reduction potential for this type of fuel in diesel engines

2. While the soot reduction capability seems to be proportional to an oxygenate concentration, even the lower concentration blends provide a significant soot reduction benefit. Since the calorific value of the lower concentration blends differ less from the calorific value of base fuel, the penalty in gravimetric BSFC is also lower.

3. Presence of an oxygenate seems to be modifying the chemical kinetics of diesel fuel burn, allowing for significant reduction of soot even in the highly sooting modes of combustion such as the pilot injection and the high EGR

4. Interestingly, the oxygenated fuels tested have consistently demonstrated reduction in the NOx emission relative to base fuel. Mechanism of this reduction must also be related to reaction kinetics but is not well understood

\subsubsection{2 $\mathrm{HCCl}$ engine and fuel development}

\subsection{Introduction}

The Homogeneous Charge Compression Ignition $(\mathrm{HCCl})$ combustion process is considered to be a very strong candidate solution for meeting extremely stringent 2010 EPA diesel emission regulations. In theory it offers very significant in-cylinder NOx and Soot reduction while still maintaining the superior diesel fuel economy advantage. If successfully developed and implemented $\mathrm{HCCl}$ technology could significantly reduced the complexity and cost of diesel after-treatment systems.

In its principle, the $\mathrm{HCCl}$ calls for some degree of homogenization of in-cylinder air/fuel mixture based on injection of the fuel early in the compression stroke. A Serious challenges associated with this concept is control of the ignition delay to prevent start of combustion occurring significantly prior to TDC (top dead center) while allowing sufficient time for charge homogenization. The strongest factors that affect the ignition delay in diesel combustion are the fuel properties and charge temperature and pressure histories prior to TDC, which can be controlled by a parameter called an effective compression ratio (ECR) and defined in Compression Ignition $(\mathrm{Cl})$ engines as:

$E C R=(\operatorname{Ptdc} / \operatorname{Pim})^{\wedge}(1 / 1.36)$

Where:

Ptdc - pressure of charge at TDC

Pim - intake manifold pressure

It is known that the flexible intake and exhaust valve timings as well as valve lift profiles offered by a Variable Valve Actuation (VVA) system can provide certain degree of ECR modulation which can become, in turn, a valuable $\mathrm{HCCl}$ technology 
enabler. Analytical study has been, therefore, undertaken to determine the best WVA strategy capable of providing the widest range of ECR modulation as well as maintaining reasonably low charge temperature in cylinder prior to TDC.

\subsection{Scope of Analysis}

The simulation of in-cylinder conditions and engine performance as affected by wide range variations in the valve timings and lift profiles has been conducted using the International V6 4.51 engine model developed in GT-Power Cycle Simulator software. Scope and range of simulation domain is as follows:

1. Varying the intake and exhaust valve opening and closing events at fixed valve lifts - see Table 9

2. Varying the intake valve closing event (IVC) and lift at fixed intake valve opening (IVO) - see Figure 7

3. Shifting the intake valve lift profile at fixed valve lift - see Figure 8

4. Varying the intake valve lift at fixed IVO and IVC - see Figure 9

Three engine operating points have been examined. They are 2000 RPM $50 \%$ load, 800 RPM $50 \%$ load and 3300 RPM $50 \%$ load.

Table 10: Scope and range of engine simulation domain (Crank angle values corresponding to valve events are based on convention: TDC start of intake=-360; TDC firing $=0$; TDC end of exhaust $=360$ )

\begin{tabular}{|c|c|c|c|c|}
\hline Case \# & IVO & IVC & EVO & EVC \\
\hline 1 & -250 & -90 & $90,132,180$ & $250,310,376$ \\
\hline 2 & -250 & -129 & $90,132,180$ & $250,310,376$ \\
\hline 3 & -250 & -180 & $90,132,180$ & $250,310,376$ \\
\hline 4 & -312 & -90 & $90,132,180$ & $250,310,376$ \\
\hline 5 & -312 & -129 & $90,132,180$ & $250,310,376$ \\
\hline 6 & -312 & -180 & $90,132,180$ & $250,310,376$ \\
\hline 7 & -377 & -90 & $90,132,180$ & $250,310,376$ \\
\hline 8 & -377 & -129 & $90,132,180$ & $250,310,376$ \\
\hline 9 & -377 & -180 & $90,132,180$ & $250,310,376$ \\
\hline
\end{tabular}




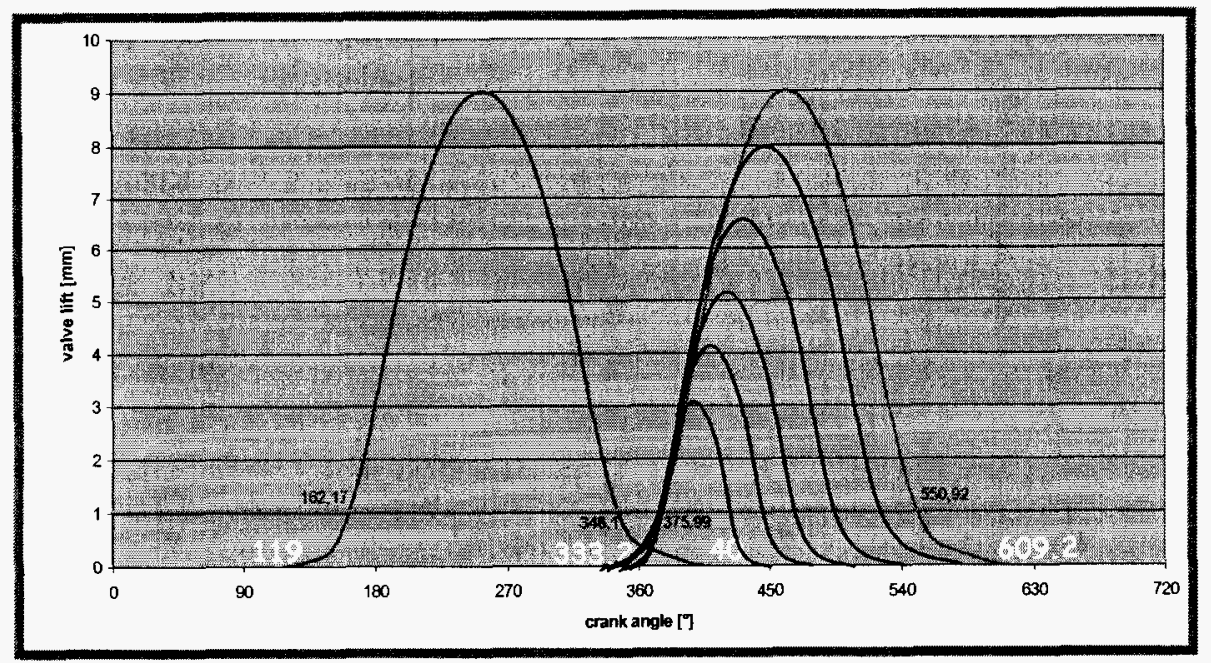

Figure 7: Intake Valve Closing w/variable lift duration

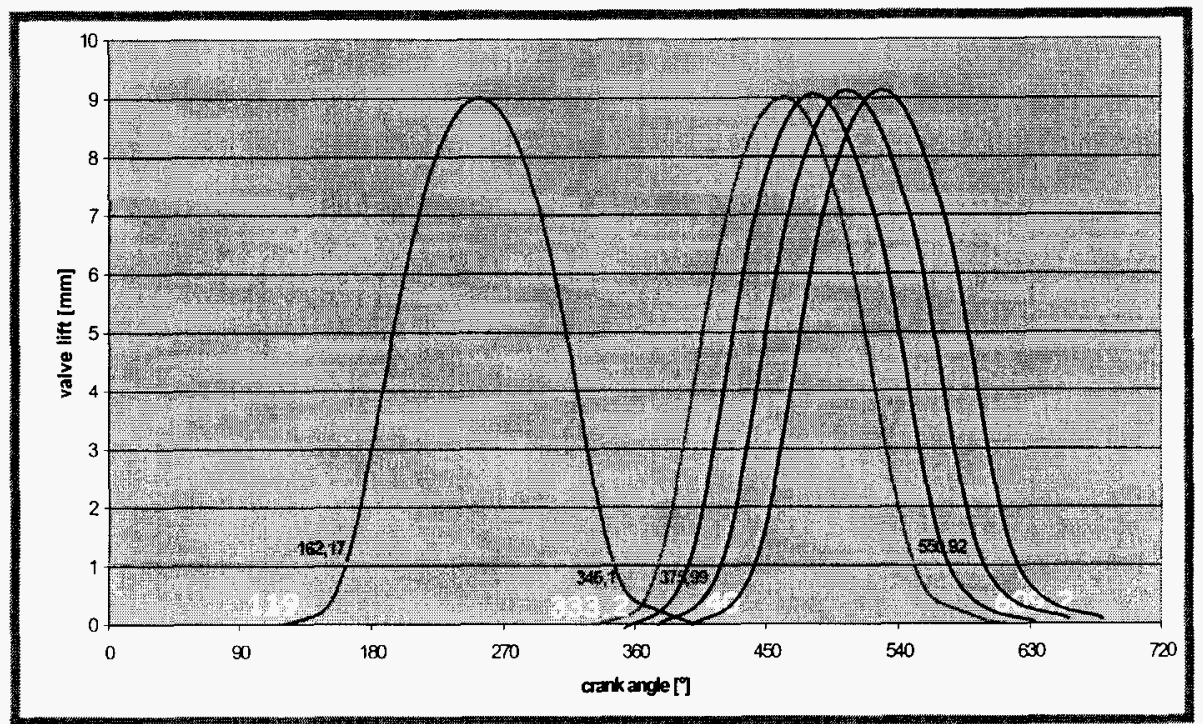

Figure 8: Valve event phasing 


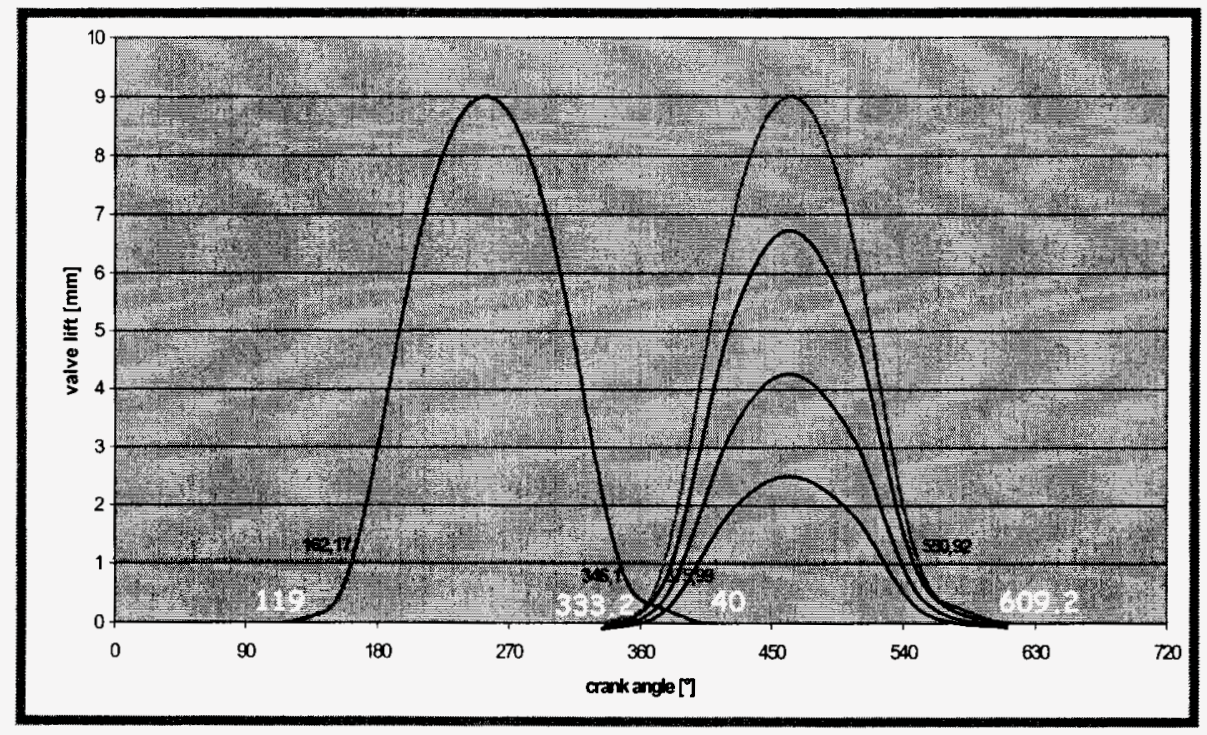

Figure 9: Variable lift with fixed duration

\subsection{Discussion of Results}

Results of the full factorial evaluation of effects of the intake and exhaust valve events variations (at $2000 \mathrm{rpm} / 50 \%$ load point) on ECR are presented in Fig. 10. As can be seen by changing the valve events alone available range of ECR modulation is rather limited. More detailed analysis of simulation data also has revealed that the cases producing lower ECR values are associated with significant fuel penalty and/or significant reduction of cylinder mass flow.

Simulation outputs from extensive sweeps of the IVC/lift modulation, the intake valve lift profile phasing and the intake valve lift modulation with fixed profile duration have been comprehensively summarized in Fig. 11. This graph illustrates the trade-offs between range of ECR available for these different WVA control strategies and the fuel consumption gain/penalty relative to the current product baseline. These correlations are plotted for several operating conditions to confirm prevailing trends.

Review of this graph leads to conclusion that the most effective VVA strategy capable to produce wide range of ECR at favorable fuel consumption potential is the IVC/lift modulation. This strategy can modulate ECR within the range of 11 to 18 with potential for BSFC improvement of $2-4 \%$. 


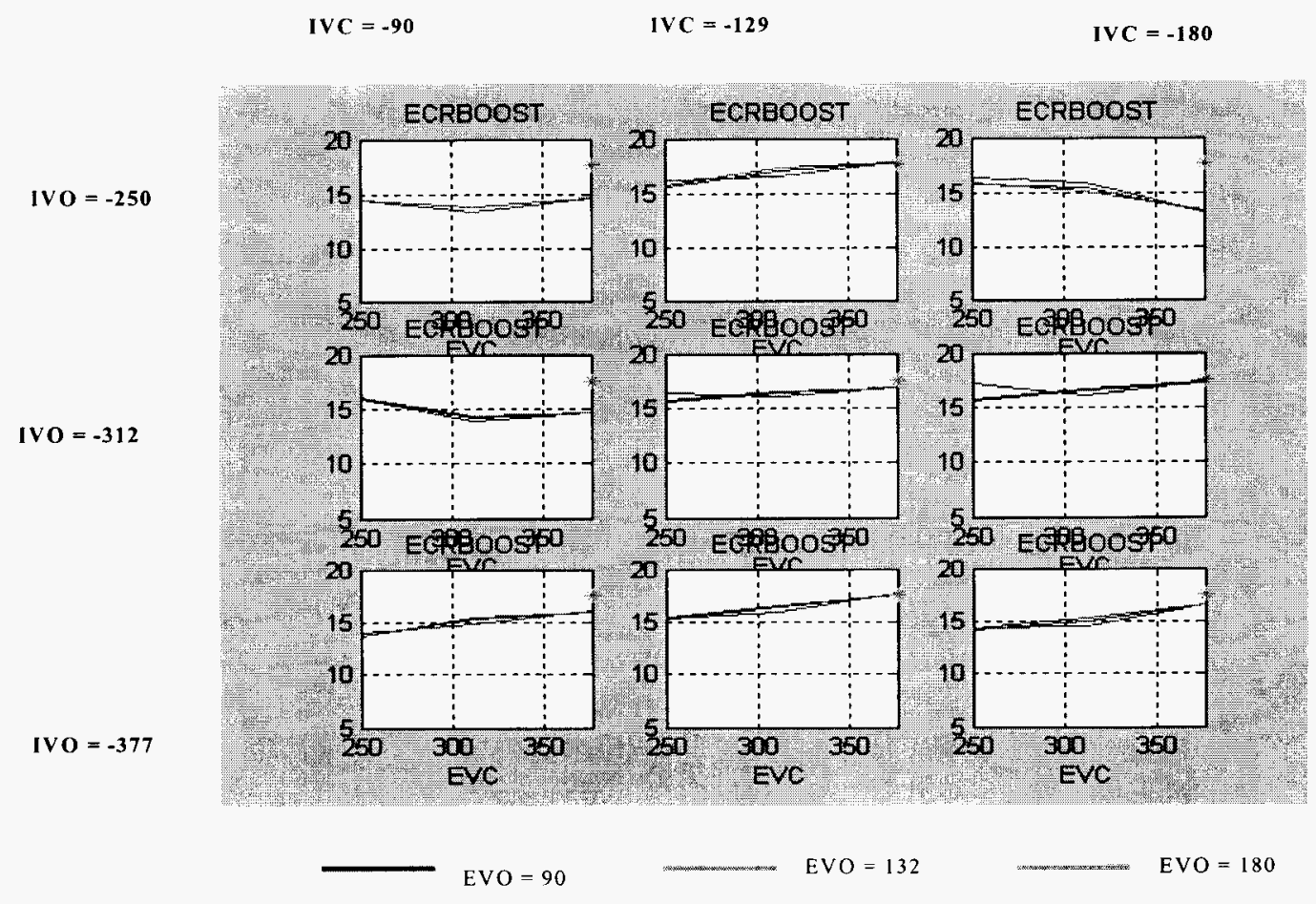

Figure 10: Results of the full factorial evaluation of effects of the intake and exhaust valve events variations (at $2000 \mathrm{rpm} / 50 \%$ load point) on ECR

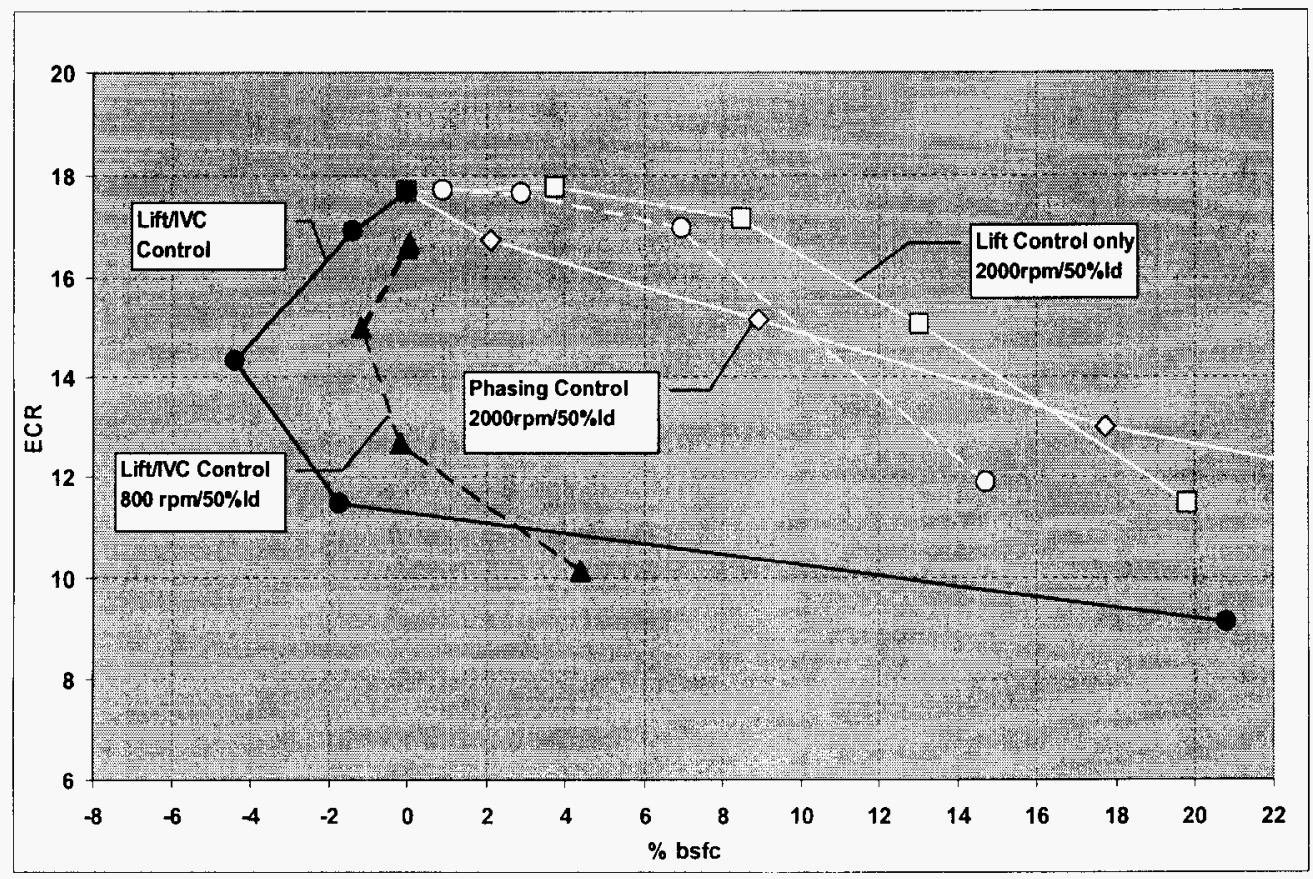

Figure 11: Summary of effect of ECR on BSFC for simulated valve strategies 


\subsection{Engine simulation conclusions}

- VVA system capable of simultaneous control of intake valve closing and intake valve lift at fixed intake valve opening has a significant potential of becoming the $\mathrm{HCCl}$ enabling technology.

- Such VVA system coupled with diesel fuel having enhanced $\mathrm{HCCl}$ properties (such as lower $\mathrm{CN}$ and lower volatility) may allow to extend effective $\mathrm{HCCl}$ combustion $\mathrm{rpm} / \mathrm{load}$ range.

\subsection{Fuel characterization and blending study}

BP has acquired 10 fuel components for blending studies. These materials are summarized below in Table 11. Twenty four blends were prepared and tested for RVP, IQT ignition delay and cetane number as shown in Table 12. Complete results are shown in Appendix 3.

Table 11: $\mathrm{HCCl}$ fuel components for blending studies

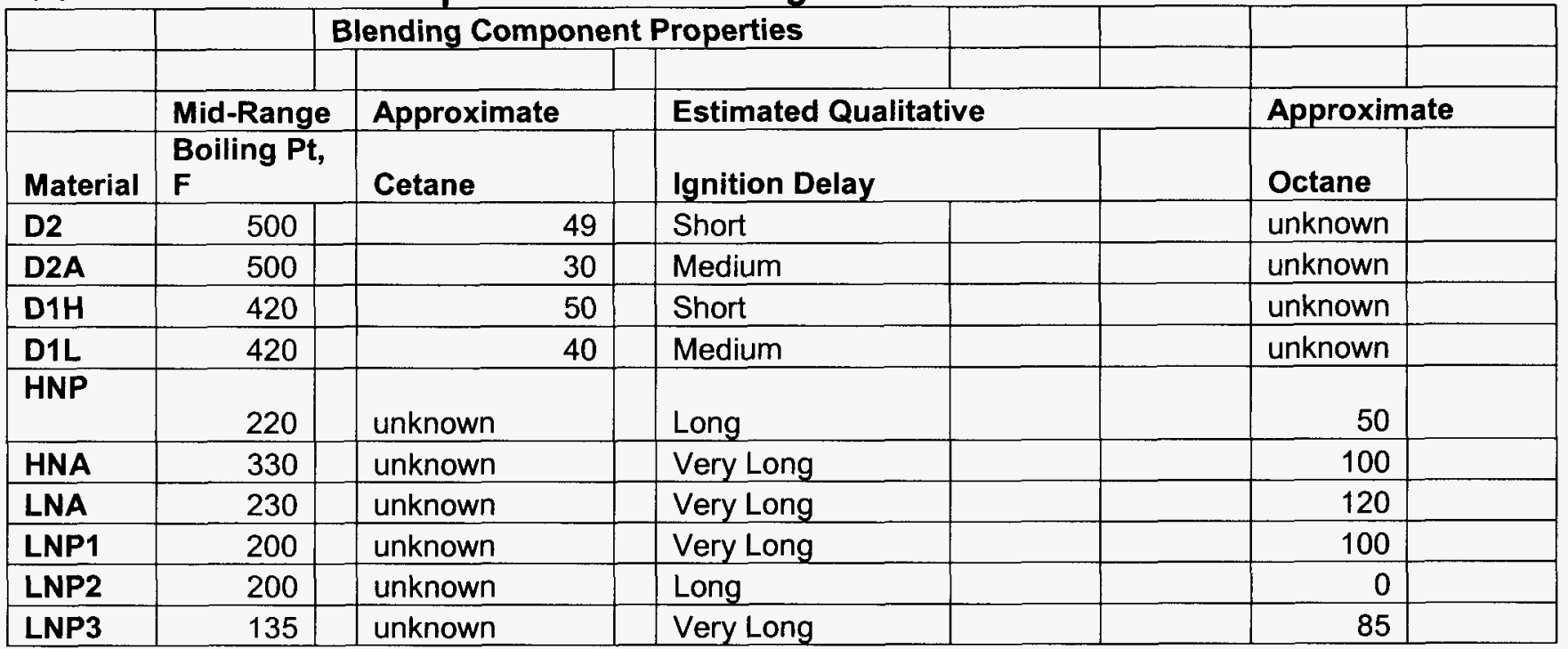

$\mathrm{D}=$ diesel; $\mathrm{N}=$ naphtha; $\mathrm{A}=$ aromatic; $\mathrm{P}=$ paraffinic; $\mathrm{L}=$ light, low; $\mathrm{H}=$ heavy, high 
Table 12. $\mathrm{HCCl}$ Fuel Candidate Blending Results

\begin{tabular}{|c|c|c|c|c|c|c|c|c|c|c|c|c|}
\hline \multicolumn{13}{|c|}{ Blends by Weight \% } \\
\hline Blend & 1 & 2 & 3 & 4 & 5 & 6 & 7 & 8 & 9 & 10 & 11 & 12 \\
\hline D2 & 100 & 50 & 50 & 50 & & & & & & & & \\
\hline \multicolumn{13}{|l|}{ D2A } \\
\hline D1H & & & & & 100 & 50 & 50 & 50 & & & & \\
\hline D1L & & & & & & & & & 100 & 50 & 50 & 50 \\
\hline HNP & & 50 & & & & 50 & & & & 50 & & \\
\hline HNA & & & 50 & & & & 50 & & & & 50 & \\
\hline \multicolumn{13}{|l|}{ LNA } \\
\hline LNP1 & & & & 50 & & & & 50 & & & & 50 \\
\hline \multicolumn{13}{|l|}{ LNP2 } \\
\hline \multirow{2}{*}{\multicolumn{13}{|c|}{ LNP3 }} \\
\hline & & & & & & & & & & & & \\
\hline $\begin{array}{l}\text { Test Data } \\
\text { Rvp }\end{array}$ & $\begin{array}{r}1 \\
036\end{array}$ & 2 & 3 & $\begin{array}{r}4 \\
2.15\end{array}$ & $\begin{array}{r}5 \\
015\end{array}$ & 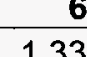 & 7 & 8 & 9 & $\frac{10}{136}$ & 11 & $\frac{12}{302}$ \\
\hline IQT ignition & 4.06 & 4.62 & 8.03 & 5.52 & 4.61 & 5.03 & 8.86 & $\frac{0.08}{6.08}$ & 5.63 & 5.67 & 10.9 & $\frac{0.02}{7.16}$ \\
\hline delay & 6 & 8 & 9 & 4 & 2 & 5 & 2 & 8 & 2 & 4 & 9 & 4 \\
\hline IQT cetane & 48.8 & & 27.9 & 37.2 & 43.4 & 40.2 & 26.1 & 34.4 & 36.6 & 36.4 & 22.6 & 30.4 \\
\hline number & 6 & 43.3 & 9 & & 4 & $\underline{2}$ & 5 & 2 & 3 & & & 2 \\
\hline
\end{tabular}

\begin{tabular}{|l|r|r|r|r|r|r|r|r|r|r|r|r|}
\hline Blend & 13 & 14 & 15 & 16 & 17 & 18 & 19 & 20 & 21 & 22 & 23 & 24 \\
\hline D2 & 50 & 50 & & & & & & & & & 25 & \\
\hline D2A & & & 100 & 50 & & & & & 50 & 50 & & 25 \\
\hline D1H & & & & & & 50 & & 50 & & & & 25 \\
\hline D1L & 50 & & & 50 & 50 & & 50 & & & & 25 & \\
\hline HNP & & & & & & & & & & & & 25 \\
\hline HNA & & & & & & & & & & 50 & & \\
\hline LNA & & 50 & & & 50 & 50 & & & 50 & & & \\
\hline LNP1 & & & & & & & 50 & 50 & & & & \\
\hline LNP2 & & & & & & & & & & & 25 & 25 \\
\hline LNP3
\end{tabular}

\begin{tabular}{|l|r|r|r|r|r|r|r|r|r|r|r|r|}
\hline Test Data & $\mathbf{1 3}$ & $\mathbf{1 4}$ & $\mathbf{1 5}$ & $\mathbf{1 6}$ & $\mathbf{1 7}$ & $\mathbf{1 8}$ & $\mathbf{1 9}$ & $\mathbf{2 0}$ & $\mathbf{2 1}$ & $\mathbf{2 2}$ & $\mathbf{2 3}$ & $\mathbf{2 4}$ \\
\hline Rvp & 0.29 & 0.91 & 0.08 & 0.55 & 0.88 & 0.87 & 1.54 & 1.52 & 0.78 & 0.23 & 4.03 & 3.35 \\
\hline IQT ignition & 4.40 & 6.82 & 10.7 & 6.99 & 7.76 & 9.78 & & 4.77 & 28.3 & 24.1 & 5.82 & 6.07 \\
delay & 7 & 7 & 1 & 1 & 1 & 2 & 5.29 & 5 & 2 & 1 & 4 & 3 \\
\hline IQT cetane & 45.2 & 31.5 & 23.0 & 30.9 & & 24.4 & 38.5 & 42.1 & & 14.3 & 35.6 & 34.4 \\
number & 8 & 3 & 5 & 7 & 28.7 & 6 & 8 & 1 & 13.2 & 4 & 5 & 9 \\
\hline
\end{tabular}

Based on the blending results above, three fuel blends were selected for $\mathrm{HCCl}$ testing. The three blends and their properties are shown below in Table13. These fuels provide a range of IQT cetane and aromaticity and some variation in volatility. Note that all fuels will be somewhat similar to JP4 in volatility, and will therefore require additional precautions in fuel handling, such as adequate grounding to prevent static ignition. 
Table 13 - Selected fuel blends for $\mathrm{HCCl}$ single cylinder engine testing

\begin{tabular}{|c|c|c|c|}
\hline \multicolumn{4}{|c|}{$\begin{array}{c}\text { Table } 7 \\
\text { Engine Test Blends (55 gallons) }\end{array}$} \\
\hline Engine Test Blend & $21507-31-1$ & $21507-31-2$ & $21507-31-3$ \\
\hline Test & Fuel 1 & Fuel 2 & Fuel 3 \\
\hline API Gravity, ${ }^{\circ} \mathrm{API}$ & 44.65 & 51.98 & 48.41 \\
\hline Specific Gravity, 60F/60F & 0.8033 & 0.7712 & 0.7865 \\
\hline \multicolumn{4}{|l|}{ Distillation } \\
\hline Initial Boiling Point, ${ }^{\circ} \mathrm{F}$ & 119.5 & 201.9 & 149.8 \\
\hline $10 \%$ distilled, ${ }^{\circ} \mathrm{F}$ & 205.1 & 208.9 & 20839 \\
\hline $20 \%$ distilled, ${ }^{\circ} \mathrm{F}$ & 222.2 & 213.5 & 216.8 \\
\hline $30 \%$ distilled, ${ }^{\circ} \mathrm{F}$ & 231.3 & 217.9 & 224.7 \\
\hline $40 \%$ distilled, ${ }^{\circ} \mathrm{F}$ & 241 & 226.6 & 235.1 \\
\hline $50 \%$ distilled, ${ }^{\circ} \mathrm{F}$ & 254.3 & 242.9 & 249.1 \\
\hline $60 \%$ distilled, ${ }^{\circ} \mathrm{F}$ & 271.5 & 290.6 & 278.6 \\
\hline $70 \%$ distilled, ${ }^{\circ} \mathrm{F}$ & 303.8 & 377.3 & 339.1 \\
\hline $80 \%$ distilled, ${ }^{\circ} \mathrm{F}$ & 346.1 & 404.5 & 377.4 \\
\hline $90 \%$ distilled, ${ }^{\circ} \mathrm{F}$ & 385.2 & 443 & 429.2 \\
\hline Final Boiling Point, ${ }^{\circ} \mathrm{F}$ & 541.6 & 489.9 & 537 \\
\hline Reid vapor pressure, psi & 2.64 & 1.49 & 2.05 \\
\hline Carbon, mass \% & 86.66 & 85.8 & 86.42 \\
\hline Hydrogen, mass \% & 11.91 & 13.82 & 12.9 \\
\hline Nitrogen, ppm & 25 & $<1$ & 12 \\
\hline Sulfur, ppm & 293 & 5 & 143 \\
\hline SFC Aromatics, vol\% & 60.02 & 28.69 & 44.88 \\
\hline Lower heating value, BTU/Ib & 17872.45 & 19066.2 & 18297.13 \\
\hline Lower heating value, BTU/gal & 119563.5 & 122453.9 & 119846.4 \\
\hline
\end{tabular}

\subsection{HCCI Engine Test Results}

The complete $\mathrm{HCCl}$ test results are shown in Appendix 2. Performance of the above three fuels were compared to the ULS base fuel shown in Table 9

Although the scope of this work has been limited primarily to investigation of the engine emission performance at a single operating point, the results show the undisputable advantages of customizing hydrocarbon fuel blends to achieve clean $\mathrm{HCCl}$ type diesel combustion. Reducing cetane number and increasing fuel volatility. a re both required to achieve good performance in the $\mathrm{HCCl}$ engine. . All of the "HCCl" fuels have demonstrated very significant potential in reducing soot emissions relative to the base ULS diesel fuel. Fuel \# 3 has demonstrated best performance in the sense that, for the optimized soot-NOx trade-off point, the approximately $90 \%$ reduction in soot was coupled to approximately $30 \%$ reduction in NOx , relative to the best point for the base fuel.

It needs to be emphasized that there are certain chemical properties related to combustion kinetics of the fuel which at present time are not well understood In order to fully evaluate the potential of these fuels and the $\mathrm{HCCl}$ engine, more extensive engine mapping and fuel composition studies are necessary. 


\subsection{Task 10: Program Management}

\subsubsection{Goal - Task 10}

The recipient shall provide technical leadership and management direction to ensure that the program delivers its goals on time, within budget and in a safe and environmentally acceptable manner. Good communications with the DOE, participants, and subcontractors will be maintained.

\subsubsection{Milestones - Task 10}

A detailed briefing shall be presented within (60) days of the end of the budget period. The briefings shall be given by the Recipient to explain the plans, progress, and results of the project effort, both technical and administrative.

- Status: A briefings were presented to DOE management on June $8^{\text {th }}, 2004$. at Praxair Technical Center in Tonawanda, NY and December $14^{\text {th }}, 2004$ in Morgantown, WV

\subsubsection{Discussion - Task 10}

All progress reports were completed and submitted on time. All key objectives were completed. A 6 month no-cost extension was granted to allow completion of Task 8 . and part of Task 2.

We participated in a DOE sponsored peer review in Houston on June, 2003. In addition, three briefings were held with the DOE: July 2003, June 2004. and December, 2004.

A paper was submitted for the Spring AlChE meeting, under the natural gas utilization topic in April 2004 and a similar paper was presented at the March 2003 ACS meeting. The program remains under budget through the second quarter, 2004.

\subsection{Conclusions}

- An advanced material system LCM61/MM2 has met our flux, life and cyclabiltiy targets for this budget period. This material system is suitable for the first stage of a high pressure OTM hydrogen or syngas process; a more robust film material is required for the higher temperature second stage.

- Several promising high temperature OTM film material candidates have been fabricated and are undergoing testing.

- The LCM61/MM2 and several LCM65 systems are suitable for a low pressure syngas application which could be commercialized early on, as part of an integrated technology development roadmap.

- A new fabrication technique has been developed that allows the manufacture of thin, dense OTM films on porous substrates.

- An OTM-3 reactor has been shown to have a very high hydrogen yield with almost no NOx emissions. The reactor is also very efficient at capturing $\mathrm{CO} 2$.

- The OTM-3 will reduce the costs of recovering the carbon dioxide created from reforming natural gas .by $50 \%$ or more. This device could be a BACT candidate 
for hydrogen production if $\mathrm{NOx}$ and $\mathrm{CO} 2$ are regulated pollutants and would therefore be significantly advantaged over SMR.

- The OTM-2 reactor shows potential to reduce ATR syngas capital costs by 28 to $44 \%$ based on a 25,000 BPD FTGL plant with cryogenic oxygen.

- Adding the BP oxygenate at a 5\% oxygen level to conventional ultra-low sulfur diesel fuel significantly reduces soot and NOx emissions with only minimal impact on fuel consumption and engine efficiency.

- The $\mathrm{HCCl}$ engine promises to be the next generation internal combustion engine which will be capable of meeting 2010 EPA emission regulations. The engine promises to reduce soot and NOx formation in the cylinder with no loss of efficiency, thereby reducing the need or complexity of after-treatment technology.

- VVA system capable of simultaneous control of intake valve closing and intake valve lift at fixed intake valve opening has a significant potential of becoming the $\mathrm{HCCl}$ enabling technology.

- The $\mathrm{HCCl}$ fuel will likely resemble,JP4 in volatility, but will have specific ignition delay and cetane requirements to achieve optimal performance.

- The best fuel found in this study has an aromatic content of $\sim 45$ volume percent and a Reid vapor pressure of $\sim 2$ psi. with an estimated IQT cetane of 25

\subsection{References}

1. Robinson et al, Topical Report for "Development of OTM Syngas Process and Testing of Syngas-Derived Ultra-clean Fuels in Diesel Engines and Fuel Cells", US DOE Award No. DE-FC26-01NT41096, Budget Period 1, October 2001.

2. Robinson et al, Quarterly Project Status Report for Period ending December 31, 2001 for "Development of OTM Syngas Process and Testing of Syngas-Derived Ultra-clean Fuels in Diesel Engines and Fuel Cells", US DOE Award No. DEFC26-01NT41096, March 2002.

3. Robinson, et al, Topical Report for "'Development of OTM Syngas Process and Testing of Syngas-Derived Ultra-clean Fuels in Diesel Engines and Fuel Cells", US DOE Award No. DE-FC26-01NT41096, Budget Period 2, February 2003. 


\section{Appendix 1}

International Truck and Engine SCTE Results 


\section{Baseline vs Oxygenated Fuel Soot/Nox Trade-off @ Mode \#4}

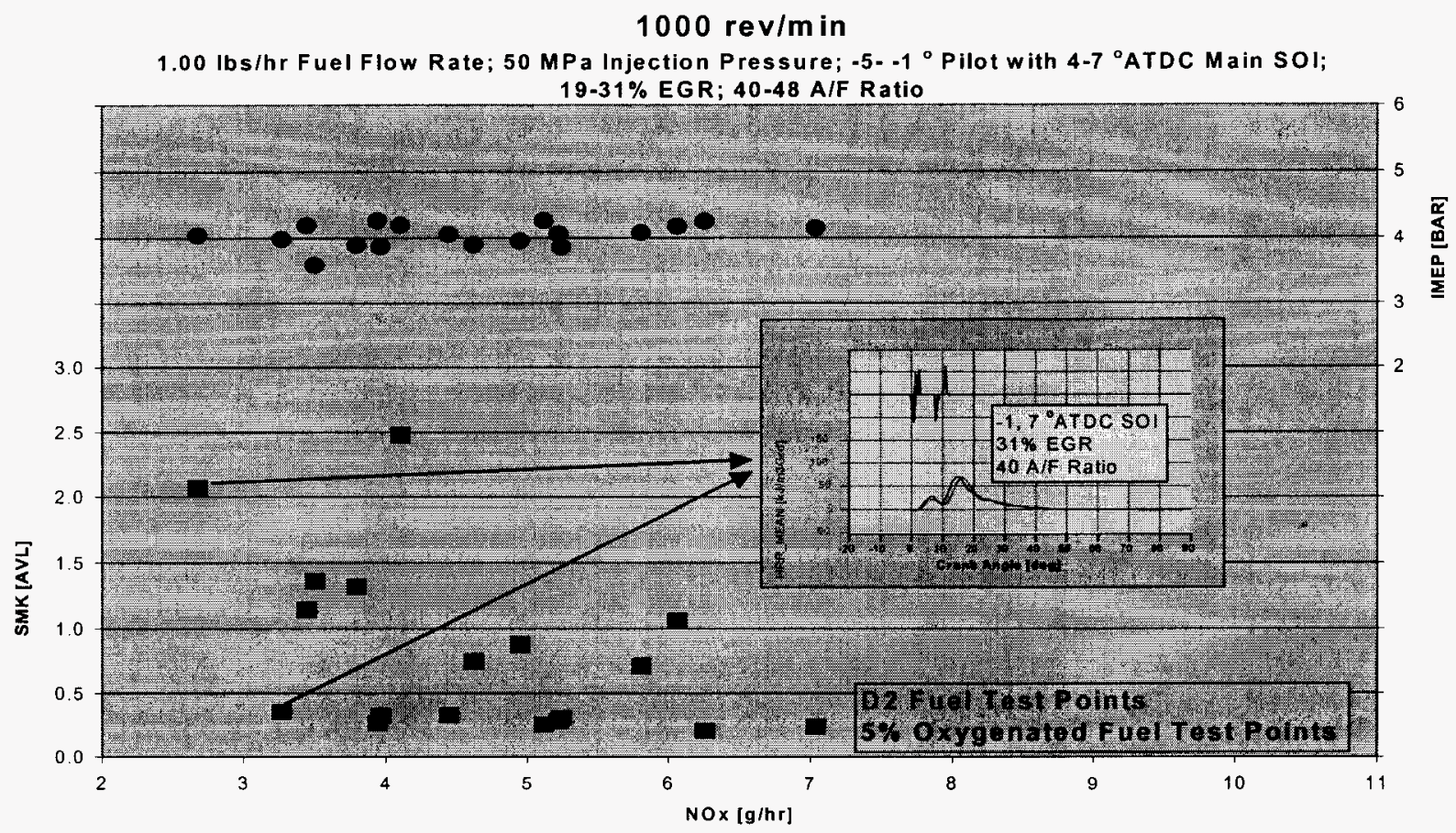

Fig 1

Baseline vs Oxygenated Fuel BSFC/Nox Trade-off @ Mode \#4 $1000 \mathrm{rev} / \mathrm{m}$ in $1.00 \mathrm{lbs} / \mathrm{hr}$ Fuel Flow Rate; $50 \mathrm{MPa}$ Injection Pressure; -5--1 ${ }^{\circ}$ Pilot with $4-7^{\circ} \mathrm{ATDC} \mathrm{Main}$ SOI; $19-31 \%$ EGR; 40-48 A/F Ratio

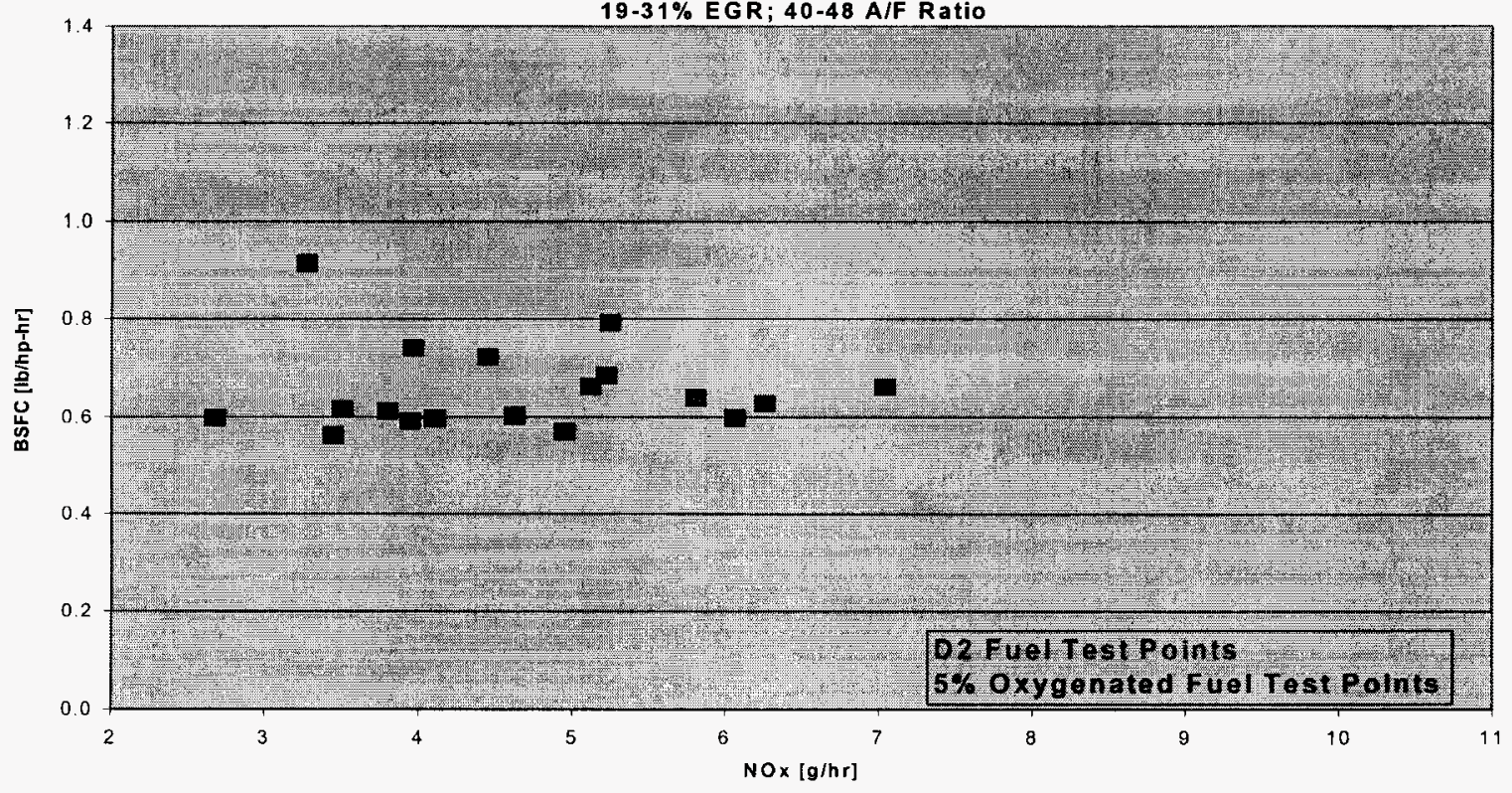

Fig 2 


\section{Baseline vs Oxygenated Fuel Soot/Nox Trade-off @ Mode \#6}

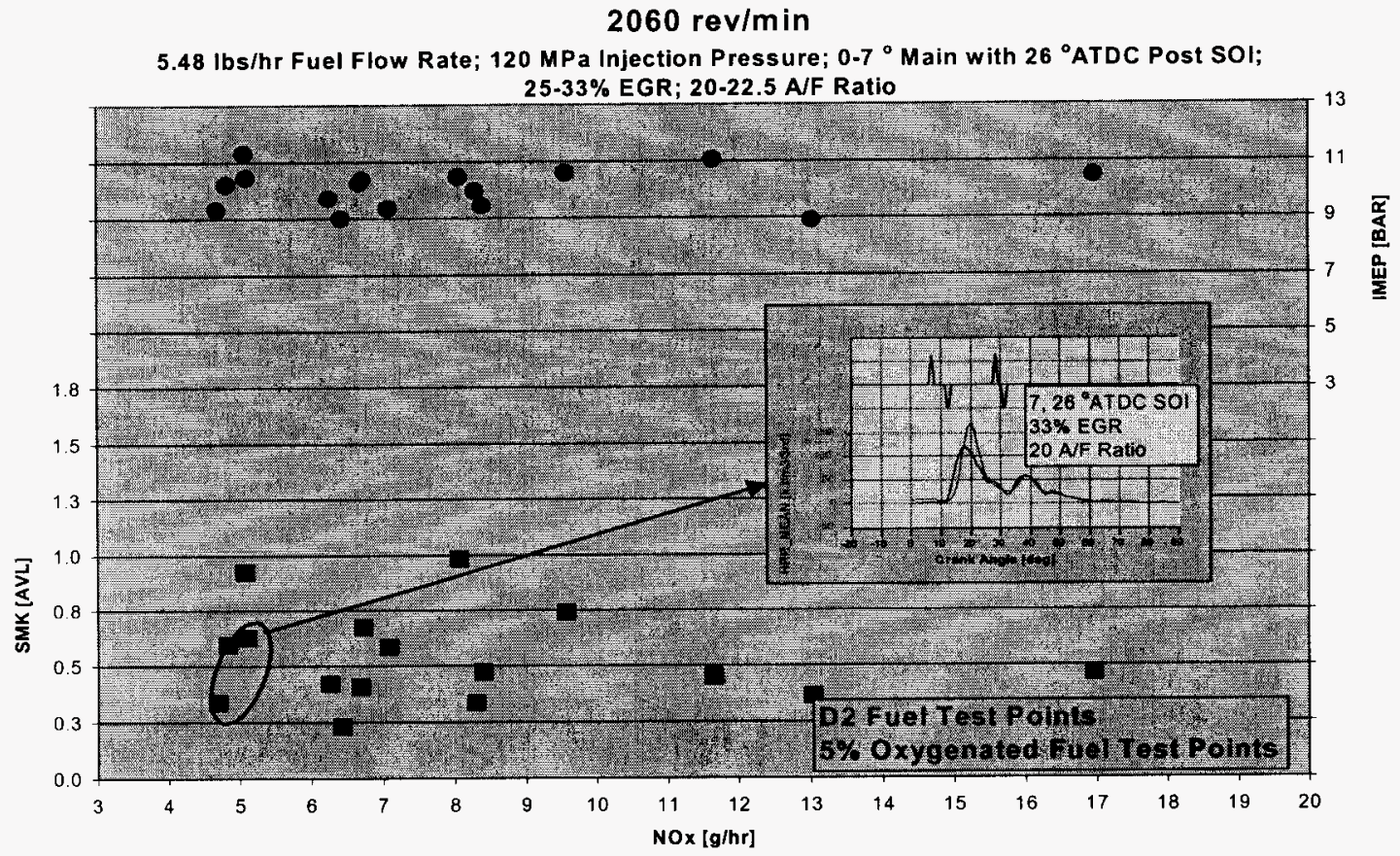

Fig. 3

Baseline vs Oxygenated Fuel BSFC/Nox Trade-off @ Mode \#6

\section{$2060 \mathrm{rev} / \mathrm{min}$}

$5.48 \mathrm{lbs} / \mathrm{hr}$ Fuel Flow Rate; $120 \mathrm{MPa}$ Injection Pressure; $0-7^{\circ}$ Main with $26^{\circ} \mathrm{ATDC}$ Post SOI; 25-33\% EGR; 20-22.5 A/F Ratio

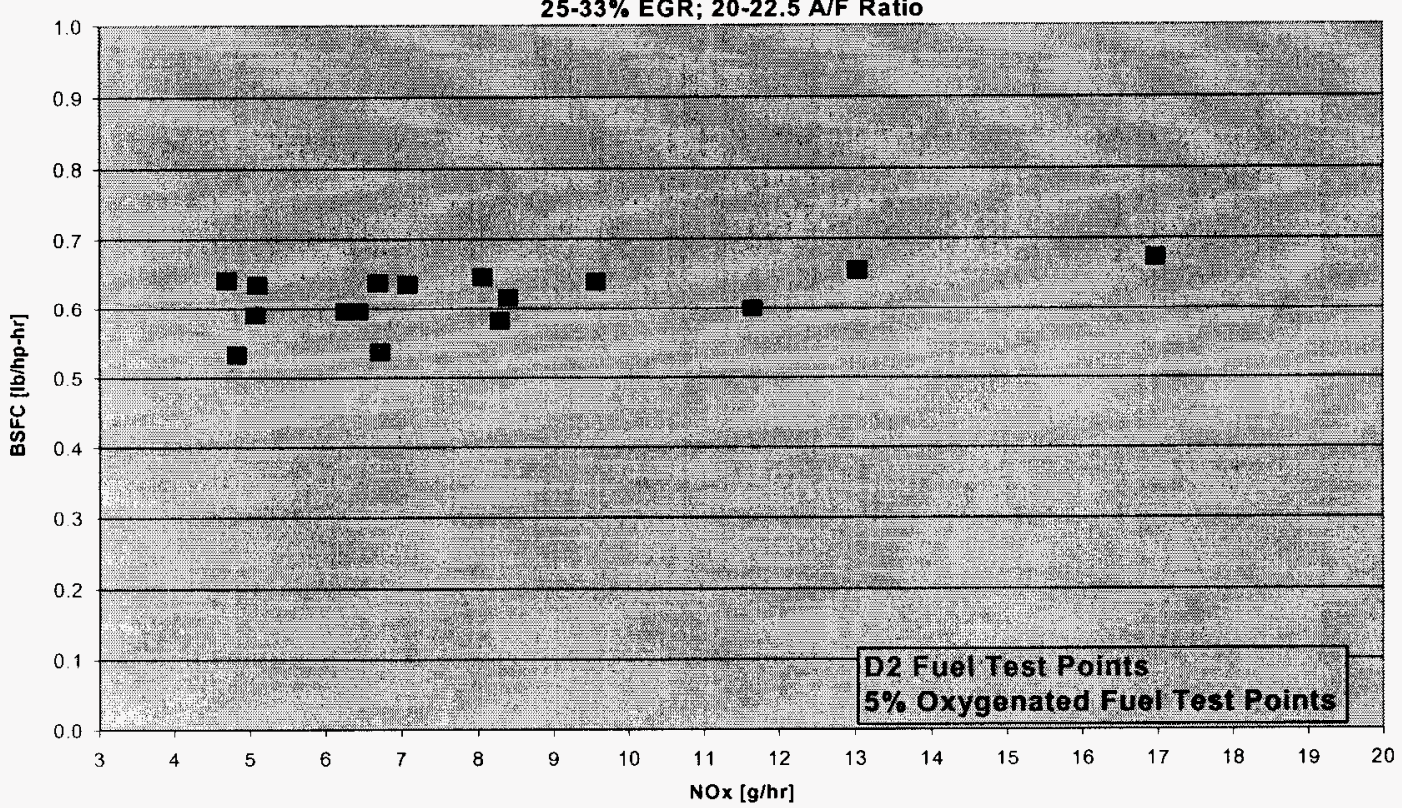

Fig. 4 


\section{Baseline vs Oxygenated Fuel Soot/Nox Trade-off @ Mode \#7}

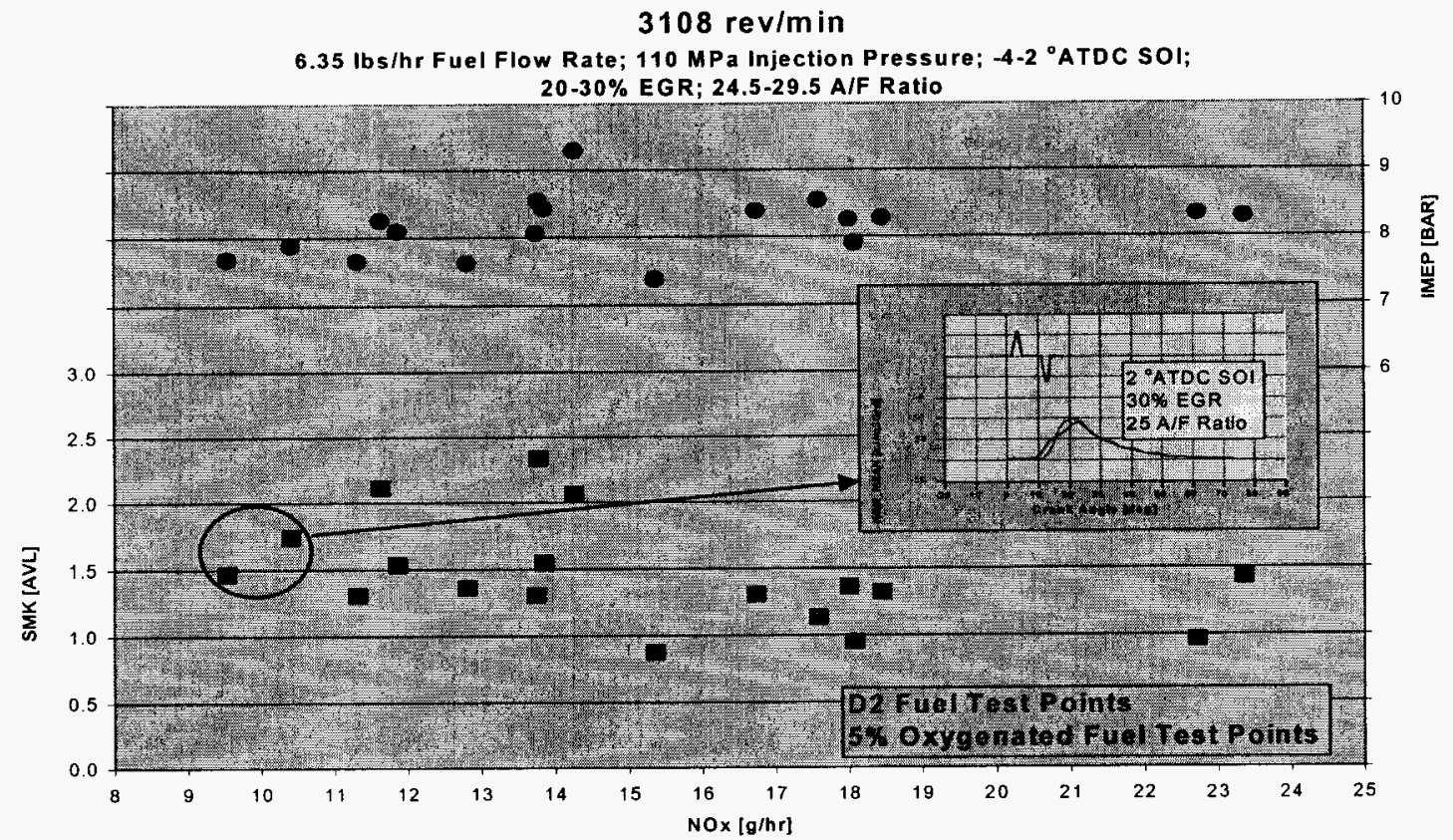

Fig. 5

Baseline vs Oxygenated Fuel BSFC/Nox Trade-off @ Mode \#7 $3108 \mathrm{rev} / \mathrm{min}$ $6.35 \mathrm{lbs} / \mathrm{hr}$ Fuel Flow Rate; $110 \mathrm{MPa}$ Injection Pressure; 4-2 ${ }^{\circ} \mathrm{ATDC}$ SOI; 20-30\% EGR; 24.5-29.5 A/F Ratio

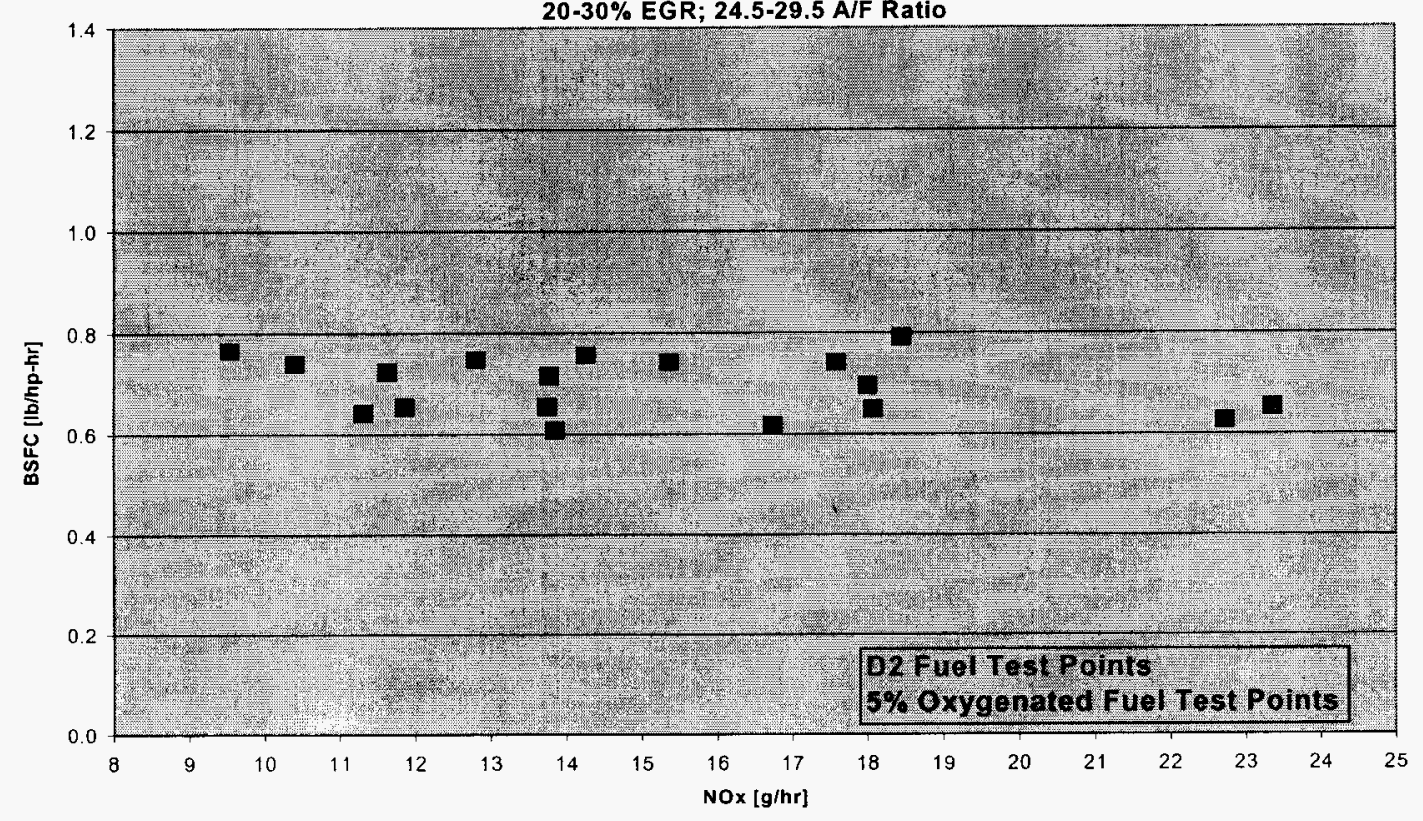

Fig. 6 
Baseline vs Oxygenated Fuel Soot/Nox Trade-off @ Mode \#8

\section{$3000 \mathrm{rev} / \mathrm{min}$}

15.24 lbs/hr Fuel Flow Rate; $150 \mathrm{MPa}$ Injection Pressure; -5-1 ${ }^{\circ} \mathrm{ATDC}$ SOI; 15\% EGR; 18.7 A/F Ratio

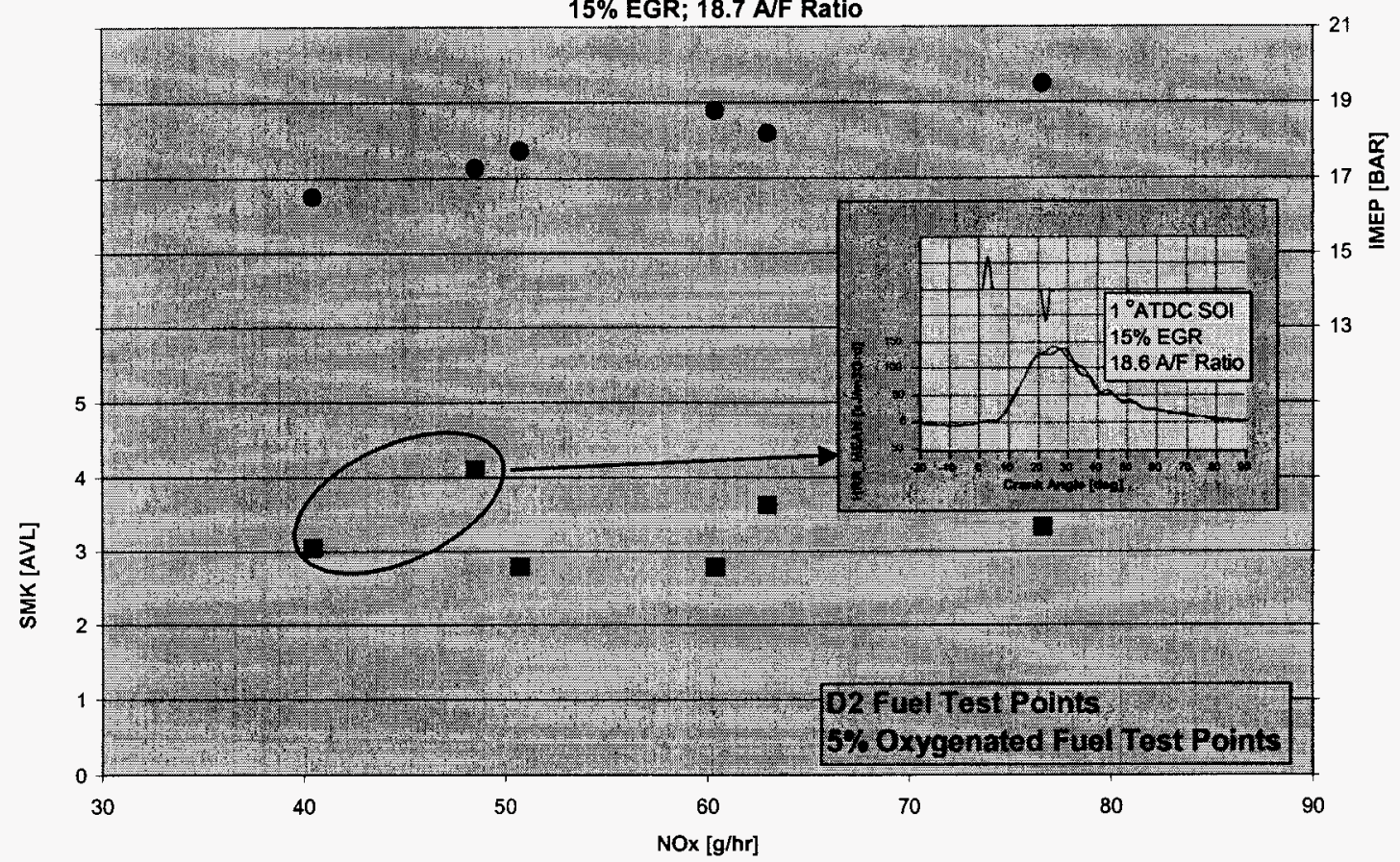

Fig. 7

\section{Baseline vs Oxygenated Fuel BSFC/Nox Trade-off @ Mode \#8}

$3000 \mathrm{rev} / \mathrm{min}$

15.24 Ibs/hr Fuel Flow Rate; $150 \mathrm{MPa}$ Injection Pressure; -5-1 ${ }^{\circ} \mathrm{ATDC}$ SOI; 15\% EGR; 18.7 A/F Ratio

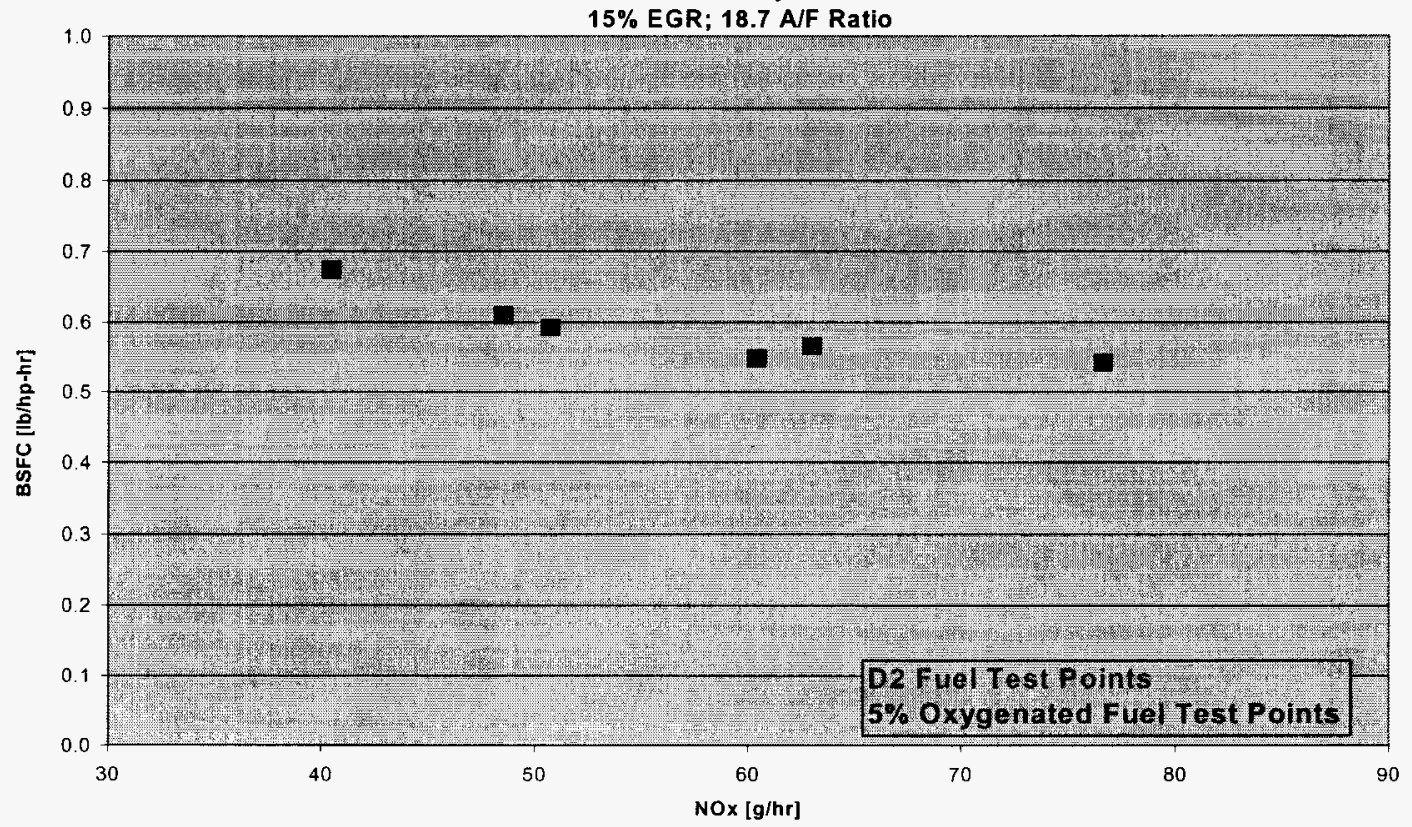

$\underline{\text { Fig } 8}$ 
Table 2a
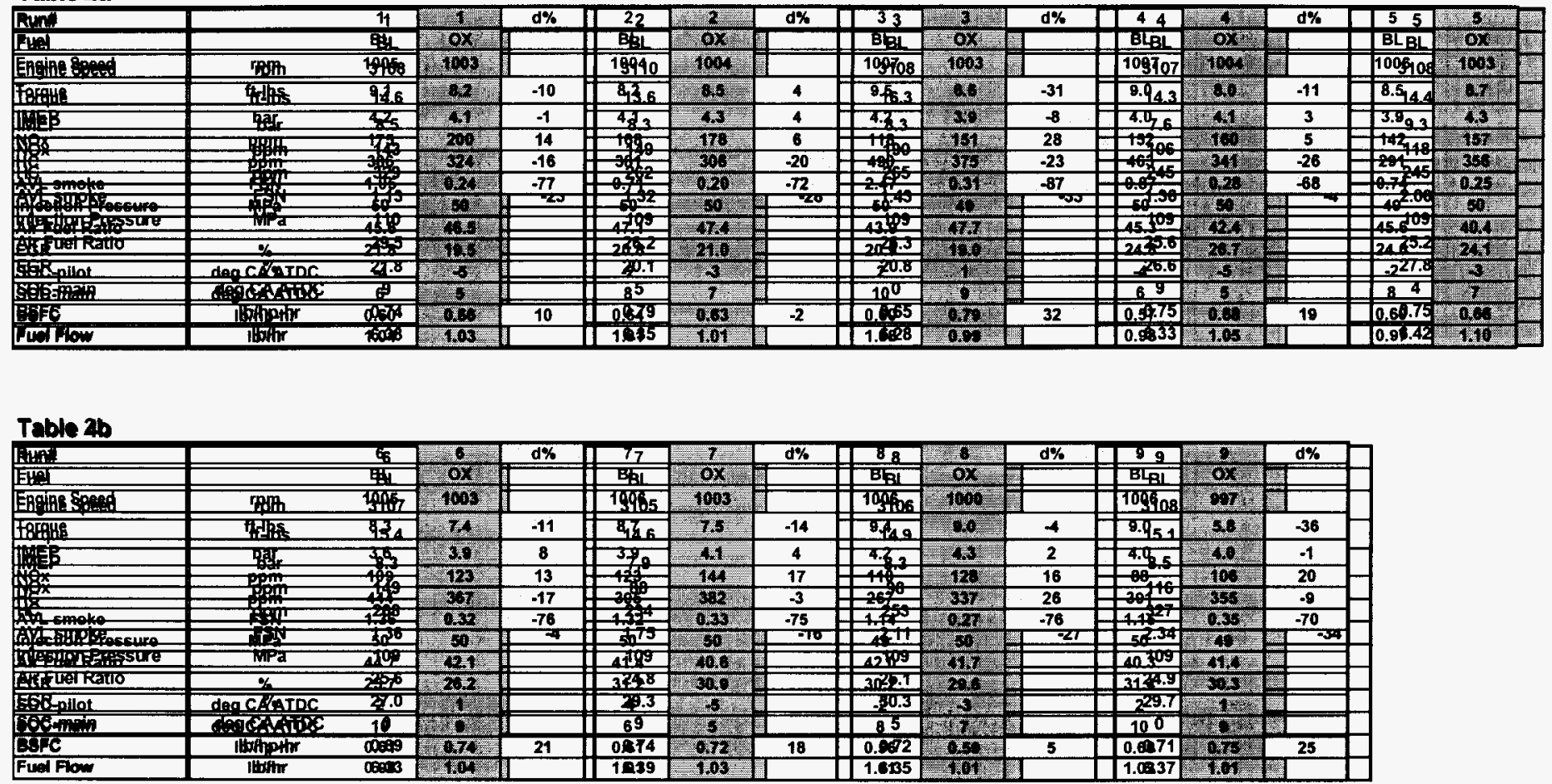

Table 3a

\begin{tabular}{|c|c|c|c|c|c|c|c|c|c|c|c|c|c|}
\hline Run\# & & 1 & 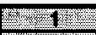 & $d \%$ & 2 & 2 & $d \%$ & 3 & 3 & $d \%$ & 4 & I & $d \%$ \\
\hline Fuel & & $B L$ & ox: & & $\overline{B L}$ & $a x$ & & $\mathrm{BL}$ & ox & & $B L$ & ox & \\
\hline Engine Speed & $\mathrm{rpm}$ & 2061 & 2063 & & 2059 & 2058 & & 2 & 2058 & & 2086 & 2093 & \\
\hline Torque & $\mathrm{ft}-\mathrm{lbs}$ & 23.3 & 2,4 & 3 & 20.8 & 2183 & 2 & 21.9 & 23.5 & 7 & 26.0 & $=231$ & -10 \\
\hline IMEP & bar & 11.1 & 100 & .10 & 10.5 & a. & -15 & 10.3 & 3.0 & .12 & 10.4 & OT & -6 \\
\hline \begin{tabular}{|l} 
NOx \\
\end{tabular} & ppm & 130 & Q5 & -28 & 184 & $\frac{164}{14}$ & -22 & 78 & 76 & 4 & 78 & 7 & -6 \\
\hline $\mathrm{HC}$ & $\mathrm{ppm}$ & 462 & 232 & -50 & 388 & sis & -19 & 327 & 233 & -27 & 313 & Th & -31 \\
\hline AVL smoke & FSN & 0.45 & 0.53 & -27 & 0.47 & 0.38 & -23 & 0.41 & 0.23 & -44 & 0.67 & 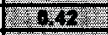 & -37 \\
\hline Injection Pressure & $\mathrm{MPa}$ & 118 & 120 & & 118 & Tt & & 117 & 1110 & & 118 & m & \\
\hline Air Fuel Ratio & & 21.8 & 21.7 & & 22.4 & 1280 & & 20.8 & $20 . \mathrm{R}^{2}$ & & 20.9 & 208. & \\
\hline EGR & $\%$ & 25.3 & 78 & & 25.2 & 26.7 & & 31.9 & 11.1. & & 30.6 & R192 & \\
\hline SOC-main & deg CA ATDC & 9 & क & & 4 & 4 & & 12 & T. & & 9 & res & \\
\hline SOC-post & deg CA ATDC & 32 & 39 & & 31 & 42 & & 32 & 32 & & 32 & 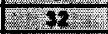 & \\
\hline BSFC & lb/hp-hr & 0.60 & 0.53 & -3 & 0.67 & 0.68 & -1 & 0.64 & 0060 & -8 & 0.54 & E.690 & 11 \\
\hline Fuel Flow & $\mathrm{Ib} / \mathrm{hr}$ & 5.48 & .811 & & 5.48 & 548 & & 5.48 & 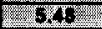 & & 5.48 & 30.15 & \\
\hline
\end{tabular}

Table 3b

\begin{tabular}{|c|c|c|c|c|c|c|c|c|c|c|c|c|c|}
\hline Run\# & & 5 & 5 & $d \%$ & 6 & 6 & $d \%$ & 7 & 7 & $\mathrm{d \%}$ & 8 & 8 & $d \%$ \\
\hline Fuel & & BL & OX & & $\mathrm{BL}$ & ox & & BL & $a x$ & & $\mathrm{BL}$ & ox & \\
\hline Engine Speed & $r p m$ & 2062 & 2062 & & 2062 & 2058 & & 2062 & 2058 & & 2060 & 2058 & \\
\hline Torque & $\mathrm{ft}-\mathrm{lbs}$ & 21.9 & 22.7 & 4 & 22.0 & 21.8 & -1 & 23.8 & 26.3 & 11 & 21.6 & 22.0 & 2 \\
\hline IMEP & bar & 10.6 & 0.5 & -11 & 10.5 & 23 & -11 & 11.3 & 102 & .9 & 10.5 & (5) & -11 \\
\hline NOx & $\mathrm{ppm}$ & 111 & 97 & -13 & 62 & 57 & -8 & 62 & 5. & .5 & 99 & $\mathrm{TT}$ & -12 \\
\hline HC & $\mathrm{ppm}$ & 340 & 5003 & -11 & 268 & 233 & .13 & 290 & 225 & -22 & 351 & $25:$ & -28 \\
\hline AVL smoke & FSN & 0.74 & 0.17 & -36 & 0.63 & 0.54 & -46 & 0.92 & 0.50 & .36 & 0.98 & $\frac{0.50}{0.56}$ & 41 \\
\hline Injection Pressure & $\mathrm{MPa}$ & 118 & 120 & & 117 & $120 \%$ & & 119 & 118 & & 120 & (2) & \\
\hline Air Fuel Ratio & & 20.9 & 21.0 & & 19.9 & 10,9 & & 19.8 & 19.0 & & 19.7 & rth & \\
\hline EGR & $\%$ & 31.7 & 30.9 & & 32.5 & 32.8 & & 32.2 & $3,3.3 \%$ & & 32.6 & 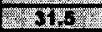 & \\
\hline SOC-main & deg CA ATDC & 4 & A & & 12 & 9. & & 9 & 6 & & 4 & 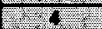 & \\
\hline SOC-post & $\operatorname{deg}$ CA ATDC & 32 & 32 & & 32 & 5 & & 32 & 32 & & 32 & I & \\
\hline BSFC & $\mathrm{ib} / \mathrm{hp}-\mathrm{hr}$ & 0.64 & 0.62 & -3 & 0.63 & 0.064 & 2 & 0.59 & 0.53 & -10 & 0.65 & 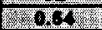 & -2 \\
\hline Fuel Flow & $\mathrm{lb} / \mathrm{hr}$ & 5.48 & 5.40 & & 5.48 & 3./8 & & 5.48 & 3.48 & & 5.48 & 6.60 & \\
\hline
\end{tabular}


Table 5

\begin{tabular}{|c|c|c|c|c|c|c|c|c|c|c|}
\hline Run\# & & 1 & 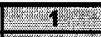 & $d \%$ & 2 & 2 & $d \%$ & 3 & 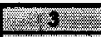 & $d \%$ \\
\hline Fuel & & $\mathrm{BL}$ & OD $\mathrm{H}$ & & $\mathrm{BL}$ & Dis & & $\mathrm{BL}$ & 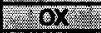 & \\
\hline Engine Speed & $\mathrm{pm}$ & 2998 & 83942 & & 2998 & singen & & 2997 & 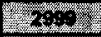 & \\
\hline Torque & ft-lbs & 49.6 & 8a.4 & -2 & 46.8 & 1,6 & -4 & 44.0 & 10 & -10 \\
\hline IMEP & bar & 19.5 & 188 & 4 & 18.2 & $: .177$ & -3 & 17.3 & 165 & -4 \\
\hline NOX & $\mathrm{ppm}$ & 358 & 298 & -21 & 289 & 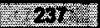 & -18 & 223 & 100 &.-15 \\
\hline $\mathrm{HC}$ & ppm & 22 & 17. 0 & 259 & 23 & Fo & 143 & 23 & 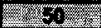 & 117 \\
\hline AVL smoke & FSN & 3.32 & 216 & -16 & 3.62 & 218 & -23 & 4.10 & $\operatorname{sing}$ & -26 \\
\hline Injection Pressure & $\mathrm{MPa}$ & 150 & (76, & & 149 & P & & 149 & (20) & \\
\hline Air Fuel Ratio & & 18.5 & $16 \mathrm{O}$ & & 18.8 & $18 \mathrm{TE}$ & & 18.8 & 1100 & \\
\hline EGR & $\%$ & 14.7 & 15:5 & & 14.5 & 20 & & 14.3 & 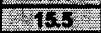 & \\
\hline SOC-main & $\operatorname{deg}$ CA ATDC & 0 & 0 & & 3 & 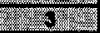 & & 6 & C. & \\
\hline BSFC & $\mathrm{Ib} / \mathrm{hp}-\mathrm{h} \mathrm{s}$ & 0.54 & 003 & 2 & 0.57 & 0.50 & 4 & 0.61 & $\sqrt{a t y}=$ & 10 \\
\hline Fuel Flow & $\mathrm{lb} / \mathrm{hr}$ & 15.31 & Wh & & 15.27 & Thy & & 15.31 & TSER & \\
\hline
\end{tabular}




\title{
Appendix 2 \\ International Truck and Engine HCCI Test Results
}

\author{
Evaluation of HCCI Fuels in Diesel Single-Cylinder Test Engine
}

\section{Background}

In the last decade the search for new technological ways of controlling in-cylinder emission of diesel engine without compromising its traditional advantages of a high fuel economy and superior torque characteristics has increased interest in the alternative modes of diesel combustion. Traditional diesel combustion is known as a mixing controlled process in which fuel is injected in the form of a high pressure fuel jet into the high pressure and high temperature air, ignited very soon thereafter, and then undergo both combustion and mixing while injection lasts. While high efficiency of this type of combustion is very well established the heterogeneity of air-fuel mixture formed in such process imposes certain practical limits on reduction ability of emissions such as Nox and soot. One of the alternative modes of diesel combustion which recently gained the significant interest is a Homogeneous Charge Compression Ignition (HCCI) combustion. Conceptually, in this case, the fuel is injected significantly ahead of its ignition, allowed to pre-mix thoroughly with air to form a homogenous charge and then self-ignited and burned., usually, with a much lower amount of soot and Nox emission being formed. It needs to be understood, however, that despite of apparent simplicity of this concept the abundant amount of conducted research has indicated existence of many technological barriers inhibiting successful application of the HCCI concept in today's diesel technology

\section{Work Objective}

It is well known that some of these barriers are related to the fuel properties. For a successful HCCI combustion the fuel needs to mix fast with an air and, additionally, to have prolonged ignition delay allowing for the complete fuel-air premix and shift of the ignition point into the vicinity of TDC position of the piston. The fuel volatility and the cetane number (CN) are clearly the properties which enhance these processes, accordingly.

The objective of this work, therefore, has been to formulate three different blends of the hydrocarbon based fuels having a distinctly different volatility and $\mathrm{CN}$ properties, test them in the diesel single cylinder test engine operating in the HCCI-like mode of combustion and to compare their relative emission performance against the baseline obtained for ULS base fuel. 


\section{Test Fuels}

The extensive study of multi-component blends of hydrocarbon fuels has been performed by BP-AMOCO to generate concise matrix of test fuels characterized by relatively wide ranges of volatility and $\mathrm{CN}$ that would be still compatible with ignitibility and combustion constrains typical for diesel combustion. As result of this study three test fuel have been selected and custom fabricated for purpose of this work:

- Test fuel \#1 - 90\%/10\% blend of gasoline aromatics (petroleum naphtha) and No 2 Diesel

- Test fuel \#2 - 35\%/65\% blend of kerosene (petroleum distillate) and gasoline aromatics (petroleum naphtha)

- Test fuel \#3 - 50\%/50\% blend of test fuel \#1 and test fuel \#2

The ULS fuel has been used as the baseline. Fig. 1 schematically shows the composition of these test fuels.

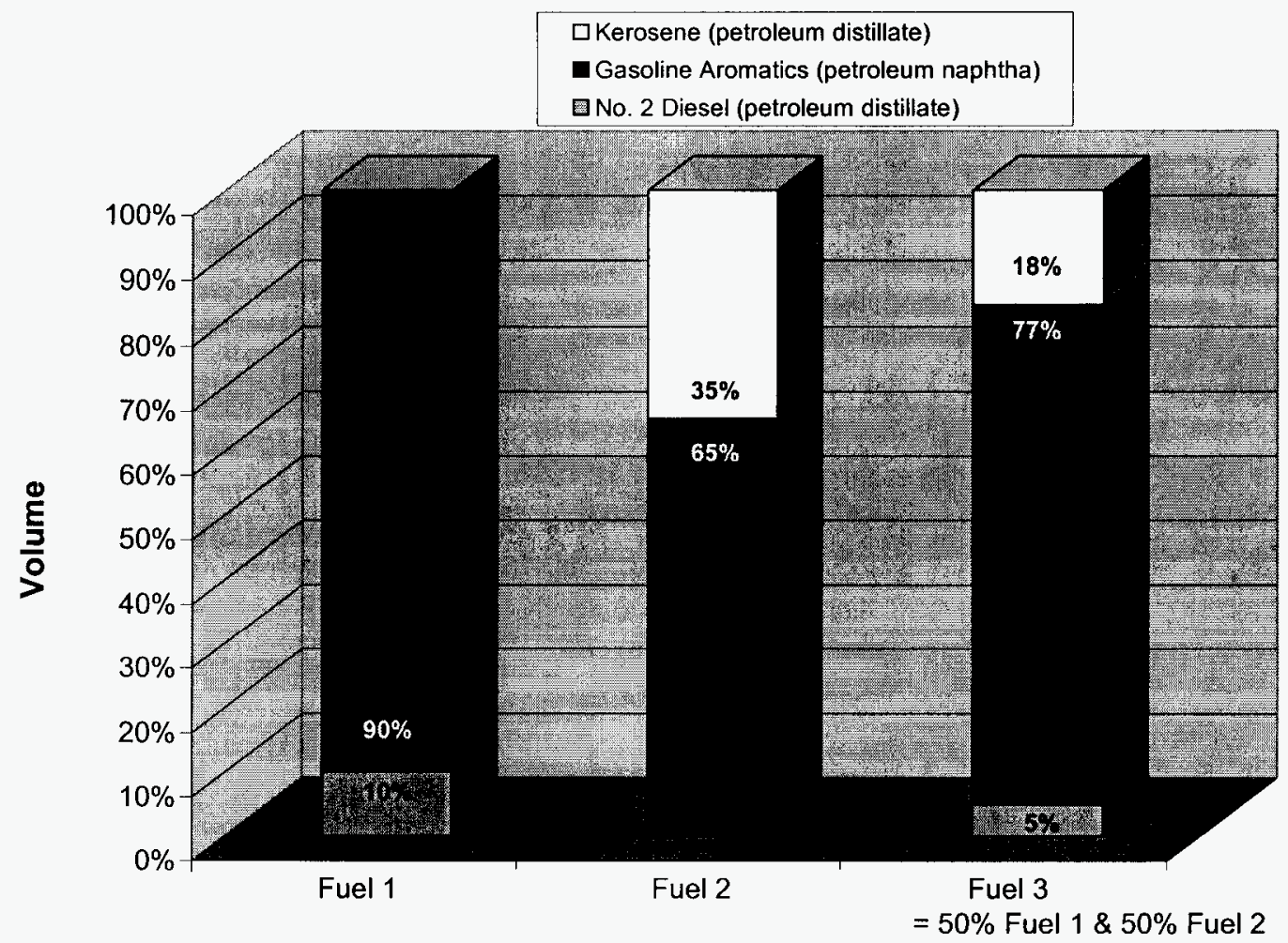

Fig 1 


\section{Description of Engine Test}

Testing has been conducted on ITEC Single-Cylinder Test Engine (SCTE) with the 95mm bore $\mathrm{x}$ $104 \mathrm{~mm}$ stroke cylinder-crank module having displacement of .751 . In order to enable the HCCI-like combustion the piston for this test has been modified to reduced compression ratio (CR) of 15 and engine has been equipped with common rail injection system capable of multiple injection. In addition, the SCTE had a wide range of exhaust gas re-circulation (EGR) control and had a special intake port swirl modulating device allowing to vary amount of the air-fuel mixing during pre-mix phase of HCCI-like combustion. To ensure good quality of results comparison the all fuel tests have been run at 2000rpm and 4.5 bar BMEP load. Such conditions have been well established as conducive to maintain the stable and consistent HCCIlike combustion.

Type of HCCI-like combustion selected in this work (ideal HCCI combustion in which entire amount of fuel is perfectly pre-mixed with available air is not realistic to be achieved in real diesel !) was a partially premixed combustion based on a triple-shot injection process. This mode has been demonstrated to have significant potential for the emission improvement relative to the conventional single-shot injection during the work with conventional diesel fuel prior to this investigation. In the triple-shot injection the first very early injection premixes optimized amount of the fuel which "cool" burn is initiated by second injection. Relatively low temperature combustion continues throughout this phase till the beginning of a final injection which burns fast but relatively clean. Although details of this mode of combustion is not fully understood yet it is believed to be dependant strongly on a kinetics of reactions involved. Finally, the test methodology applied in this work involves Statistical Design of Experiment (DOE). This methodology is capable to provide a widest possible interrogation domain of important engine control parameters and corresponding emission responses of individual fuels tested. In addition, as it will become evident in the discussion of results, DOE allows to better understand effects of the individual control parameters on performance (responses) under investigation. The specific test design used was a central composite Box- Benhken array in which three control parameters, namely the EGR level, start of injection of second injection shot and intake port swirl level have been varied through three levels resulting in the15-point test for each fuel. Fig 2 illustrates configuration of parameters and levels relevant for

this test design. The levels of the main test parameters have been pre-optimized and selected for each of individual fuels according to their specific combustion characteristics. Some other parameters, external to DOE array (such as injection pressure, timing and quantity of the first injection and quantity of second injection) have been optimized with respect to observed responses - primarily Nox, soot and BSFC - for each set of DOE parameter settings. 


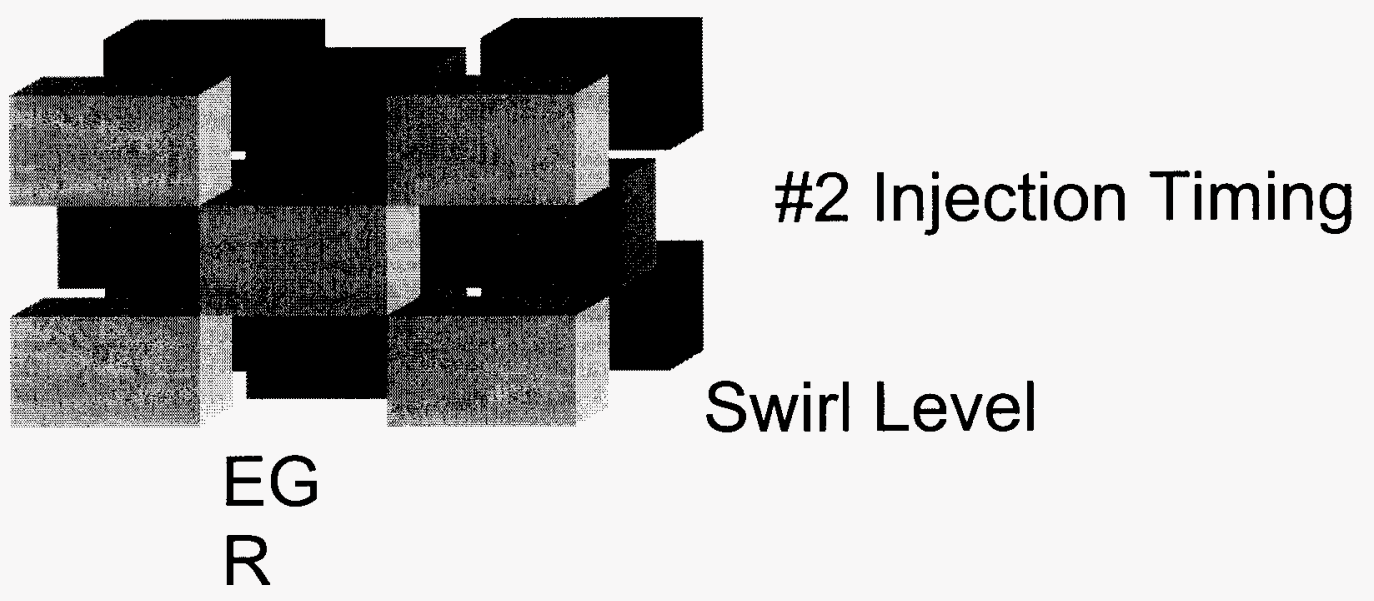

Fig 2

\section{Discussion of Results}

The results of the soot-Nox trade-offs obtained from DOE based parameter sweeps (with external parameters optimized for each point) are shown in Fig. 3. From the cursory look at this graph, by comparing the scatters of test points for individual fuels it is becoming evident that all "HCCl" fuels demonstrate very significant reduction in soot emission. Test fuel \#1, for the values of BSNOx $>.2 \mathrm{~g} / \mathrm{hp}$-hr shows lowest smoke number $<.1$ FSN which is apprx by a factor of ten lower than lowest smoke obtained with base fuel. This level of soot emission represents almost "smokeless" combustion. Although observed reductions in the Nox for the "HCCI" fuels, relative to base fuel, are not so dramatic as the reductions in soot, they are still very significant. Table 1 summarizes BSNOx and soot values recorded for the best Nox-soot trade-off points with the base fuel and individual " $\mathrm{HCCl}$ " fuels and evaluates relative improvements (or penalties) with respect to base fuel

\section{Table 1}

\begin{tabular}{|l|c|c|c|c|c|c|c|}
\cline { 2 - 8 } \multicolumn{1}{c|}{} & Base Fuel & \multicolumn{2}{l|}{ Fuel \#1 } & \multicolumn{2}{l|}{ Fuel \#2 } & \multicolumn{2}{l|}{ Fuel \#3 } \\
\hline & Value & Value & $\%$ diff to base & Value & $\%$ diff to base Value & $\%$ diff to base \\
\hline BSNOx,g/hp-hr & 0.15 & 0.17 & 10.00 & 0.09 & -43.33 & 0.10 & -33.33 \\
\hline Soot, FSN & 1.35 & 0.40 & -70.37 & 0.20 & -85.19 & 0.10 & -92.59 \\
\hline
\end{tabular}




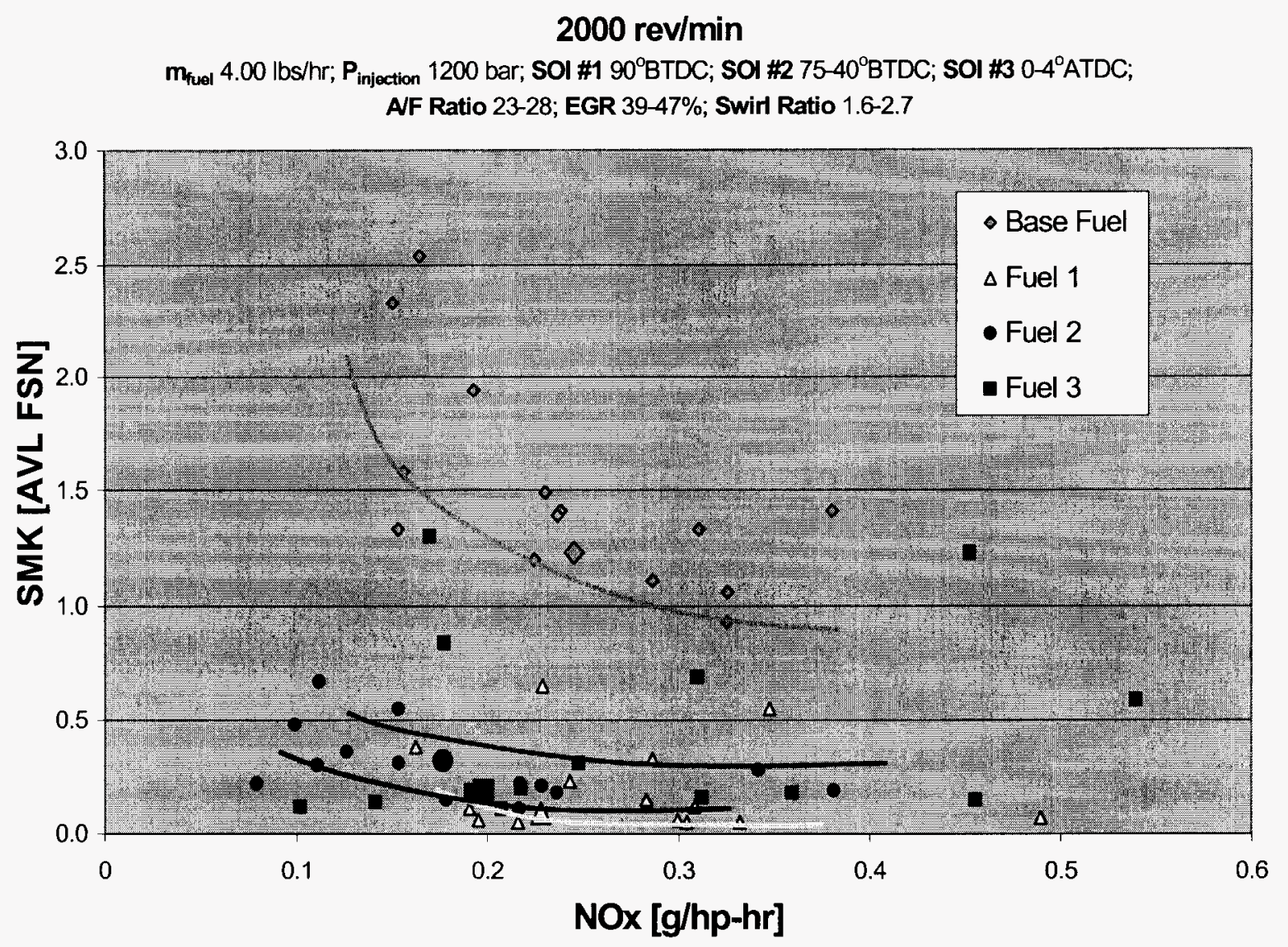

\section{Fig 3}

Fig. 4 provides the comparison of $\mathrm{HC}$ emission and break specific fuel consumption (BSFC) for "HCCI" fuels and base fuel. As it is typical for an HCCI-like combustion "HCCI" fuels show increase in the $\mathrm{HC}$ emission levels relative to the base fuel. Interestingly, fuel \#1 primarily gasoline-like aromatics - produces highest level of $\mathrm{HC}$ than other two blends. This behavior correlates with the fact that fuel \#1 have been showing some difficulty in reliable ignition and stable combustion. Actually, both fuel \#1 and fuel \#3 have required, at certain test points, auxiliary intake air heating to stabilize the ignition, It is, most probably, indicating that selected compression ratio $\mathrm{CR}=15$ was somewhat too low for these fuels. Review of the $\mathrm{BSFC}$ for the base and the "HCCI" fuels does not indicate any significant deterioration in fuel consumption for "HCCI" fuels. In order, however, to make a fair judgment on this issue the calorific values of base and "HCCl" fuels would need to be carefully taken into account, which has not been done. 


\section{$2000 \mathrm{rev} / \mathrm{min}$}

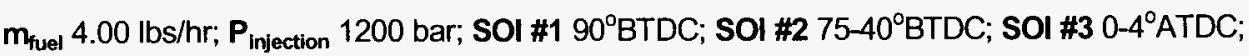

\section{AF Ratio 23-28; EGR 39-47\%; Swirl Ratio 1.6-2.7}

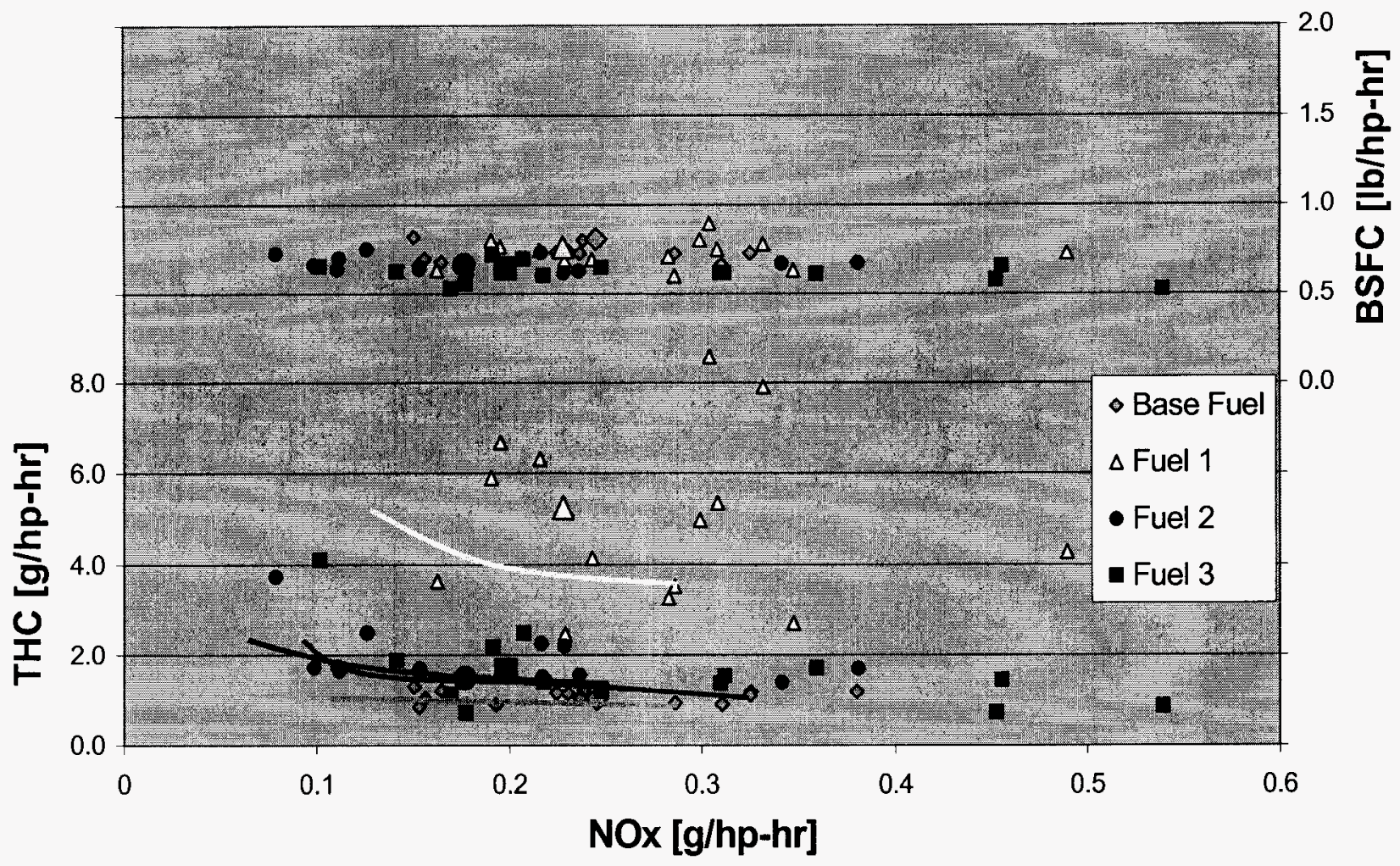

Fig. 4

To provide some insight into combustion thermodynamics of evaluated fuels the cylinder pressures have been measured and then post-processed to obtain corresponding traces of Apparent Heat Release Rates (AHRR). In internal combustion engine research an AHHR is considered to be an approximate "signature" of combustion process. To allow for a meaningful comparison of AHRRs between the base and test fuels, the cylinder pressures shown in Fig. 5 have been measured at the EGR, injection timing and intake swirl settings being selected as close as possible. Enlarged points of the data sets corresponding to individual fuels shown in Fig 3 are representative of those conditions for which cylinder pressure measurements have been taken. Fig 6. shows AHRRs obtained from cylinder pressures shown in Fig. 5. The traces shown in the upper sections of Fig. 5 and Fig. 6 represent the injection timing commands for individual injection events executed for each of the fuels. As it can be seen the timing strategy applied to individual fuels is almost identical assuring that observed differences in the cylinder pressures and corresponding AHRRs are result of the differences in combustion of different fuels and not the result of injection strategy. Review of both of the cylinder pressures and AHRRs traces clearly indicates very significant differences in combustion 


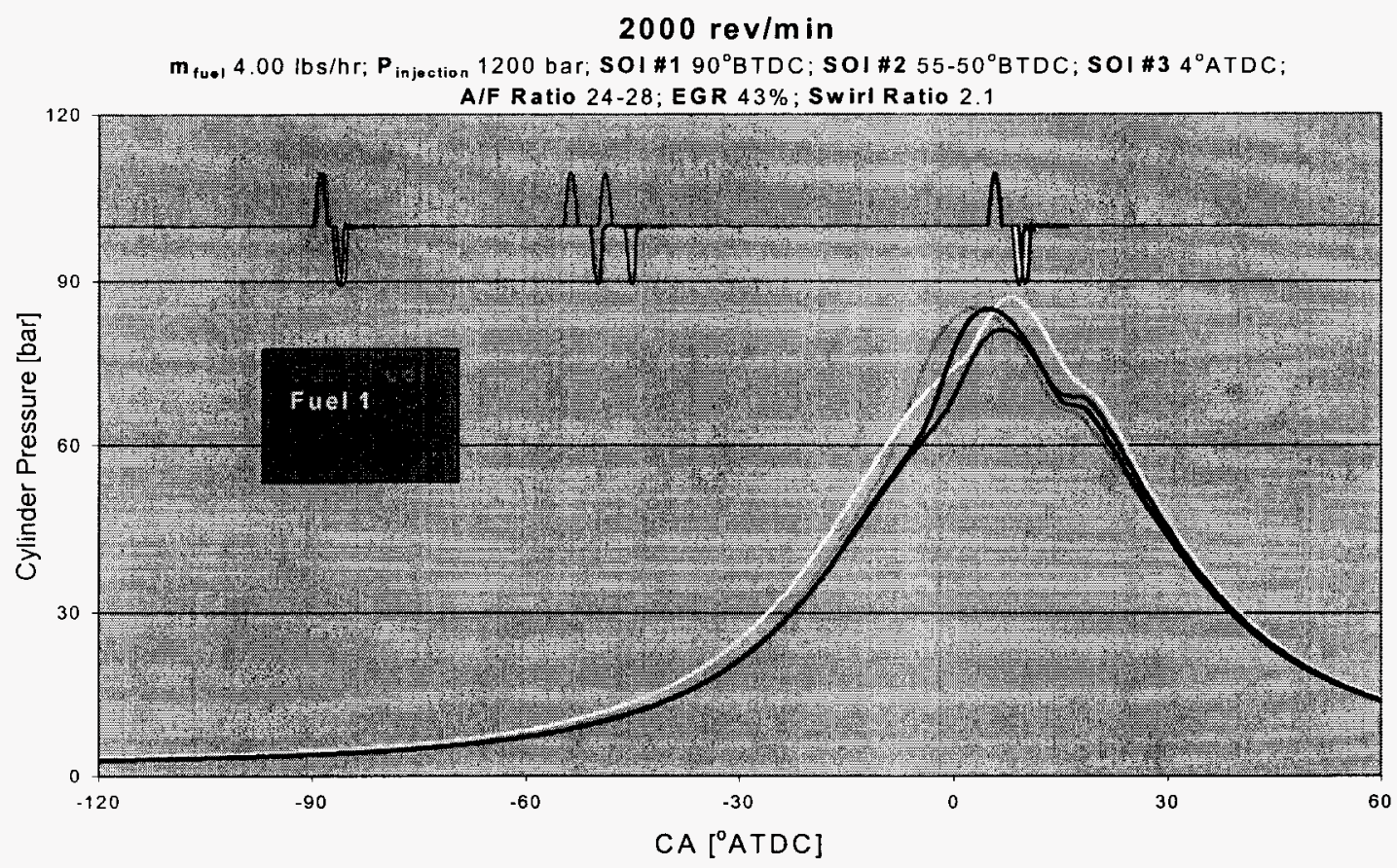

Fig 5

Cylinder Pressure Traces

between different fuels - a feature that can be attributed to the different fuel specific chemical kinetics involved.

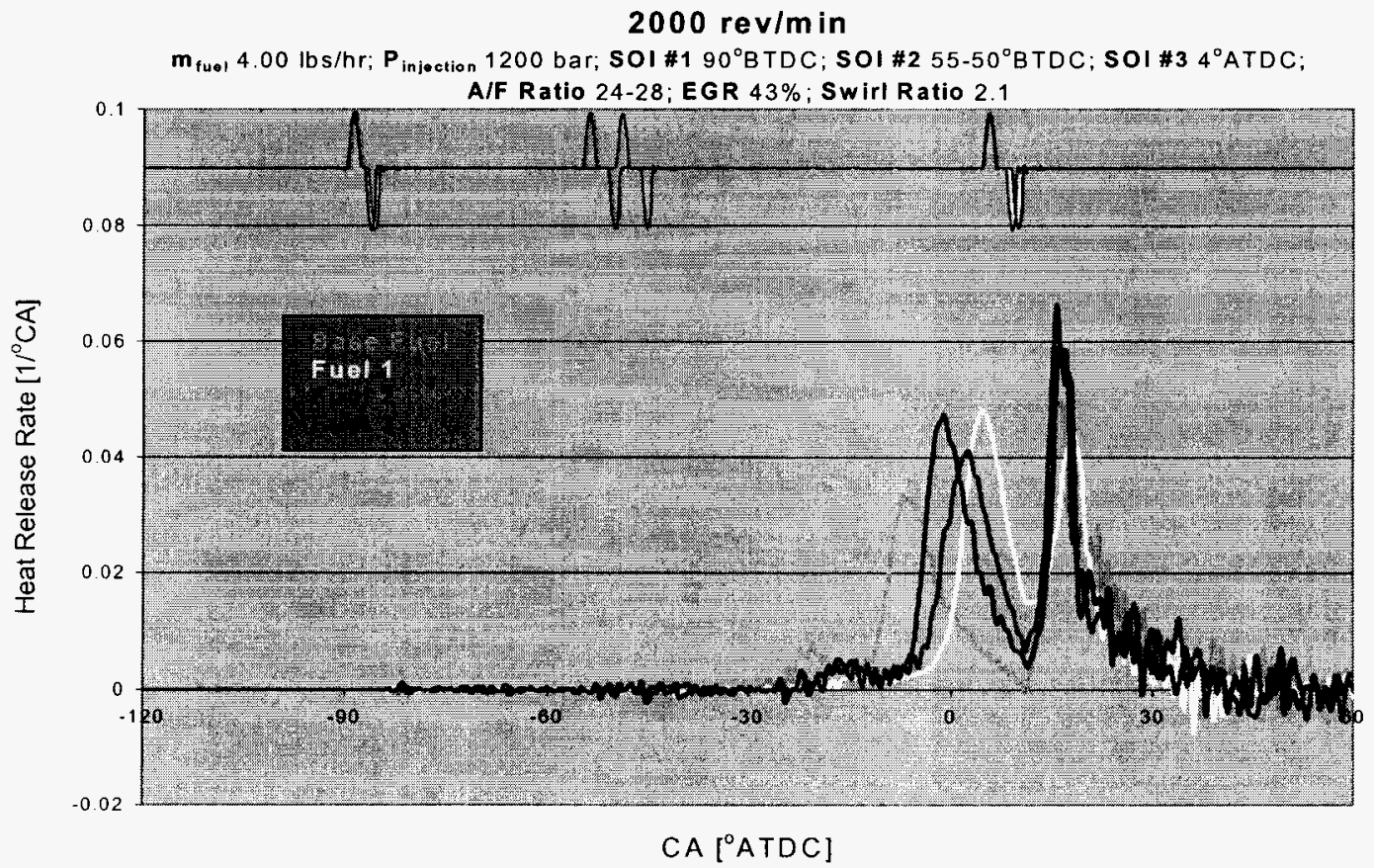

Fig. 6 


\begin{abstract}
AHRRs Traces
From the comparison of first "humps" of heat release rates in Fig.6 it can be clearly seen that ignition delay for all of the "HCC" fuels is longer than of the base fuel. This means that the more of "HCCI" fuel is premixed with the air before the ignition event. Also, the first AHRR "hump" for "HCCl" fuels is lower and more spread out than the one for the base fuel indicating that the "cool" flame reaction rates are lower for "HCCI" fuel than for base fuel. More of premixed "HCCI" fuel causes much higher second AHRR hump what could suggest existence of a higher local temperatures in the combustion space and, therefore, higher smoke and Nox. But, since the "HCCI" fuel- air mixture is better homogenized and locally leaner the local temperatures are, most probably, actually not much higher than in case of the poorly homogenized based fuel-air mixture and the production of Nox is contained. On the other hand, the higher local air-fuel ratios related to the better charge homogenization lead to reduction of the soot.
\end{abstract}

Use of the DOE methodology allows to evaluate the general trends of effects that the DOE control parameters - i.e. the EGR, timing of second injection and the intake swirl - have on main response characteristics under investigation -i.e. Nox and soot - for individual fuels. Fig. 7 shows respective response plots for base fuel, Fig. 8 response plots for fuel \#1, Fig. 9 response plots for fuel \#2 and, finally, Fig. 10 response plots for fuel \#3.

The principal observations that can be made out of the analysis of the response plots for individual fuels are as follows:

- Decreasing amount of EGR has a decreasing effect on Nox regardless of fuel - a characteristic well established for conventional diesel fuel

- There seems to be an optimum in EGR level helping soot reduction for the fuel \#1 and fuel \#3 while the fuel \#2 shows a monotonic deteriorating effect of increasing EGR on smoke, typical for the conventional diesel fuel represented by base fuel

- "V"-shaped response of the Nox to timing of second injection, which is apparent for all fuels, indicates that the range of this parameter was very well optimized with respect to Nox in DOE array

- Smoke production for all "HCCI" fuels is evidently reduced by advancing start of second injection while the base fuel shows optimum in smoke for the mid-level of second injection; These difference in the smoke responses is probably related to the difference in fuel volatility and its co-effect on mixing

- As expected, in general, swirl seems to have stronger effect on soot than on Nox formation; there are definite optima in a level of swirl with respect to smoke for all fuels except for fuel \#2 which prefers lower swirl.

- Nox formation for fuel \#1 seems to be relatively strongly increasing with increasing swirl; all other fuels show either a low sensitivity of Nox to swirl - like the base fuel and fuel \#2 or show the optimum in swirl for Nox - case of the fuel \#3 

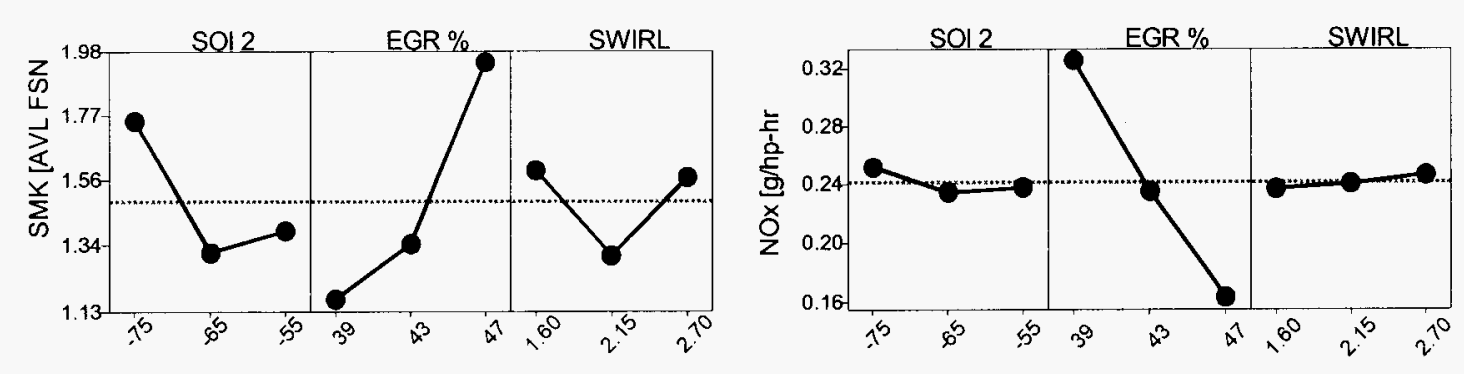

Fig. 7

Response Plots for Base Fuel
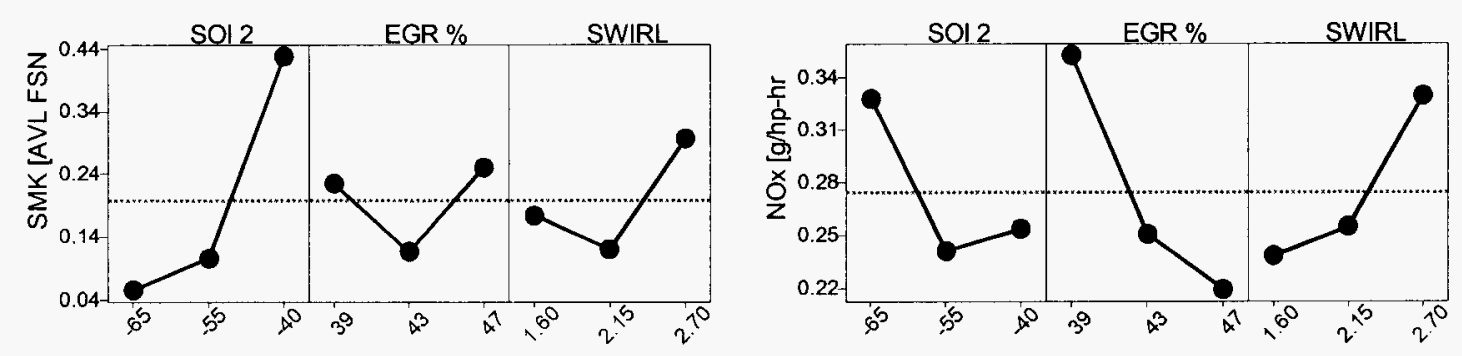

Fig. 8

Response Plots for Fuel \#1
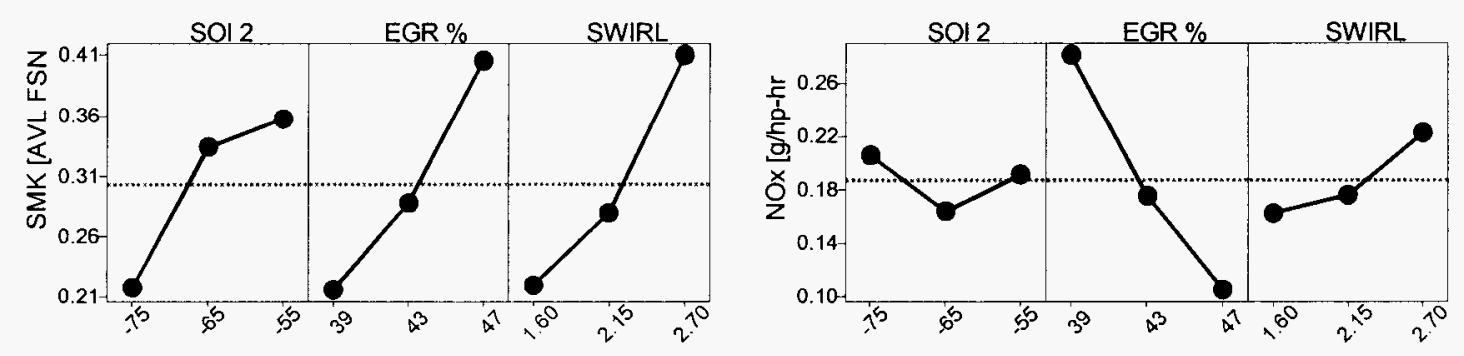

Fig. 9

Response Plots for Fuel \#2 

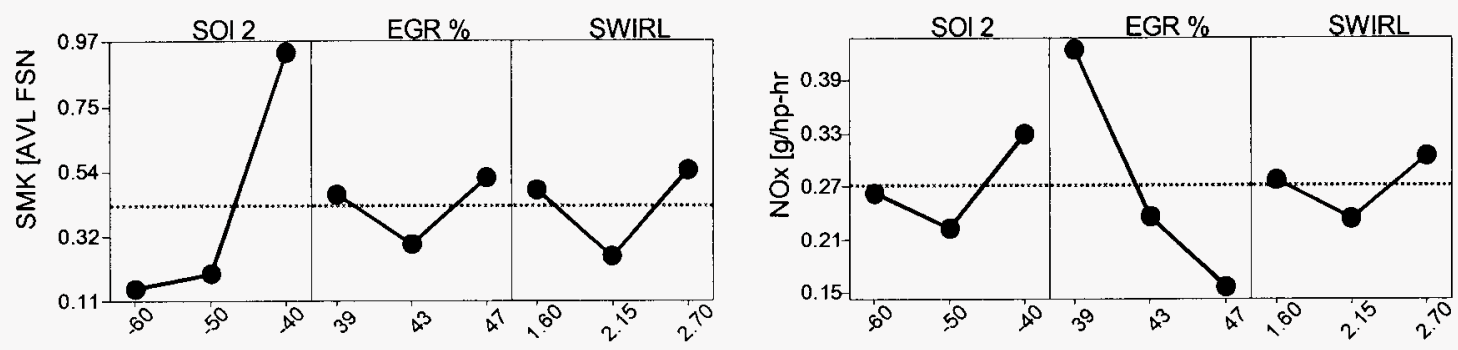

Response Plots for Fuel \#3

Fig. 10

\section{Conclusions}

Although the scope of this work has been limited primarily to investigation of the engine emission performance on single operating point the results show the undisputable advantages of customized hydrocarbon fuel blends for a clean HCCI type diesel combustion. Optimized lower cetane number and increased volatility of fuel are clearly the physical properties enhancing its HCCI diesel combustion compatibility. It needs to be emphasized that there are also certain chemical properties related to a combustion chemical kinetics of the fuel that make it suitable for HCCI use which at present time are not well understood. All of the "HCCI" fuels have demonstrated very significant potential in reducing emission of soot relative to the base diesel fuel. Fuel \# 3 has demonstrated best performance in the sense that, for the optimized soot-Nox trade-off point, the approximately $90 \%$ reduction in soot was coupled to approximately $30 \%$ in Nox reduction, relative to the best point for base fuel.

In order to fully evaluate the potential of tested fuels the more extensive engine mapping would be necessary. Considering the complexity of the HCCI process and its investigation the much more extensive program would be needed to complete such a task. 


\section{Appendix 3 \\ BP Preparation of HCCI Fuels}

\section{Development of OTM Syngas Process and Testing of Syngas Derived Ultra-clean Fuels in Diesel Engines and Fuel Cells Budget Period 3 \\ DOE Cooperative Agreement No. DE-FC26-01NT41096 \\ Task 8: Fuel and Engine Testing}

Date: $\quad$ October 30, 2004

Author: $\quad$ Leslie R. Wolf

Global Fuels Technology

BP Amoco Oil

$150 \mathrm{~W}$. Warrenville Rd.

Naperville, Il. 60563-8460

\section{Summary}

Laboratory scale fuel blends were made using ten different gasoline or distillate refinery blending components. Testing of these blends for ignition and volatility properties allowed the determination of blending characteristics for these properties. From these results, three larger scale (55 gallons) blends with selected ignition quality and volatility were produced.

\section{Results and Discussion}

The ten refinery streams described in Table 1 were blended according to the compositions shown in Table 2 to make laboratory scale samples. These samples were tested for Reid vapor pressure, single-plate distillation (ASTM D86) and ignition quality (IQT tester). Test results are shown in Table 3.

Table 1

\begin{tabular}{|l|l|}
\hline Material & Description \\
\hline D2 & High cetane full boiling range No. 2 diesel fuel \\
\hline D2A & Low cetane heavy aromatic distillate \\
\hline D1H & High cetane No. 1 diesel fuel \\
\hline D1L & Low cetane No.1 diesel fuel \\
\hline HNP & Low octane heavy paraffinic naphtha \\
\hline HNA & High octane heavy aromatic naphtha \\
\hline LNA & High octane light aromatic naphtha \\
\hline LNP1 & High octane light paraffinic naphtha \\
\hline LNP2 & Low octane light paraffinic naphtha \\
\hline LNP3 & Intermediate octane very light paraffinic naphtha \\
\hline
\end{tabular}


From the data in Table 3, blending characteristics for IQT cetane number and density (API gravity) were developed (see Appendix 1 for discussion of IQT cetane number relative to ASTM D613 cetane number). It was found that IQT cetane number blended as a linear volume fraction weighted sum. Density could be calculated assuming ideal mixing (i.e. no volume change). 

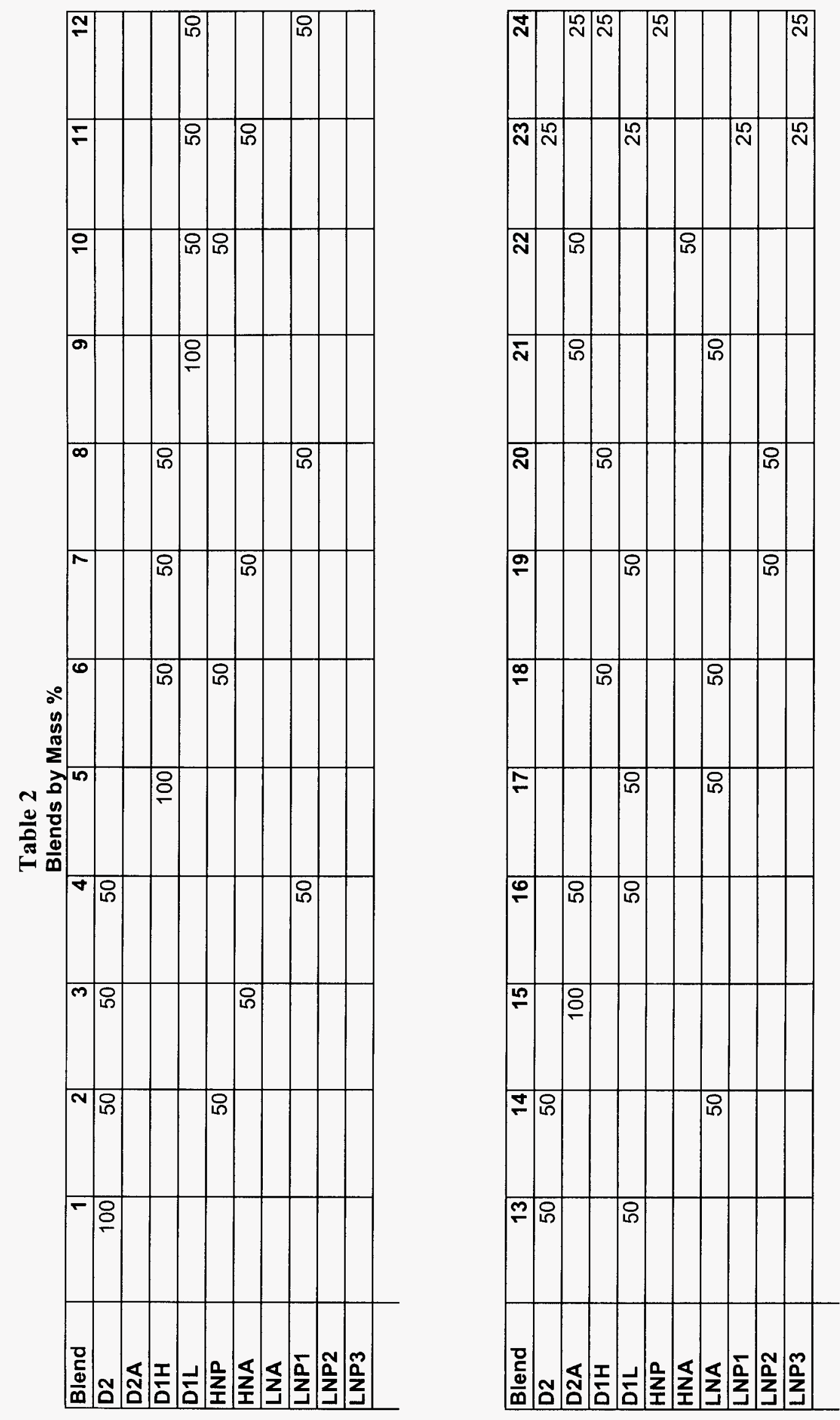


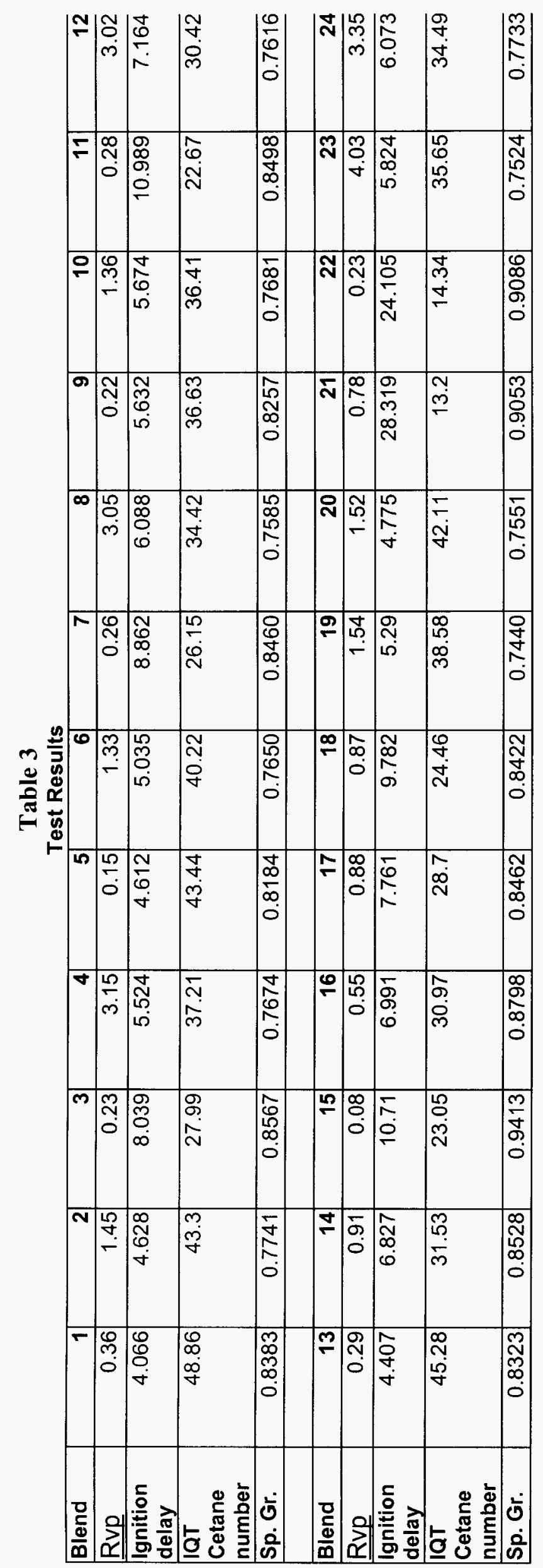


Table 4 gives blending values for density and IQT cetane derived from data in Table 3.

\begin{tabular}{|l|c|c|}
\hline \multicolumn{3}{|c|}{ Table 4 } \\
\hline Blending Properties \\
\hline M2 & Blending Density & Blending IQT Cetane Number \\
\hline D2A & 0.8388 & 50.0 \\
\hline D1H & 0.9426 & 22.1 \\
\hline D1L & 0.8201 & 43.3 \\
\hline HNP & 0.8240 & 38.2 \\
\hline HNA & 0.7182 & 36.8 \\
\hline LNA & 0.8758 & 6.5 \\
\hline LNP1 & 0.8683 & 10.0 \\
\hline LNP2 & 0.7070 & 25.6 \\
\hline LNP3 & 0.6888 & 40.0 \\
\hline
\end{tabular}

Blend distillation data are given in Table 5. Figure 1 summarizes the volatility described by $10 \%, 50 \%$ and $90 \%$ evaporated temperatures as a function of the IQT cetane number.

Engine Test Fuels

Engineers at International Truck and Engine Company (IT\&E) selected property ranges for engine test fuels. High volatility (i.e. low distillation temperatures) and cetane ranging from very low (16) to moderate (35) were desired. Estimated properties for six blends were calculated to span the desired property ranges. Table 6 shows the composition of the six blends and calculated properties. From these six blends, IT\&E engineers selected three blends: P2, P3, and P6. These three blends were blended at 55 gallons scale. In addition to the blend components, lubricity improver was added at 0.01 to $0.02 \%$ to provide adequate fuel system protection. Table 7 shows test results on the final blends.

\begin{tabular}{|l|c|c|c|c|c|c|}
\hline \multicolumn{7}{|c|}{ Table 6 Proposed Blends, Mass \% } \\
\hline MateriallBlend & P1 & P2 & P3 & P4 & P5 & P6 \\
\hline D2A & 10 & 10 & & 10 & 5 & 5 \\
\hline D1L & & & 35 & 25 & 17.5 & 17.5 \\
\hline HNA & 35 & 25 & 10 & 10 & 22.5 & 17.5 \\
\hline LNA & 15 & 25 & 10 & 10 & 12.5 & 17.5 \\
\hline LNP1 & 40 & 40 & & & 20 & 20 \\
\hline LNP2 & & & 45 & 45 & 22.5 & 22.5 \\
\hline & & & & & & \\
\hline $\begin{array}{l}\text { Calculated } \\
\text { IQT Cetane }\end{array}$ & 16 & 16 & 35 & 36 & 26 & 26 \\
\hline Estimated T10 & 174 & 169 & 212 & 214 & 203 & 217 \\
\hline Estimated T90 & 445 & 438 & 393 & 462 & 414 & 431 \\
\hline
\end{tabular}




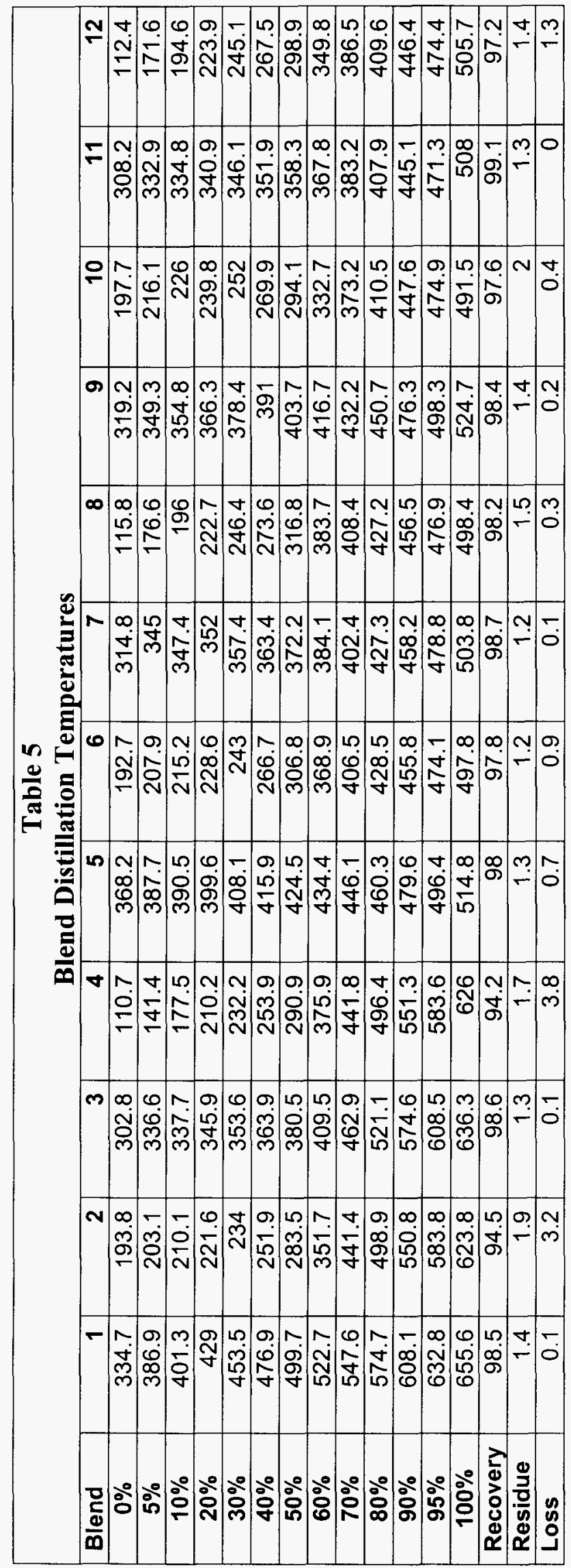

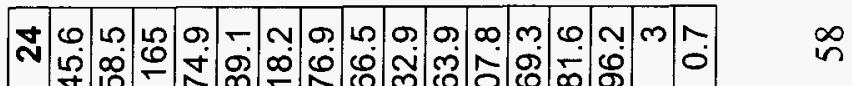
䒹

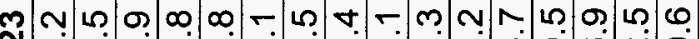

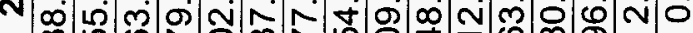

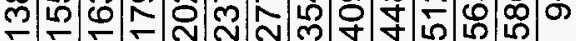

N 寸 N $\infty$ गे

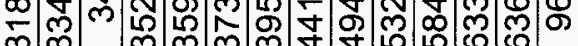

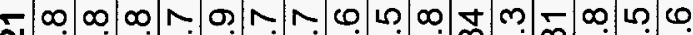
N NลN N N N

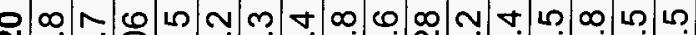
N

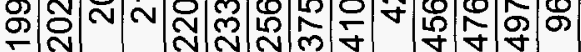

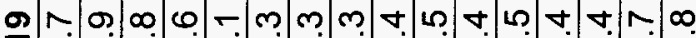

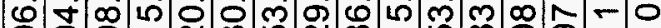
\%워

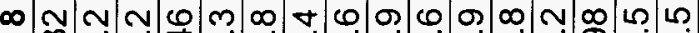
Nิ N

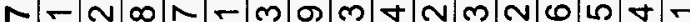

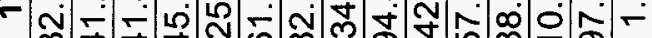
ले 志 d

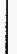

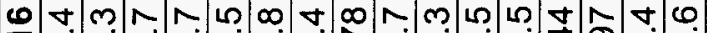

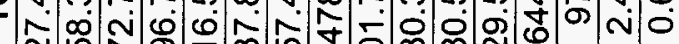
ले लि लि

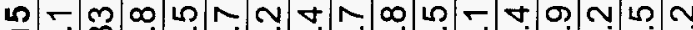
mై

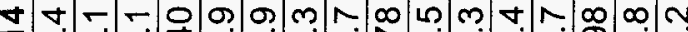

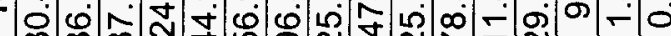

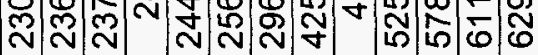

$m \nabla N-\omega \sim \omega \infty \omega \sigma \omega m-N-\infty N$ लै

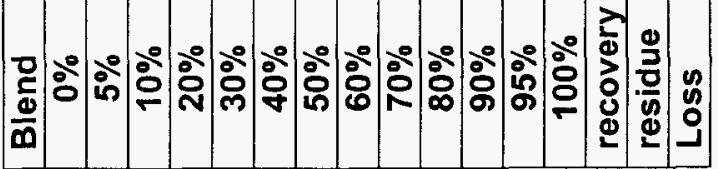


ลิ

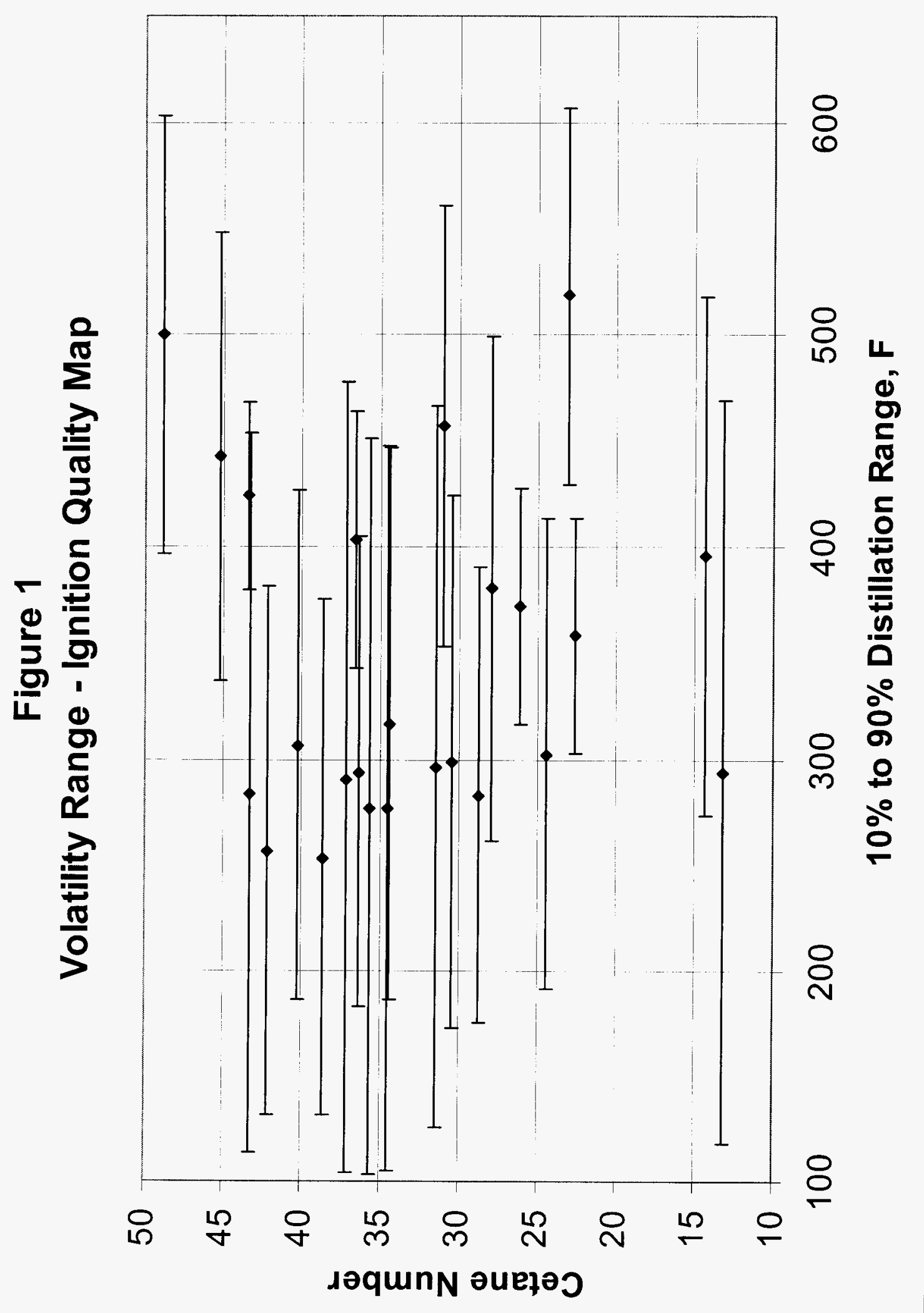




\begin{tabular}{|c|c|c|c|}
\hline \multicolumn{4}{|c|}{$\begin{array}{c}\text { Table } 7 \\
\text { Engine Test Blends (55 gallons) }\end{array}$} \\
\hline Engine Test Blend & 21507-31-1 & 21507-31-2 & $21507-31-3$ \\
\hline Test & Fuel 1 & Fuel 2 & Fuel 3 \\
\hline API Gravity, ${ }^{\circ} \mathrm{API}$ & 44.65 & 51.98 & 48.41 \\
\hline Specific Gravity, 60F/60F & 0.803293 & 0.771201 & 0.786504 \\
\hline \multicolumn{4}{|l|}{ Distillation } \\
\hline Initial Boiling Point, ${ }^{\circ} \mathrm{F}$ & 119.5 & 201.9 & 149.8 \\
\hline $10 \%$ distilled, ${ }^{\circ} \mathrm{F}$ & 205.1 & 208.9 & 20839 \\
\hline $20 \%$ distilled, ${ }^{\circ} \mathrm{F}$ & 222.2 & 213.5 & 216.8 \\
\hline $30 \%$ distilled, ${ }^{\circ} \mathrm{F}$ & 231.3 & 217.9 & 224.7 \\
\hline $40 \%$ distilled, ${ }^{\circ} \mathrm{F}$ & 241 & 226.6 & 235.1 \\
\hline $50 \%$ distilled, ${ }^{\circ} \mathrm{F}$ & 254.3 & 242.9 & 249.1 \\
\hline $60 \%$ distilled, ${ }^{\circ} \mathrm{F}$ & 271.5 & 290.6 & 278.6 \\
\hline $70 \%$ distilled, ${ }^{\circ} \mathrm{F}$ & 303.8 & 377.3 & 339.1 \\
\hline $80 \%$ distilled, ${ }^{\circ} \mathrm{F}$ & 346.1 & 404.5 & 377.4 \\
\hline $90 \%$ distilled, ${ }^{\circ} \mathrm{F}$ & 385.2 & 443 & 429.2 \\
\hline Final Boiling Point, ${ }^{\circ} \mathrm{F}$ & 541.6 & 489.9 & 537 \\
\hline Reid vapor pressure, psi & 2.64 & 1.49 & 2.05 \\
\hline Carbon, mass \% & 86.66 & 85.8 & 86.42 \\
\hline Hydrogen, mass $\%$ & 11.91 & 13.82 & 12.9 \\
\hline Nitrogen, ppm & 25 & $<1$ & 12 \\
\hline Sulfur, ppm & 293 & 5 & 143 \\
\hline SFC Aromatics, vol\% & 60.02 & 28.69 & 44.88 \\
\hline Lower heating value, BTU/lb & 17872.45 & 19066.2 & 18297.13 \\
\hline Lower heating value, BTU/gal & 119563.5 & 122453.9 & 119846.4 \\
\hline \multicolumn{4}{|l|}{ Cetane Number } \\
\hline IQT Cetane Number & & & \\
\hline
\end{tabular}


Appendix 1

Test Methods and Descriptions

Test methods reported used in this work are based on the standard ASTM methods or standardized in-house methods given in Table A1. A short description is also provided.

\begin{tabular}{|c|c|c|}
\hline \multicolumn{3}{|c|}{$\begin{array}{c}\text { Table A1 } \\
\text { Test Methods }\end{array}$} \\
\hline Test & Method & Description \\
\hline API Gravity, ${ }^{\circ} \mathrm{API}$ & ASTM D4052 & $\begin{array}{l}\text { Calculated from specific } \\
\text { gravity data }\end{array}$ \\
\hline Specific Gravity, 60F/60F & ASTM D4052 & $\begin{array}{l}\text { Specific gravity at } 60^{\circ} \mathrm{F} \\
\text { compared to water at } 60^{\circ} \mathrm{F} \text { by } \\
\text { calibrated oscillating tube }\end{array}$ \\
\hline Distillation & ASTM D86 & $\begin{array}{l}\text { Single-plate, atmospheric } \\
\text { distillation }\end{array}$ \\
\hline Reid vapor pressure, psi & ASTM D5191 & $\begin{array}{l}\text { Dry vapor pressure equivalent } \\
\text { at } 100^{\circ} \mathrm{F} \text {, instrumental method }\end{array}$ \\
\hline Carbon, mass \% & BP internal method & Instrumental, high precision \\
\hline Hydrogen, mass $\%$ & BP internal method & Instrumental, high precision \\
\hline Nitrogen, ppm & ASTM D5762 & $\begin{array}{l}\text { Instrumental, } \\
\text { chemilumenescence detection }\end{array}$ \\
\hline Sulfur, ppm & ASTM D5453 & Instrumental, UV fluorescence \\
\hline SFC Aromatics, vol\% & ASTM D5186 & $\begin{array}{l}\text { Supercritical Fluid } \\
\text { Chromatography }\end{array}$ \\
\hline Lower heating value, BTU/lb & ASTM D4809 & Bomb calorimetry \\
\hline Cetane Number & ASTM D613 & Engine test* \\
\hline IQT Cetane Number & ASTM D6890 & AET instrumental** \\
\hline
\end{tabular}

*The ASTM D613 single-cylinder, compression ignition engine test measures cetane number by determination of critical compression ratio at which the fuel ignites. The engine compression ratio is varied manually to find the minimum required to ignite the fuel. This is the standard method with the cetane scale defined by zero equal to performance of methyl naphthalene and one hundred equal to performance of $n$-hexadecane. In practice, heptamethyl nonane, cetane number 15 , is used in place of methyl naphthalene. Intermediate cetane numbers are defined by volumetric mixtures of the two pure chemicals. For example, 40 cetane number is the performance for a mixture of 70.6 volume $\%$ heptamethyl nonane and 29.4 volume $\% \mathrm{n}$ hexadecane.

** The ASTM D6890 method uses the ignition quality tester (IQT) instrument made by AET. This instrument injects sample into a heated, air-pressurized chamber and measures the time delay (milliseconds) until a rapid pressure rise is observed. The delay time is related to ignition quality and is correlated to the ASTM D613 cetane number by an equation based on the time delays of the same two chemicals, heptamethyl nonane and n-hexadecane, and their mixtures. 